\title{
WestVirginiaUniversity
}

THE RESEARCH REPOSITORY @ WVU

Graduate Theses, Dissertations, and Problem Reports

2012

\section{The Three W's of Hazardous Waste: Who, Why, and Where?}

Christa Dean Jensen
West Virginia University

Follow this and additional works at: https://researchrepository.wvu.edu/etd

\section{Recommended Citation}

Jensen, Christa Dean, "The Three W's of Hazardous Waste: Who, Why, and Where?" (2012). Graduate Theses, Dissertations, and Problem Reports. 3573.

https://researchrepository.wvu.edu/etd/3573

This Dissertation is protected by copyright and/or related rights. It has been brought to you by the The Research Repository @ WVU with permission from the rights-holder(s). You are free to use this Dissertation in any way that is permitted by the copyright and related rights legislation that applies to your use. For other uses you must obtain permission from the rights-holder(s) directly, unless additional rights are indicated by a Creative Commons license in the record and/ or on the work itself. This Dissertation has been accepted for inclusion in WVU Graduate Theses, Dissertations, and Problem Reports collection by an authorized administrator of The Research Repository @ WVU.

For more information, please contact researchrepository@mail.wvu.edu. 


\title{
The Three W's of Hazardous Waste: Who, Why, and Where?
}

\author{
by \\ Christa Dean Jensen \\ Dissertation submitted to the \\ College of Business and Economics \\ at West Virginia University \\ in partial fulfillment of the requirements \\ for the degree of \\ Doctor of Philosophy \\ in \\ Economics \\ Brian Cushing, Ph.D. \\ Stratford Douglas, Ph.D. \\ Donald J. Lacombe, Ph.D. \\ Peter V. Schaeffer, Ph.D. \\ Karen Turner, Ph.D. \\ Randall W. Jackson, Ph.D., Chair \\ Department of Economics \\ Morgantown, West Virginia \\ 2012
}

Keywords: environmental accounting, hazardous waste, input-output, spatial econometrics, spatial interaction modeling

Copyright 2012 Christa Dean Jensen 


\author{
Abstract \\ The Three W's of Hazardous Waste: \\ Who, Why, and Where? \\ by \\ Christa Dean Jensen \\ Doctor of Philosophy in Economics \\ West Virginia University \\ Randall W. Jackson, Ph.D., Chair
}

In the late 1960s and 1970s, amid changing attitudes about the environment and emerging sustainability concerns, countries around the world began regulating multiple aspects of hazardous waste. Initial regulations, and those occurring since, all share the broader goals of curbing hazardous waste generation and regulating hazardous waste trade, but with few signs of progress. Using input-output analysis and spatial interaction modeling, this dissertation analyzes various dimensions of the hazardous waste problem in the United States and the United Kingdom. The overall objective is to develop methods to answer the following questions: 1) who is generating hazardous waste; 2) why is hazardous waste being generated; and 3) where is hazardous waste going? New methods for analyzing the generation of hazardous waste, identifying the parties that are ultimately accountable for this generation, and exploring the relationships that exist within the market for hazardous waste trade are provided and successfully demonstrated. In the United States, only a few sectors of the economy are accountable for most of the direct industrial hazardous waste generation. Hazardous waste multipliers provide additional information with respect to direct, indirect, and total accountability of the different industrial generators. The results from an attribution analysis show that household consumption drives a large portion of industrial hazardous waste generation but that foreign exports are accountable for the most hazardous waste generated per million dollars of expenditure. The analysis of hazardous waste trade within the United Kingdom suggests that characteristics related to health, educational attainment, and the presence of a hazardous waste landfill are all associated with hazardous waste flows. Significant region-specific effects for both origins and destinations are also identified. 


\section{Acknowledgements}

I have always been the type of person who is interested in everything and never wants to stop learning. This is both a blessing and a curse. It means that I have acquired a broad range of knowledge and interests through my many years the education system but it also the reason that there have been so many years in the education system. I would like to take this opportunity to thank the people who have been influential over the last six years.

First, I would like to thank Dr. Anthon Eff at Middle Tennessee State University for showing me that the tools of economics can be used to study almost anything. This was the primary reason that I chose to attain a Ph.D. in Economics. Dr. Eff was also responsible for my application to West Virginia University and the Regional Research Institute and for his suggestion, I am forever grateful. It was indeed just the right place for me.

The next person I would like to thank is Dr. Randall Jackson; the problem is that I could spend this entire dissertation thanking him for various reasons and it still wouldn't be enough. He has been more than a dissertation advisor, he has also been a mentor, a motivator, and, at times, a life coach. Rather than holding my hand and leading me through graduate school, he chose to stand behind me and only intervene when I went astray. This is undoubtedly the reason for my success and as I complete my degree, leaves me feeling fully prepared for whatever lies ahead. I could not be more grateful for all that he has done and provided for me. A fellow student once told him that there was a lucky star overhead on the day he walked into Dr. Jackson's office and I wholeheartedly believe that this was true in my case as well.

My other dissertation committee members, Dr. Brian Cushing, Dr. Stratford Douglas, Dr. Donald Lacombe, Dr. Peter Schaeffer, and Dr. Karen Turner, have also each played an important role in not only this dissertation but in my education and professional development as well. I am thankful for their patience and unwaivering support through this entire process. I would like to extend an additional thank you to Dr. Donald Lacombe for his assistance 
in coding some of the newer techniques used in Chapter 4 and for the use of his computer, which spent many days and nights running my dissertation code. I would also like to include a special thank you to Caigan McKenzie for acting as my personal copy-editor for this dissertation, it was much appreciated!

I also need to acknowledge the assistance, space, and academic family that I have received during my time at the Regional Research Institute (RRI). The RRI was very much my academic home and the faculty, staff, and fellow students that I encountered helped to shape my path as a researcher. I found it exhilirating to work with so many people from so many different fields of study and acknowledge that they all had a part to play in my research development.

I am also indebted to the RRI and the Department of Economics for their generous support for travel to academic conferences over the years. I have been extremely fortunate to present my research to many audiences across the United States and internationally. This has worked wonders for my ability to disseminate my research and has allowed me the opportunity to meet many colleagues outside of the West Virginia University campus who have also greatly influenced my work. I cannot possibly list them all here but would like to express my gratitude for their support and invaluable comments and advice.

I would also like to thank the fellow students both at West Virginia University and elsewhere with whom I shared hours of homework and study time, an office space, a conference hotel room, and/or time on a train across the U.K.; they all helped me more than they know. I would especially like to thank Rachel Mathers, Dash Kelley, Stuart McIntyre, and Juan Tomás Sayago Gómez for not only the help they have provided in class and on this dissertation, but for lasting friendships that have developed along the way.

I would be remiss not to mention the influence of Dr. Karen Turner and Dr. Max Munday on both my personal research agenda as a whole and on this dissertation. They were instrumental in helping me find the confidence to stick to my interest in waste and invaluable for their advice on U.K. data and practices.

Finally, I should also acknowledge the support of my family. I was never afraid of failure knowing they were all always behind me. That, I believe, is the greatest gift a family could provide for each other. Early in life, my Mom and Dad taught me that through hard work and perserverance, I could accomplish anything. Thanks to their guidance and support, I am where I am today. I would also like to thank my husband for his steadfast belief in my ability to complete this dissertation, which was at times stronger than my own. 


\section{Contents}

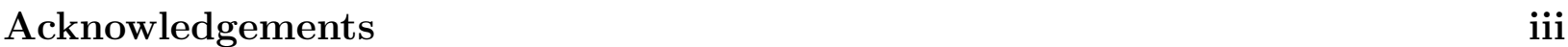

List of Figures $\quad$ vii

List of Tables $\quad$ viii

1 Introduction $\quad 1$

1.1 The Economics of Hazardous Waste . . . . . . . . . . . . . . . . . 2

1.2 Hazardous Waste Generation . . . . . . . . . . . . . . . . . . . . 3

1.3 Hazardous Waste Trade . . . . . . . . . . . . . . . . . . . . . . . 4

2 Enhancing Hazardous Waste Accounting through Economic Modeling 6

2.1 Methodological Background . . . . . . . . . . . . . . 7

2.2 Accounting Framework . . . . . . . . . . . . . . . . . . . . 9 9

2.3 Data . . . . . . . . . . . . . . . . . . . . 15

2.4 Results and Discussion . . . . . . . . . . . . . . . . . . . . . . . . . . . . . . . .

2.4.1 Production Accounting . . . . . . . . . . . . . . . 16

2.4.2 Consumption Accounting . . . . . . . . . . . . . . . 27

2.5 Conclusions . . . . . . . . . . . . . . . . . . . 31

3 Examining Sub-National Hazardous Waste Flows in the United Kingdom 33

3.1 Hazardous Waste Trade . . . . . . . . . . . . . . . . . . . . . . 34

3.2 Hazardous Waste Regulation . . . . . . . . . . . . . . . . . . . . . . . . . . . . . . . . . 37

3.3 Methodology . . . . . . . . . . . . . . . . . . . . . . . . . . . . . . . . . . . .

3.4 Data . . . . . . . . . . . . . . . . . . . . . 43

3.5 Analytical Results . . . . . . . . . . . . . . . . . . . . . . 46

3.6 Conclusions . . . . . . . . . . . . . . . . . . . . . 51

4 Spatial Dependence in Hazardous Waste Flow Relationships 53

4.1 Spatial Econometric Spatial Interaction Literature . . . . . . . . . . . . . . 54

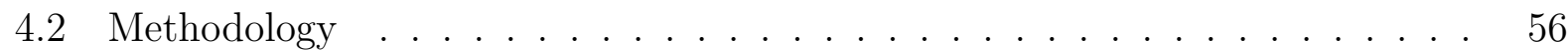

4.3 Analytical Results . . . . . . . . . . . . . . . . . . . 60

4.4 Conclusions . . . . . . . . . . . . . . . . . . . . 70 
5 Conclusions

5.1 Conclusions . . . . . . . . . . . . . . . . . . 72

5.2 Future Research . . . . . . . . . . . . . . . . . . . . . . . . 74

$\begin{array}{ll}\text { References } & 78\end{array}$ 


\section{List of Figures}

1.1 Stylized Hazardous Waste Reduction Relationships . . . . . . . . . . . . . . 2

2.1 Total U.S. Hazardous Waste Generation by Industry for 2007 . . . . . . . . . 17

2.2 Relationship between Direct vs. Total Hazardous Waste Intensity . . . . . . 23

3.157 U.K. Regions of Analysis . . . . . . . . . . . . . . . . 43

4.1 Barrier to trade between spatial units A and B (hashed units) . . . . . . . 58

4.2 Significant Region-Specific Effects for Origins of Hazardous Waste Flows . . 65

4.3 Significant Region-Specific Effects for Destinations of Hazardous Waste Flows 67

4.4 Significant Region-Specific Summary Effects of Hazardous Waste Flows . . . 69 


\section{List of Tables}

2.1 BEA U.S. National Accounting Structure . . . . . . . . . . . . . . . . . 10

2.2 Jackson's 1998 Modification of U.S. National Accounting Structure . . . . . 11

2.3 Total Hazardous Waste Generation and Intensity by Industry, 2007 . . . . . 18

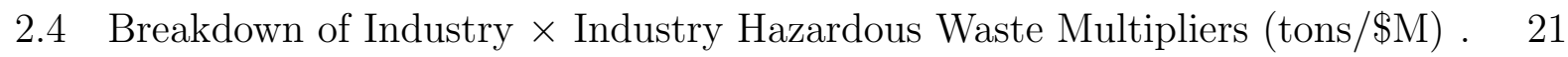

2.5 Direct Hazardous Waste Generation for Intermediate and Final Demand, 200725

2.6 Hazardous Waste Attribution by Final Consumer (tons) . . . . . . . . . . . 29

2.7 Hazardous Waste Attribution by Final Consumer (intensities) . . . . . . . . 30

3.1 Hazardous Waste and Regional Characteristics Variables . . . . . . . . . . . 44

3.2 Descriptive Statistics for Hazardous Waste and Regional Characteristics Vari-

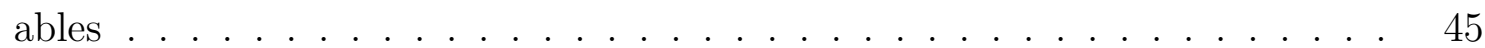

3.3 Variable Associations with Hazardous Waste Flows . . . . . . . . . . . . . 47

4.1 Variable Associations with Hazardous Waste Flows with Region-Specific Effects 61

4.2 Region-Specific Effects for the Origins of Hazardous Waste Flows $(\theta)$. . . . 64

4.3 Region-Specific Effects for the Destinations of Hazardous Waste Flows $(\phi)$. 66

4.4 Region-Specific Summary Effects of Hazardous Waste Flows $(\theta+\phi) \ldots$ 


\section{Chapter 1}

\section{Introduction}

In a world where economic development and benefits are often at odds with environmental quality and consequences, it is critically important to develop research that considers both. As researchers and policymakers strive to come up with ways to reduce the amount of hazardous waste generated and to reduce the amount of transport that takes place during the cradle-to-grave life cycle of hazardous waste, there are three questions concerning hazardous waste that are necessary to answer and fully understand: 1) who is generating it; 2) why is it being generated; and 3) where is it going? This dissertation aims to begin answering these questions by using economic methods to analyze various dimensions of the hazardous waste problem. This research provides new information to policymakers on the generation of industrial hazardous waste, the parties that are accountable for this hazardous waste generation, and the relationships that exist within the market for hazardous waste trade.

Chapter 2 examines industrial hazardous waste generation in the context of an inputoutput framework to link industrial hazardous waste generation to economic activity. Chapters 3 and 4 examine hazardous waste trade patterns using a spatial interaction modeling framework, which has long been used in many disciplines to study commodity flows, migration, and many other aspects of social behavior. Here, the economics of hazardous waste reduction are discussed briefly before providing additional detail on the two areas of focus. 


\subsection{The Economics of Hazardous Waste}

There are trade-offs among the benefits of the goods and services produced by hazardous waste generating industries and the negative externalities of the hazardous waste being produced. For this reason, immediately reducing hazardous waste generation to zero is highly unlikely. For example, hazardous waste is generated in the process of making lifesaving medications and equipment, fuels that power almost all modes of transportation, and the plastic and electronic gadgets that greatly simplify and enhance everyday life.

Figure 1.1: Stylized Hazardous Waste Reduction Relationships

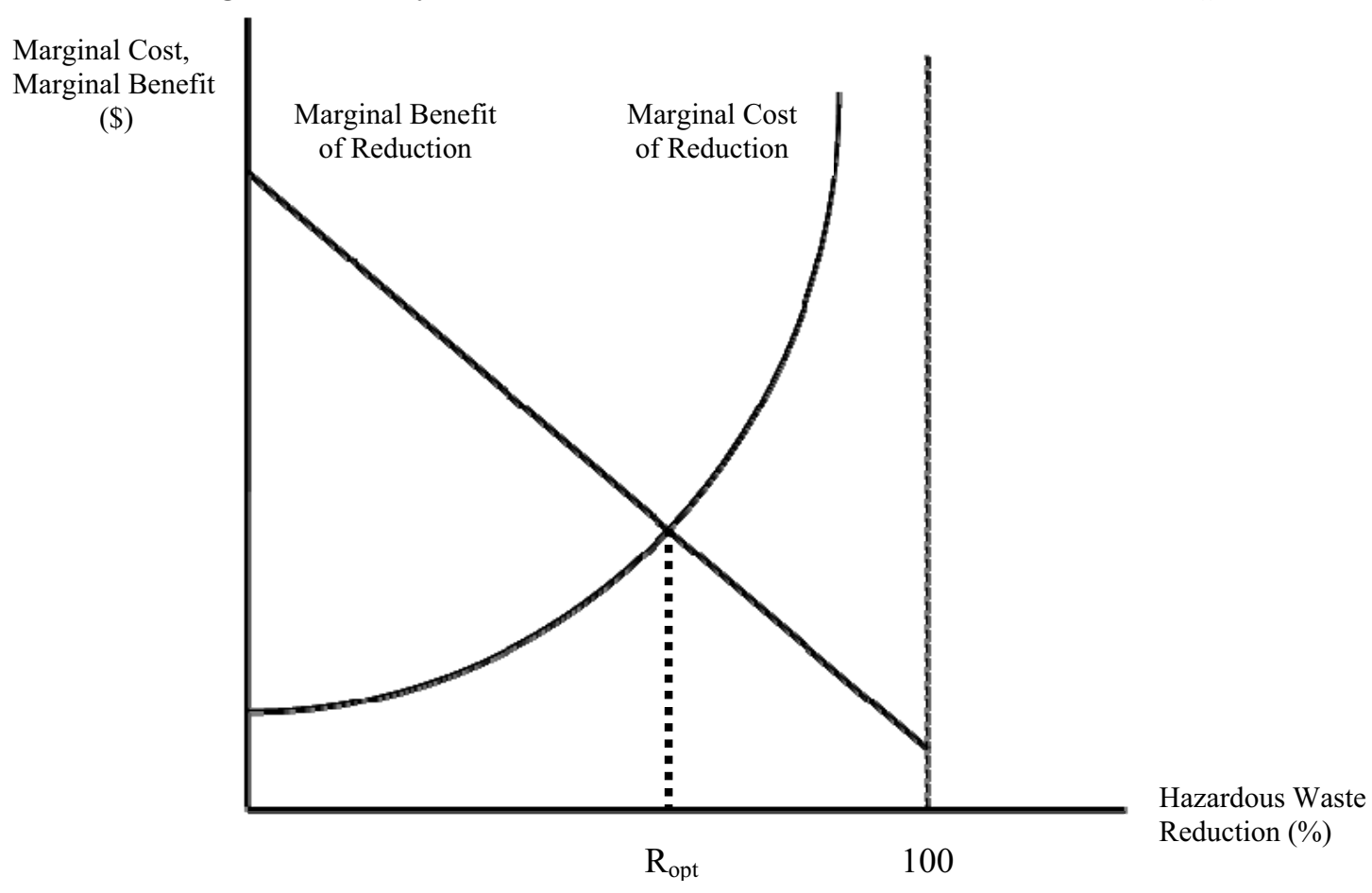

Although this dissertation does not attempt to determine the optimal amount of hazardous waste generation (or the level at which hazardous waste generation is effectively minimized), Figure 1.1 displays a stylized graph that generalizes how one might use economic principles to conceptualize the optimal level of hazardous waste reduction $\left(R_{\text {opt }}\right)$. The upward-sloping marginal cost curve indicates that as hazardous waste generation is reduced, the cost of reducing hazardous waste generation by an additional unit increases. As hazardous waste reduction approaches $100 \%$, industries might have to adopt cleaner technologies 
that are more expensive to operate or indeed the market might lose products that cannot be produced sans hazardous waste generation. The downward-sloping marginal benefit curve implies that as hazardous waste generation is reduced, the benefit of reducing generation by an additional unit decreases. In general, as less hazardous waste is produced, the possible negative health and environmental effects of hazardous waste subside, decreasing the benefit of additional reduction. Of course, this stylized example might not hold for all types of hazardous waste.

\subsection{Hazardous Waste Generation}

Hazardous waste generation has increased dramatically over time. Much of this increase is due to industrialization, changing and increasing consumption patterns, and increased economic activity in general. Amid changing attitudes about the environment and increasing sustainability concerns, many nations around the world aim to curb waste generation, especially that of hazardous waste. Beginning in the late 1970s and occurring increasingly since, governments and international bodies have passed legislation and treaties dealing with the reduction of hazardous waste generation and overall waste minimization.

Chapter 2 examines industrial hazardous waste generation in the United States for 2007. In an effort to provide policymakers with a clear foundation on industrial hazardous waste accounting, this chapter describes who, in terms of industries, is generating hazardous waste in the United States and why this generation is occurring, in terms of final demand groups. First, a simple industry level analysis examines how hazardous waste is generated in the United States. Direct hazardous waste generation by industry as well as direct hazardous waste intensity, i.e. hazardous waste generated per million dollars of industry output, are examined. Even this simple analysis begins to provide insights into producer accountability. The next step is to use economic modeling to provide further insight on producer accountability and to examine why hazardous waste is being generated. More specifically, which final demand groups are accountable for industry output and in turn, industrial hazardous waste generation.

This chapter uses the commodity by industry input-output framework to calculate haz- 
ardous waste multipliers and conduct analyses in hazardous waste accounting. Combining the input-output framework and data on hazardous waste generation to calculate hazardous waste multipliers helps in determining direct and indirect accountability for industrial hazardous waste generation. Also a final demand attribution analysis assigns accountability for industrial hazardous waste generation to final demand groups.

Such analyses provide information that policymakers need to inform and fashion rational and effective hazardous waste reduction laws in the United States. By understanding the relationships between economic activity and hazardous waste generation, policymakers can aim regulations at the producers and consumers who are accountable directly, indirectly, or in total. Results from this chapter suggest that regulations on production technologies as well as consumption patterns might be necessary to make large strides towards hazardous waste minimization in the United States. The methodologies and accounting techniques developed here serve as an example for other nations and pollutants as well.

\section{$1.3 \quad$ Hazardous Waste Trade}

As global economic activity increases, there has not only been a dramatic increase in hazardous waste generated; but due to its harmful nature, there are fewer and fewer places to dispose of it. With globalization on the rise in many markets, it has become commonplace for cities, regions, and even nations to export and/or import hazardous waste. The final $W$, where, of hazardous waste is examined by analyzing data on hazardous waste shipments within the United Kingdom. The research presented in Chapters 3 and 4 extends the literature on international hazardous waste trade to the case of sub-national or intranational shipments. This is an important aspect of hazardous waste trade as over $95 \%$ of hazardous waste generated in developed areas, such as the United States and the United Kingdom, is traded and managed within national boundaries. Also, analyzing hazardous waste shipments within a nation provides insights into movements and relationships over which national policymakers have full jurisdictional authority.

Chapter 3 examines hazardous waste shipments in the United Kingdom in an effort to understand the characteristics associated with hazardous waste moving from one region to 
another. In the past, trade in hazardous waste has often been modeled as the one-sided relationship that exists between management or disposal locations and various destinationspecific characteristics. Chapter 3 proposes a variant of the traditional spatial interaction model to take a closer look at both sides of the hazardous waste flow relationship. Hazardous waste flows are analyzed as a function of economic, demographic, and hazardous waste related characteristics at the origin and destination regions and as a function of adjacency and the distance between the two regions.

Chapter 4 builds on Chapter 3 and uses a spatial econometric variant of the spatial interaction model to test whether region-specific effects exist within the United Kingdom's hazardous waste flows and whether these region-specific effects are spatially structured. Results suggest that there are significant region-specific effects for both origin and destination regions but that no significant spatial dependence exists in these effects for either the origins or destinations.

The final chapter of this dissertation concludes and provides possible directions for future research on the three $W$ 's of hazardous waste. 


\section{Chapter 2}

\section{Enhancing Hazardous Waste Accounting through Economic Modeling}

The reduction of solid wastes is becoming a primary focus of numerous national administrations and environmental agencies around the world, the United States (U.S.) notwithstanding. Many proposed waste minimization strategies include specific goals and regulations for the reduction of hazardous waste generation due to its high-risk, negative externalities on human health and the environment. Since human and natural systems are inherently connected, environmental policies can significantly affect the economy; and economic policies can also have considerable impacts on the environment. The connections between economic activity and industrial hazardous waste generation have yet to be fully explored. A better understanding of these connections is critical to the implementation of effective hazardous waste reduction strategies.

To provide additional information to industry and policy decisionmakers, this chapter provides a closer examination of the economic processes and interrelationships through which hazardous waste is generated, i.e., the hazardous waste economy. Detailed information on the current state of the hazardous waste economy can be used to identify how hazardous waste is being generated, why this hazardous waste is being generated, and which activities might best be targeted in hazardous waste reduction strategies. 
While multiple modeling techniques can be employed to relate environmental outcomes to economic activity, it is important to select a method that is transparent, easily interpreted, and consistent with the goals at hand. For these reasons, environmental accounting methods based on an input-output framework are proposed as a means to examine the relationships between economic activity and industrial hazardous waste generation within the U.S. Hazardous waste generation is accounted for not only in terms of direct generation but in terms of direct, indirect, and total hazardous waste intensities (hazardous waste generated per million dollars of output) as well as generation attributed to final demand groups. The results are analyzed from multiple perspectives and discussed in terms of policy relevance.

The remainder of this chapter is organized as follows. Section 2.1 provides a brief review of the literature on input-output based environmental accounting. Section 2.2 briefly describes the modeling framework employed in this paper. Section 2.3 describes the data on both the economy and industrial hazardous waste generation in the U.S. Section 2.4 presents the results and examines their policy relevance. Section 2.5 concludes.

\subsection{Methodological Background}

Wassily Leontief was one of the first economists to use the input-output framework for an environmental application (Leontief, 1970). In this seminal paper, Leontief's goal was to incorporate environmental externalities into the input-output framework to model the interdependence between the economic system and its inherent environmental consequences. To do so, a pollution creation sector and a pollution cleaning sector were integrated within the traditional input-output model. This paper sparked an interest in incorporating environmental information into models of the economic system.

Afterwards, a divergence in the literature on quantifying the economy's impact on the environment ensued. One branch of the literature pursued the analytical adaptation of the Leontief (1970) model (Lowe, 1979; Duchin, 1990; Qayum, 1991; Arrous, 1994; Luptacik and Bohm, 1999; Allan et al., 2007) while the other followed more of a satellite accounts approach to extending the input-output system to include environmental information. The latter direction consists of so-called environmentally extended input-output systems that 
have been used for many years to investigate many types of environmental factors including energy intensities (Wright, 1974; Bullard and Herendeen, 1975; Miller and Blair, 1985; Cruz, 2010), water (Lenzen and Foran, 2001; Dietzenbacher and Velazquez, 2007) and $\mathrm{CO}_{2}$ emissions (Gale, 1995; McGregor et al., 2008). For a more complete review of the history of theoretical extensions of the input-output framework as it relates to the environment and of applications of environmentally extended input-output systems, see Richardson (1972, Chapter 11), Forsund (1985), Miller and Blair (1985, Chapter 7), Forssell and Polenske (1998), Cruz et al. (2005), and Miller and Blair (2009, Chapter 10).

Environmentally extended input-output frameworks are also directly related to another literature on input-output based attribution analyses as they relate to environmental issues. Wiedmann et al. (2006) introduced an input-output approach for reallocating ecological footprint data by economic sector, final consumption group, sub-national geographic specification, and by socioeconomic group. Using a commodity by industry input-output approach (supply and use table framework), they allocate the United Kingdom's ecological footprint to detailed consumption categories. Jensen et al. (2012) use a similar approach with an industry by industry system and outline different input-output based environmental accounting techniques. The inherent assumptions, benefits, and drawbacks of each specification are described in detail and these techniques are applied to an analysis of total commercial and industrial waste arisings in Wales, United Kingdom.

Within the literature specifically focusing on carbon $\left(\mathrm{CO}_{2}\right)$ accounting, there is an ongoing debate over appropriate accounting methodologies in terms of responsibility, i.e., production versus consumption accounting. Production accounting allocates emissions to the sectors and processes (typically industries and households) that physically emit pollutants into the atmosphere, and consumption accounting allocates the same emissions to the final users of the goods and services (Munksgaard and Pedersen, 2001). Gallego and Lenzen (2005), Lenzen et al. (2007), Peters (2008), and Andrew and Forgie (2008) also explore the consideration of shared responsibility between the production and consumption sides of the economy. Although the issues of responsibility also apply in the case of hazardous waste generation, this chapter analyzes results from both production and consumption accounting frameworks but leaves the examination of issues relating to responsibility to future research. 
Yet another literature on waste input-output (WIO) models also warrants discussion. First introduced in Nakamura (1999) and Nakamura and Kondo (2002), the WIO model incorporates waste creation and waste management into the input-output framework. Nakamura and Kondo (2009) provide a comprehensive overview of the WIO model, its extensions, and its applications. To date, the WIO model has been used to analyze sustainable consumption (Takase et al., 2005), end-of-life appliances (Kondo and Nakamura, 2004), and its relationship to other modeling frameworks such as materials flows analysis (Nakamura and Nakajima, 2005), life cycle analysis and life cycle cost analysis (Rebitzer and Nakamura, 2008), and linear programming (Kondo and Nakamura, 2005). Data on U.S. waste management technologies are not yet available to enable an analysis as in depth as that of the WIO model, but progress can be made towards accounting for U.S. hazardous waste generation in different ways.

Although similar in motivation to both Jensen et al. (2012) and the WIO model, this chapter uses the commodity by industry framework and analyzes the current state of the U.S. hazardous waste economy. This research provides information that not only allows decisionmakers to choose between policies or programs aimed at reducing hazardous waste generation from the production or consumption sides of the economy, but also provides information on each perspective once this decision is made. Additionally, this chapter also contributes to the growing literature on U.S. hazardous waste, which is skewed towards hazardous waste trade, the siting of hazardous waste management and disposal facilities, and the cleanup of sites contaminated by hazardous materials.

\subsection{Accounting Framework}

National input-output accounts for the U.S. are made available by the Bureau of Economic Analysis (BEA) as a system of commodity by industry accounts. Although much of the academic input-output literature focuses on industry-based (interindustry) accounts, many nations now publish their national accounts in the commodity by industry framework. ${ }^{1}$

\footnotetext{
${ }^{1}$ The availability of commodity by industry national accounts has been encouraged by the United Nations (U.N.). Since 1968, the U.N. has published a handbook of international standards for the collection and reporting of commodity by industry national accounts statistics, the U.N. System of National Accounts.
} 
Rather than converting immediately to a system of interindustry accounts, this section provides a methodology for incorporating hazardous waste data and implementing input-output accounting methods using the commodity by industry structure. This framework provides detailed information on the relationships that exist among industries and the commodities they use and produce. It also allows for the consideration of not only each industry's primary output, but also the production of secondary commodity outputs, or byproducts, that are an important consideration in environmental applications.

The U.S. system of national accounts is structured as in Table 2.1:

Table 2.1: BEA U.S. National Accounting Structure

\begin{tabular}{lcccc}
\hline & Commodities & Industries & Final Demand & Total Output \\
\hline Commodities & & $\mathbf{U}$ & $\mathbf{e}$ & $\mathbf{q}$ \\
Industries & $\mathbf{V}$ & & & $\mathbf{g}$ \\
Value Added & & $\mathbf{Z}$ & & \\
Total Inputs & $\mathbf{q}^{\prime}$ & $\mathbf{g}^{\prime}$ & & \\
\hline
\end{tabular}

Let $n$ represent the number of industries in the economy and $k$ represent the number of commodities. $\mathbf{U}$ is the $k \times n$ Use matrix where each column describes the corresponding industry's use of commodities in their production process, $\mathbf{V}$ is the $n \times k$ Make matrix where each row describes the amount of each commodity produced by a given industry, $\mathbf{e}$ is a $k \times 1$ vector of total commodity final demand that includes household consumption, government expenditures, investment, foreign exports, and foreign imports (negative values), and $\mathbf{Z}$ is a $3 \times n$ matrix of value added that includes rows for employee compensation, taxes, and gross operating surplus. Then, $\mathbf{q}$ is a $k \times 1$ vector of total commodity output and $\mathbf{g}$ is an $n \times 1$ vector of total industry output.

Within the U.S. data, each column of $\mathbf{U}$ describes the total value of each row commodity used by an industry irrespective of the commodity's origin of production. This means that domestically produced as well as imported commodity inputs are included within $\mathbf{U}$. In the past, the literature has referred to this form of the Use matrix as "import-ridden." Therefore, direct and total requirements matrices calculated using this form of the Use matrix will include both imported and domestically produced input requirements. For example, the 
industry by commodity total requirements matrix published by the BEA represents the total row industry input (domestically produced and imported) per million dollars of total column commodity final demand.

As the objective of this chapter is to account for domestically generated hazardous waste, the imported commodity inputs need to be removed. This adjustment for imports can happen in two ways. First, if it is available, an import matrix representing each industry's use of imported commodities can be used. The import matrix would simply be subtracted from the "import-ridden" Use matrix to yield a domestic Use matrix. However, it is often the case that an import matrix is unavailable. Jackson (1998) provides a second approach for adjusting for imports. His approach is also designed to remove imported inputs from the requirements table specifications but does so without the additional information provided in the import matrix.

The structure of the U.S. national accounts is adjusted for imports as represented by Table 2.2:

Table 2.2: Jackson's 1998 Modification of U.S. National Accounting Structure

\begin{tabular}{lcccc}
\hline & Commodities & Industries & Final Demand & Total Output \\
\hline Commodities & & $\mathbf{U}$ & $\mathbf{e}$ & $\mathbf{s}$ \\
Industries & $\mathbf{V}$ & & & $\mathbf{g}$ \\
Imports & $\mathbf{m}^{\prime}$ & & & $\mathbf{m}^{\prime} \iota$ \\
Value Added & & $\mathbf{Z}$ & & \\
Total Inputs & $\mathbf{s}^{\prime}$ & $\mathbf{g}^{\prime}$ & & \\
\hline
\end{tabular}

$\mathbf{U}, \mathbf{V}, \mathbf{Z}$, and $\mathbf{g}$ are defined as before. However, in this system of accounts, the negative values for commodity imports have been removed from final demand and are appended to $\mathbf{V}$ as positive values, $\mathbf{m}$, representing a "rest-of-world" row of the Make matrix. e now includes only household consumption, government expenditures, investment, and foreign exports. s is a $k \times 1$ vector of total commodity supply and $\mathbf{m}^{\prime} \iota$ is the value of total commodity imports. Jackson and Schwarm (2011) also discuss this adjustment in the context of moving from a system of national to regional accounts.

Since V represents the relationships that exist between commodity and industry output, 
the standardized version of this matrix provides information for tranformation from commodity to industry space. When $\mathbf{V}$ is standardized by total commodity supply rather than total commodity output, then premultiplication by this matrix not only acts to transform from commodity to industry space but also rids the transformed matrix of imported inputs. This will become more apparent in the detailed description of the methodological framework that follows.

The effect of either approach is to focus any analyses on the impacts to the domestic economy as a result of final demand changes. When integrated with data on U.S. industrial hazardous waste generation, these methods will account for hazardous waste that is generated within U.S. borders to satisfy domestic and export final demand. Although an imports matrix is available for the system of U.S. national accounts, this chapter implements the second approach so that the methodology presented can be replicated for nations or regions for which an import matrix is not available. ${ }^{2}$

Using the system represented by Table 2.2, the following equations describe the basic identities underlying this approach:

$$
\begin{gathered}
\mathbf{s}=\mathbf{U} \iota+\mathbf{m}+\mathbf{e} \\
\mathbf{g}=\mathbf{V} \iota+\mathbf{h} \\
\mathbf{h}=\hat{\mathbf{p}} \mathbf{g}
\end{gathered}
$$

where $\mathbf{s}$ is a $k \times 1$ vector of total commodity supply, $\mathbf{U}$ is the $k \times n$ "import-ridden" Use matrix, $\iota$ is a summation vector of appropriate dimension, $\mathbf{m}$ is a $k \times 1$ vector of commodity imports (positive values), $\mathbf{e}$ is a $k \times 1$ vector of total commodity final demand, $\mathbf{g}$ is an $n \times 1$ vector of total industry output, $\mathbf{V}$ is the $n \times k$ Make matrix, $\mathbf{h}$ is an $n \times 1$ vector of each industry's total production of scrap, and $\mathbf{p}$ is an $n \times 1$ vector that represents each industry's ratio of the value of scrap produced to total industry output. The ${ }^{\wedge}$ symbol indicates the diagonalization of a vector.

\footnotetext{
${ }^{2}$ Note that direct and total requirements values will differ between the two approaches due to the difference in actual or implied distribution of imported commodity inputs. Although not performed for reasons related to generalization, when available, the use of the import matrix is the preferred method for removing imported commodity inputs from the Use matrix.
} 
Standardized tables are calculated as follows:

$$
\begin{gathered}
\mathbf{B}=\mathbf{U} \hat{\mathbf{g}}^{-1} \\
\mathbf{D}=\mathbf{V} \hat{\mathbf{s}}^{-1} \\
\mathbf{W}=(\mathbf{I}-\hat{\mathbf{p}})^{-1} \mathbf{D}
\end{gathered}
$$

where $\mathbf{B}$ is the $k \times n$ standardized Use matrix where each column details the value of inputs of each commodity per dollar's worth of the respective industry's output, $\mathbf{D}$ is the $n \times k$ standardized Make matrix where each column details the proportion of the respective commodity's output produced by each industry, and $\mathbf{W}$ is the $n \times k$ standardized Make matrix that has been adjusted for scrap output. ${ }^{3}$ It is now possible to define the total requirements matrix in both industry by commodity and industry by industry space as follows:

$$
\begin{gathered}
\mathbf{L}_{I \times C}=\mathbf{W}(\mathbf{I}-\mathbf{B W})^{-1} \\
\mathbf{L}_{I \times I}=(\mathbf{I}-\mathbf{W B})^{-1}
\end{gathered}
$$

As previously mentioned, the multiplication of the standardized Use matrix and the Make matrix that is standardized by total commodity supply essentially removes imported commodity inputs, resulting in a $k \times k$ matrix of direct requirements in commodity by commodity space, BW, whose elements represent domestic commodity inputs per million dollars' worth of commodity output. A similar direct requirements matrix in industry by industry space, defined as WB, can also be calculated that represents domestic industry inputs per million dollars' worth of industry output. The total requirements matrices, or multiplier matrices, defined above represent the domestic row industry input per million dollars of total column commodity final demand, $\mathbf{L}_{I \times C}$, and the domestic row industry input per million dollars of total column industry final demand, $\mathbf{L}_{I \times I}$, respectively.

\footnotetext{
${ }^{3}$ Methods derived by the Bureau of Economic Analysis are used for the treatment of Noncomparable Imports and the production of Scrap, Second-hand and Used Goods (see Horowitz and Planting (2006) for additional details on these methods).
} 
The final equation that identifies the full accounting framework can be written in terms of either of these total requirements matrices:

$$
\begin{gathered}
\mathbf{g}=\left(\mathbf{L}_{I \times C}\right) \mathbf{e} \\
\mathbf{g}=\left(\mathbf{L}_{I \times I}\right) \mathbf{W e}
\end{gathered}
$$

In the case of (2.10), We represents the transformation of total commodity final demand, e, to industry final demand. All model specifications within this chapter are open with respect to households, meaning that households are exogenous to the production system.

To incorporate information on industrial hazardous waste generation, a vector of direct hazardous waste intensities, $\omega$, is included. Each element of $\omega$ represents the tons of hazardous waste generated per million dollars of industry output. The hazardous waste data can be incorporated in either specification of the system as follows:

$$
\begin{gathered}
\omega \mathbf{g}=\omega\left(\mathbf{L}_{I \times C}\right) \mathbf{e} \\
\omega \mathbf{g}=\omega\left(\mathbf{L}_{I \times I}\right) \mathbf{W e}
\end{gathered}
$$

The addition of the industry-specific direct hazardous waste intensities transforms the inputoutput framework from one that accounts for total domestic industry output, as in (2.9) and (2.10), to one that accounts for total domestic industrial hazardous waste generation.

$\omega\left(\mathbf{L}_{I \times C}\right)$ and $\omega\left(\mathbf{L}_{I \times I}\right)$ can now be labeled hazardous waste multiplier matrices. The elements of $\omega\left(\mathbf{L}_{I \times C}\right)$ represent domestic row industry hazardous waste generation per million dollars of total column commodity final demand. Hazardous waste multipliers, calculated as the column sums of $\omega\left(\mathbf{L}_{I \times C}\right)$, are interpreted as tons of hazardous waste generated within the U.S. per million dollars of commodity final demand. The elements of $\omega\left(\mathbf{L}_{I \times I}\right)$ represent domestic row industry hazardous waste generation per million dollars of total column industry final demand. Multipliers calculated from this matrix are interpreted as tons of hazardous waste generated within the U.S. per million dollars of industry final demand.

Using this general accounting framework, relationships within the U.S. hazardous waste economy can be examined from either a production accounting approach or a partial consumption accounting approach. The production accounting approach allocates hazardous 
waste generation to the industries (and, consequently, the production processes) that physically generate hazardous waste. The partial consumption accounting approach is used to allocate the same industrial hazardous waste generation to the final demand sectors of the economy. Different representations of results from both approaches are discussed in section 2.4 .

\subsection{Data}

Input-output data for the U.S. economy were obtained from the BEA Annual Industry Accounts. Make and Use matrices are used along with data on value-added by industry and various final demand categories by commodity. This paper uses the same sector aggregation scheme used in all BEA Annual tables with the one exception that all government sectors have been aggregated resulting in $n=62$ industries and $k=64$ commodities; details can be found on the BEA website (www.bea.gov/industry/io_annual.htm). Input-output data for 2007 are used along with the data on total hazardous waste generation by industry, described below, for all accounting techniques. All economic data are in millions of U.S. dollars.

Prior to the 1960s, federal regulation of waste (including hazardous waste) was almost non-existent in the U.S. and regulations at other government levels only existed in a few states. Growing concern for both environmental and health hazards in the mid 1970s spawned the first true federal hazardous waste legislation, subtitle $\mathrm{C}$ of the Resource Conservation and Recovery Act of 1976 (RCRA). One of the main goals of this legislation in its entirety was to reduce the amount of municipal and industrial hazardous and non-hazardous waste generated within the U.S. Subtitle C of RCRA was, and remains, the primary regulatory document governing the generation, management, transportation, and disposal of hazardous waste. RCRA Subtitle C not only identified and defined different types of hazardous waste and created performance standards for its treatment, storage, and disposal, but it also established a permitting and tracking system that allows the U.S. Environmental Protection Agency (EPA) to collect data on the cradle-to-grave life cycle of hazardous waste within the U.S.

Eventually, the EPA introduced what is known as the Biennial Reporting System (BRS). The BRS is a national system that biennially collects detailed data from large quantity 
generators $^{4}$ on the generation, management, and transport of hazardous waste. Generally, hazardous waste is described as any waste that is potentially harmful to human health and/or the environment. To tightly regulate hazardous waste in accordance with RCRA legislation, the EPA needed a more descriptive and comprehensive definition. In all BRS data, and consequently in this chapter, hazardous waste is identified as waste with ignitable, corrosive, toxic, and/or reactive properties. EPA (2008) provides more information regarding the definitions of RCRA hazardous waste. RCRA hazardous wastes do not include nuclear wastes, which are regulated by the Nuclear Regulatory Commission.

BRS data for every other year between 1991 and 2007 are made publicly available by the EPA and are also accessible through a database maintained by the Right-to-Know Network (RTK NET) (http://www.rtknet.org/db/brs). Due to the amount of detail available and accessibility of the RTK NET database, it is used for all hazardous waste data within this chapter. Beginning in 2001, the EPA began requiring the generating industries to report their primary activity by North American Industry Classification System code. Data on total hazardous waste generation ${ }^{5}$ by industry for 2007 were collected and aggregated in accordance with the input-output data.

\subsection{Results and Discussion}

\subsubsection{Production Accounting}

A quick review of environmental regulations and legislation related to hazardous waste in the U.S. suggests that the federal government is committed to minimizing the amount of hazardous waste generated and that regulating industries (or source reduction) is the preferred means to doing so. Accounting for hazardous waste from the production side of the economy can take place on many levels.

\footnotetext{
${ }^{4} \mathrm{~A}$ hazardous waste generator is considered a federal large quantity generator if it "generated in any single month $1,000 \mathrm{~kg}(2,200$ pounds or 1.1 tons) or more of RCRA hazardous waste; or the generator generated in any single month or accumulated at any time, $1 \mathrm{~kg}$ ( 2.2 pounds) of RCRA acute hazardous waste; or the generator generated, or accumulated at any time, more than $100 \mathrm{~kg}$ (220 pounds) of spill cleanup material contaminated with RCRA acute hazardous waste." (EPA, 2007)

${ }^{5}$ RTK NET summary reports define tons generated as the total tons of waste generated at a BRS facility in the current (reporting) year that is either later managed on site or shipped offsite for management.
} 


\section{Direct Hazardous Waste Generation}

First, a simple industry-based analysis can address generation of hazardous waste in two different ways: 1) by examining direct hazardous waste generation by industry or 2) by examining direct hazardous waste generation per million dollars of industry output, i.e., an industry's direct hazardous waste intensity. Table 2.3 displays the results of such an analysis for 2007 sorted from highest to lowest values in terms of direct hazardous waste generation.

As shown in Figure 2.1, just six of the sixty-two industries are responsible for around 98\% of total hazardous waste generation in the U.S.: Chemical products; Petroleum and coal products; Waste management and remediation services; Primary metals; Computer and electronic products; and Fabricated metal products. These findings are consistent with an analysis of 1995 BRS data by McGlinn (2000), who also found that the petrochemical industries in the Gulf Coast region were responsible for a large majority of hazardous waste generation. The only industry within this aggregation scheme that does not produce any hazardous waste is Legal services.

Figure 2.1: Total U.S. Hazardous Waste Generation by Industry for 2007

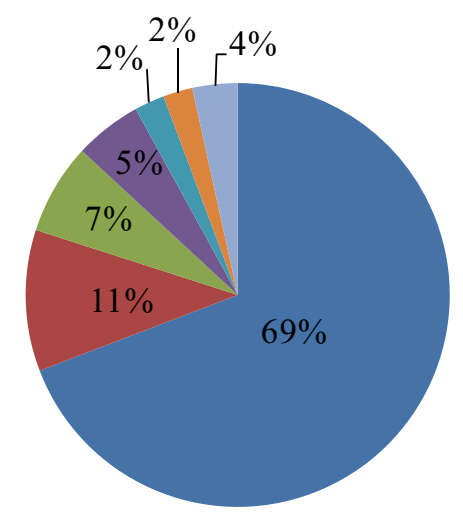

Source: http://www.rtknet.org/db/brs
- Chemical Products

Petroleum and Coal Products

- Waste Management and Remediation Services

- Primary Metals

Computer and Electronic Products

Fabricated Metal Products

- Other

Economic data are first incorporated through the element--wise division of the industrylevel direct hazardous waste generation data with known total output by industry. The result is direct hazardous waste intensity by industry. From Table 2.3, it is obvious that many of the industries that produced the largest amounts of hazardous waste are also the industries with the highest direct hazardous waste intensities, but this is not always the 
Table 2.3: Total Hazardous Waste Generation and Intensity by Industry, 2007

\begin{tabular}{|c|c|c|}
\hline Industry & $\begin{array}{r}\begin{array}{r}\text { Generation } \\
\text { (tons) }\end{array} \\
\end{array}$ & $\begin{array}{r}\text { Intensity } \\
(\text { tons } / \$ M) \\
\end{array}$ \\
\hline Chemical products & $3232,958,431.07$ & 52.92 \\
\hline Petroleum and coal products & $5,131,779.13$ & 8.83 \\
\hline Waste management and remediation services & $3,300,082.34$ & 44.11 \\
\hline Primary metals & $2,443,573.27$ & 10.21 \\
\hline Computer and electronic products & $1,096,635.19$ & 2.90 \\
\hline Fabricated metal products & $1,071,080.98$ & 3.37 \\
\hline Electrical equipment, appliances, and components & $257,747.45$ & 2.11 \\
\hline Government & $166,196.36$ & 0.06 \\
\hline Warehousing and storage & $138,068.37$ & 2.57 \\
\hline Other transportation equipment & $103,741.46$ & 0.48 \\
\hline Administrative and support services & $96,724.12$ & 0.16 \\
\hline Wholesale trade & $96,358.44$ & 0.08 \\
\hline Motor vehicles, bodies and trailers, and parts & $84,511.67$ & 0.18 \\
\hline Plastics and rubber products & $62,897.25$ & 0.31 \\
\hline Nonmetallic mineral products & $60,960.93$ & 0.52 \\
\hline Machinery & $53,912.91$ & 0.17 \\
\hline Wood products & $48,900.63$ & 0.50 \\
\hline Miscellaneous professional, scientific and technical services & $45,463.86$ & 0.04 \\
\hline Construction & $43,055.01$ & 0.03 \\
\hline Miscellaneous manufacturing & $40,780.74$ & 0.26 \\
\hline Utilities & $31,603.36$ & 0.07 \\
\hline Other transportation and support activities & $31,413.11$ & 0.23 \\
\hline Real estate & $29,741.15$ & 0.01 \\
\hline Printing and related support activities & $27,813.67$ & 0.28 \\
\hline Other services, except government & $22,917.67$ & 0.03 \\
\hline Paper products & $18,305.24$ & 0.11 \\
\hline Educational services & $17,375.34$ & 0.09 \\
\hline Furniture and related products & $17,146.32$ & 0.22 \\
\hline Rental and leasing services and lessors of intangible assets & $13,544.66$ & 0.04 \\
\hline Transit and ground passenger transportation & $13,410.18$ & 0.43 \\
\hline Rail transportation & $12,227.00$ & 0.19 \\
\hline Oil and gas extraction & $11,990.69$ & 0.04 \\
\hline Hospitals and nursing and residential care facilities & $11,597.27$ & 0.02 \\
\hline Food services and drinking places & $11,472.24$ & 0.02 \\
\hline Broadcasting and telecommunications & $6,993.38$ & 0.01 \\
\hline Apparel and leather and allied products & $6,895.83$ & 0.22 \\
\hline Textile mills and textile product mills & $6,806.64$ & 0.11 \\
\hline Pipeline transportation & $6,378.73$ & 0.18 \\
\hline Water transportation & $5,186.99$ & 0.14 \\
\hline Food and beverage and tobacco products & $4,661.59$ & 0.01 \\
\hline Mining, except oil and gas & $4,260.29$ & 0.05 \\
\hline Ambulatory health care services & $4,087.90$ & 0.01 \\
\hline Motion picture and sound recording industries & $3,851.49$ & 0.04 \\
\hline Air transportation & $3,728.62$ & 0.02 \\
\hline Retail trade & $3,642.13$ & 0.00 \\
\hline Truck transportation & $2,334.56$ & 0.01 \\
\hline Support activities for mining & $2,235.16$ & 0.02 \\
\hline Amusements, gambling, and recreation industries & $1,946.99$ & 0.02 \\
\hline Farms & $1,667.80$ & 0.01 \\
\hline Securities, commodity contracts, and investments & 756.75 & 0.00 \\
\hline Forestry, fishing, and related activities & 440.83 & 0.01 \\
\hline Management of companies and enterprises & 187.59 & 0.00 \\
\hline Computer systems design and related services & 169.61 & 0.00 \\
\hline Performing arts, spectator sports, museums, and related activities & 157.31 & 0.00 \\
\hline Publishing industries (includes software) & 136.87 & 0.00 \\
\hline Accommodation & 80.64 & 0.00 \\
\hline Social assistance & 43.06 & 0.00 \\
\hline Federal Reserve banks, credit intermediation, and related activities & 30.15 & 0.00 \\
\hline Information and data processing services & 28.75 & 0.00 \\
\hline Funds, trusts, and other financial vehicles & 4.25 & 0.00 \\
\hline Insurance carriers and related activities & 2.75 & 0.00 \\
\hline Legal services & 0.00 & 0.00 \\
\hline
\end{tabular}


case. Consider the aggregated Government industry, which includes all federal, state, and local government enterprises and activities. This industry is responsible for the eighth largest amount of hazardous waste generation in terms of physical tons. However, this same industry has a direct hazardous waste intensity of only 0.06 tons per million dollars of industry output, which is considerably lower than that of any of the other ten largest hazardous waste generators.

At this point, whether industry-level hazardous waste generation is examined as direct generation or direct intensity, it is clear that only a few industries are accountable for most of the hazardous waste in the U.S. This information can be enhanced further by using the input-output accounting framework.

\section{Hazardous Waste Multipliers}

To supplement this examination of direct hazardous waste generation, an input-output multiplier analysis is used to calculate a hazardous waste multiplier for each industry, which represents a measure of the total amount of hazardous waste generated within the economy as a result of exogenous final demand of output. An input-output multiplier analysis allows one to examine different measures of hazardous waste generated as a result of economic activity. Ultimately, these hazardous waste multipliers could also provide information on the hazardous waste impacts of changes in final demand activity that will result from any regulation put in place by decisionmakers. As this chapter is intended to provide information to decisionmakers prior to the implementation of regulations, hazardous waste impact analyses are reserved as the focus of future research. The purpose of this section is then to calculate hazardous waste multipliers, break these multipliers down into their disaggregate direct and indirect components, and to highlight the implications of this information to policy considerations.

As information on direct hazardous waste intensities are initially reported by industry, this analysis employs the industry by industry total requirements matrix, $\mathbf{L}_{I \times I}$, along with the hazardous waste intensities by industry, $\omega$, to produce a hazardous waste multiplier matrix from which Type I hazardous waste multipliers are calculated as the column sums of $\omega\left(\mathbf{L}_{I \times I}\right)$. Recall that hazardous waste multipliers calculated in this way measure the tons of 
hazardous waste generated directly and indirectly within the U.S. per million dollars of final demand for a given industry's output, i.e., each industry's total hazardous waste intensity. These hazardous waste multipliers provide useful information on their own, but disaggregation of their component parts allows one to highlight the allocation of total hazardous waste intensities to their direct and indirect components.

For clarification, the hazardous waste multipliers represent the total hazardous waste intensity of an industry, i.e., total (direct and indirect) hazardous waste generation occurring within the economy to satisfy one million dollars of final demand for an industry's output. Each industry's total hazardous waste intensity can then be broken down into its direct and indirect components: direct hazardous waste intensity represents the amount of direct hazardous waste generation by a given industry per million dollars of final demand for its output (equivalent to the amount of hazardous waste produced by the industry per million dollars of its own output) and indirect hazardous waste intensity represents indirect hazardous waste generation through supply chain production per million dollars of final demand for an industry's output.

Table 2.4 displays the breakdown of the Type I industry by industry multipliers sorted from highest to lowest direct hazardous waste intensity. The column labeled "Direct" displays direct hazardous waste intensities. The column labeled "Total" represents the Type I hazardous waste multipliers or the total hazardous waste intensities. Finally, the column labeled "Indirect" represents indirect hazardous waste intensities, the hazardous waste generated indirectly through supply chain production per million dollars of final demand, and is calculated as "Total" - "Direct." There are notable differences across sectors with respect to how the hazardous waste multiplier values are distributed.

The industry with the highest direct hazardous waste intensity is Chemical products, generating 52.92 tons of hazardous waste per million dollars of final demand. This industry also has the largest total hazardous waste intensity indicating that for every one million dollars of final demand for the output of the Chemical products industry, 66.44 tons of hazardous waste are generated (directly and indirectly) by the economy. Although this industry ranks highly in terms of both the direct and total hazardous waste intensity, this is not always the case. Further consideration of these two terms can provide additional information to 
Table 2.4: Breakdown of Industry $\times$ Industry Hazardous Waste Multipliers (tons $/ \$ M$ )

\begin{tabular}{|c|c|c|c|}
\hline Industry & Direct & Indirect & Total \\
\hline Chemical products & 52.92 & 13.52 & 66.44 \\
\hline Waste management and remediation services & 44.11 & 8.48 & 52.59 \\
\hline Primary metals & 10.21 & 4.36 & 14.57 \\
\hline Petroleum and coal products & 8.83 & 2.64 & 11.47 \\
\hline Fabricated metal products & 3.37 & 4.16 & 7.52 \\
\hline Computer and electronic products & 2.90 & 2.18 & 5.07 \\
\hline Warehousing and storage & 2.57 & 0.53 & 3.10 \\
\hline Electrical equipment, appliances, and components & 2.11 & 4.29 & 6.40 \\
\hline Nonmetallic mineral products & 0.52 & 2.52 & 3.04 \\
\hline Wood products & 0.50 & 2.26 & 2.76 \\
\hline Other transportation equipment & 0.48 & 2.86 & 3.34 \\
\hline Transit and ground passenger transportation & 0.43 & 1.66 & 2.09 \\
\hline Plastics and rubber products & 0.31 & 16.41 & 16.72 \\
\hline Printing and related support activities & 0.28 & 3.10 & 3.38 \\
\hline Miscellaneous manufacturing & 0.26 & 4.11 & 4.38 \\
\hline Other transportation and support activities & 0.23 & 0.96 & 1.19 \\
\hline Apparel and leather and allied products & 0.22 & 2.23 & 2.45 \\
\hline Furniture and related products & 0.22 & 2.99 & 3.21 \\
\hline Rail transportation & 0.19 & 1.24 & 1.43 \\
\hline Pipeline transportation & 0.18 & 2.51 & 2.69 \\
\hline Motor vehicles, bodies and trailers, and parts & 0.18 & 3.71 & 3.89 \\
\hline Machinery & 0.17 & 3.28 & 3.45 \\
\hline Administrative and support services & 0.16 & 1.33 & 1.49 \\
\hline Water transportation & 0.14 & 1.42 & 1.56 \\
\hline Paper products & 0.11 & 4.61 & 4.72 \\
\hline Textile mills and textile product mills & 0.11 & 12.17 & 12.28 \\
\hline Educational services & 0.09 & 0.93 & 1.02 \\
\hline Wholesale trade & 0.08 & 0.65 & 0.73 \\
\hline Utilities & 0.07 & 0.66 & 0.73 \\
\hline Government & 0.06 & 1.85 & 1.91 \\
\hline Mining, except oil and gas & 0.05 & 1.73 & 1.78 \\
\hline Oil and gas extraction & 0.04 & 1.46 & 1.51 \\
\hline Miscellaneous professional, scientific and technical services & 0.04 & 1.06 & 1.10 \\
\hline Rental and leasing services and lessors of intangible assets & 0.04 & 0.80 & 0.84 \\
\hline Motion picture and sound recording industries & 0.04 & 0.70 & 0.74 \\
\hline Construction & 0.03 & 2.17 & 2.20 \\
\hline Other services, except government & 0.03 & 1.83 & 1.86 \\
\hline Air transportation & 0.02 & 2.74 & 2.77 \\
\hline Food services and drinking places & 0.02 & 1.19 & 1.21 \\
\hline Support activities for mining & 0.02 & 2.60 & 2.62 \\
\hline Hospitals and nursing and residential care facilities & 0.02 & 2.66 & 2.68 \\
\hline Amusements, gambling, and recreation industries & 0.02 & 0.90 & 0.92 \\
\hline Real estate & 0.01 & 0.72 & 0.74 \\
\hline Broadcasting and telecommunications & 0.01 & 0.86 & 0.87 \\
\hline Truck transportation & 0.01 & 2.09 & 2.10 \\
\hline Forestry, fishing, and related activities & 0.01 & 2.04 & 2.05 \\
\hline Food and beverage and tobacco products & 0.01 & 2.76 & 2.76 \\
\hline Ambulatory health care services & 0.01 & 1.80 & 1.81 \\
\hline Farms & 0.01 & 4.53 & 4.53 \\
\hline Retail trade & 0.00 & 0.59 & 0.59 \\
\hline Performing arts, spectator sports, museums, and related activities & 0.00 & 0.46 & 0.46 \\
\hline Securities, commodity contracts, and investments & 0.00 & 0.33 & 0.33 \\
\hline Accommodation & 0.00 & 1.02 & 1.02 \\
\hline Computer systems design and related services & 0.00 & 0.39 & 0.39 \\
\hline Publishing industries (includes software) & 0.00 & 1.11 & 1.11 \\
\hline Management of companies and enterprises & 0.00 & 0.69 & 0.69 \\
\hline Social assistance & 0.00 & 1.22 & 1.22 \\
\hline Information and data processing services & 0.00 & 1.03 & 1.03 \\
\hline Federal Reserve banks, credit intermediation, and related activities & 0.00 & 0.39 & 0.39 \\
\hline Funds, trusts, and other financial vehicles & 0.00 & 0.39 & 0.39 \\
\hline Insurance carriers and related activities & 0.00 & 0.20 & 0.20 \\
\hline Legal services & 0.00 & 0.36 & 0.36 \\
\hline
\end{tabular}


decisionmakers as they consider options for minimizing hazardous waste generation using source reduction methods.

The ratio of direct to total hazardous waste intensity describes the percentage of total hazardous waste generation that is actually being produced by the industry in question, rather than by its suppliers. An industry with a high value for this ratio is accountable on its own for a large proportion of the total hazardous waste generated per million dollars of final demand for its output. Similarly, an industry with a low value for this ratio is not accountable on its own for a large proportion of its total hazardous waste intensity, but rather much of the total hazardous waste accounted for is generated indirectly by other industries up the supply chain. Figure 2.2 displays the data from Table 2.4 in a different manner, highlighting the dual issues of the value of total hazardous waste intensity (the hazardous waste multiplier) and the ratio of direct to total hazardous waste intensity. Industries that have a high value of total hazardous waste intensity and a high ratio of direct to total hazardous waste intensity appear towards the upper right-hand corner of Figure 2.2.

Clearly, the two industries that stand out are Chemical products and Waste management and remediation services. Their position in the figure indicates that these industries not only have a high value of total hazardous waste intensity but that the industries themselves are directly responsible for much of the hazardous waste being generated. Figure 2.2 also highlights some industries that have high values of total hazardous waste intensity but low ratios of direct to total hazardous waste intensity; namely, Plastics and rubber products and Textile and textile mill products. These industries have high total hazardous waste intensity values; however, the breakdown shows that indirect hazardous waste generation accounts for much of this total hazardous waste intensity.

The input-output multiplier analysis presented allows source reduction decisions to be made on the basis of direct accountability or total (direct and indirect) accountability. Decisionmakers would have to consider whether this information changes their views on industry accountability and to consider which groups of industries to focus on: those that are directly accountable for large amounts of hazardous waste generation or those that are holistically accountable when you consider the structure of the economy as a whole. Should an industry be held responsible for using the output of hazardous waste intensive industries within 


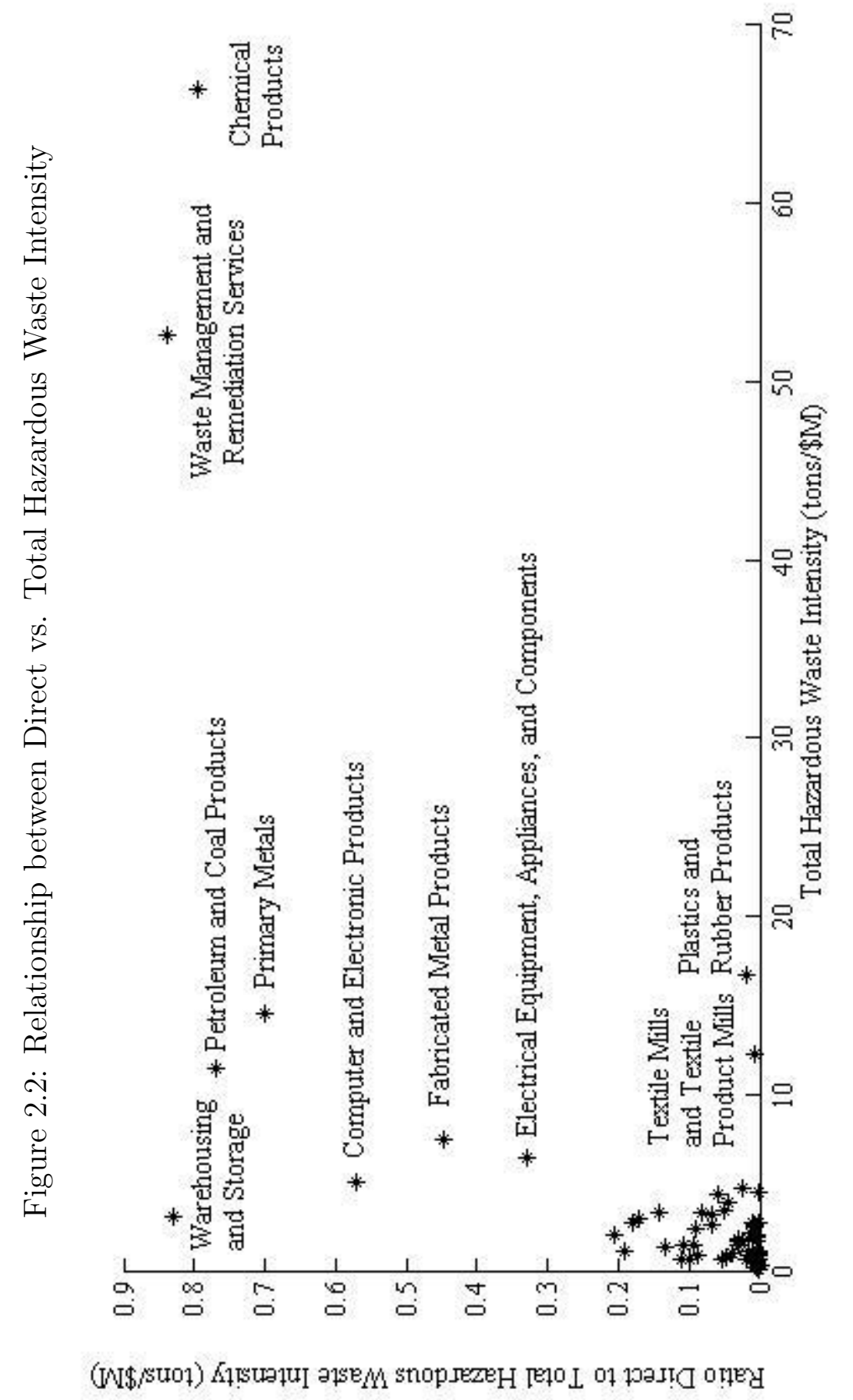


their own production process? The large variation in ratios of direct to total hazardous waste intensity observed in industries with high values of total hazardous waste intensity suggests that a blanket policy that treats all industries identically might not be desirable. Decisionmakers should find it useful to consider both total hazardous waste intensity and the ratio of the direct to total hazardous waste intensity when drafting future hazardous waste minimization policies.

\section{Intermediate vs. Final Demand}

The input-output framework can also provide information on the types of demand that are driving the production of industry output and, in turn, hazardous waste. Within this framework, demand for output can be broken down into intermediate demand and final demand. Intermediate demand represents the interindustry sales that are occurring within the economic system and final demand represents the demand for output by units that are exogenous to the system (in the framework within this chapter, these external units include household consumption, government expenditures, investment demand, and foreign exports).

This type of analysis can be used to help decisionmakers consider the potential impact of policy approaches that focus on reducing hazardous waste from the production side of the economy versus the consumption side of the economy. It has already been shown that industries with large hazardous waste multipliers are not necessarily directly accountable for much of the hazardous waste under consideration (large hazardous waste multipliers resulting from large indirect hazardous waste intensities). This section provides information on whether interindustry transactions or final demand are largely accountable for the direct hazardous waste generation within an industry to determine whether different policy approaches will have the desired effect. For example, if policymakers choose to implement an educational campaign to deter household consumption of the output of an industry that produces a large amount of direct hazardous waste generation, they should first check whether this industry produces output for final demand to be sure their policy will have a noticeable effect on hazardous waste generation.

Using the ratios of intermediate to final demand and the direct hazardous waste intensities by industry, breakdowns of direct hazardous waste generation for intermediate and 
Table 2.5: Direct Hazardous Waste Generation for Intermediate and Final Demand, 2007

\begin{tabular}{|c|c|c|c|c|c|}
\hline Industry & $\begin{array}{r}\text { Intermediate } \\
\text { (tons) } \\
\end{array}$ & & $\begin{array}{r}\text { Final } \\
\text { (tons) } \\
\end{array}$ & & $\begin{array}{r}\text { Total } \\
\text { (tons) } \\
\end{array}$ \\
\hline "Hospitals and nursing and residential care facilities & 105.92 & $1 \%$ & $11,491.35$ & $99 \%$ & $11,597.27$ \\
\hline Ambulatory health care services & 76.78 & $2 \%$ & $4,011.12$ & $98 \%$ & $4,087.89$ \\
\hline Social assistance & 2.56 & $6 \%$ & 40.51 & $94 \%$ & 43.06 \\
\hline Support activities for mining & 153.50 & $7 \%$ & $2,081.66$ & $93 \%$ & $2,235.16$ \\
\hline Amusements, gambling, and recreation industries & 143.32 & $7 \%$ & $1,803.67$ & $93 \%$ & $1,946.99$ \\
\hline Government & $12,800.24$ & $8 \%$ & $153,396.12$ & $92 \%$ & $166,196.36$ \\
\hline Apparel and leather and allied products & 640.64 & $9 \%$ & $6,253.72$ & $91 \%$ & $6,894.36$ \\
\hline Retail trade & 412.10 & $11 \%$ & $3,230.03$ & $89 \%$ & $3,642.13$ \\
\hline Funds, trusts, and other financial vehicles & 0.52 & $12 \%$ & 3.73 & $88 \%$ & 4.25 \\
\hline Construction & $5,798.23$ & $13 \%$ & $37,256.77$ & $87 \%$ & $43,055.00$ \\
\hline Educational services & $2,719.89$ & $16 \%$ & $14,655.45$ & $84 \%$ & $17,375.34$ \\
\hline Food services and drinking places & $2,171.99$ & $19 \%$ & $9,296.86$ & $81 \%$ & $11,468.85$ \\
\hline Water transportation & $1,178.66$ & $23 \%$ & $4,008.35$ & $77 \%$ & $5,187.01$ \\
\hline Furniture and related products & $4,567.25$ & $27 \%$ & $12,579.11$ & $73 \%$ & $17,146.36$ \\
\hline Other transportation equipment & $29,557.70$ & $28 \%$ & $74,170.48$ & $72 \%$ & $103,728.19$ \\
\hline Miscellaneous manufacturing & $12,402.27$ & $30 \%$ & $28,367.25$ & $70 \%$ & $40,769.52$ \\
\hline Motor vehicles, bodies and trailers, and parts & $25,674.28$ & $30 \%$ & $58,684.47$ & $70 \%$ & $84,358.76$ \\
\hline Food and beverage and tobacco products & $1,511.70$ & $32 \%$ & $3,149.90$ & $68 \%$ & $4,661.60$ \\
\hline Machinery & $17,471.91$ & $33 \%$ & $36,244.68$ & $67 \%$ & $53,716.60$ \\
\hline Air transportation & $1,222.99$ & $33 \%$ & $2,505.63$ & $67 \%$ & $3,728.62$ \\
\hline Real estate & $9,828.90$ & $33 \%$ & $19,912.25$ & $67 \%$ & $29,741.15$ \\
\hline Computer and electronic products & $372,752.98$ & $34 \%$ & $723,727.13$ & $66 \%$ & $1,096,480.11$ \\
\hline Computer systems design and related services & 59.11 & $35 \%$ & 110.49 & $65 \%$ & 169.61 \\
\hline Other services, except government & $8,152.80$ & $36 \%$ & $14,764.87$ & $64 \%$ & $22,917.67$ \\
\hline Accommodation & 28.94 & $36 \%$ & 51.70 & $64 \%$ & 80.64 \\
\hline Publishing industries (includes software) & 53.71 & $39 \%$ & 83.16 & $61 \%$ & 136.86 \\
\hline Wholesale trade & $47,456.91$ & $49 \%$ & $48,901.52$ & $51 \%$ & $96,358.43$ \\
\hline Transit and ground passenger transportation & $6,637.71$ & $49 \%$ & $6,772.47$ & $51 \%$ & $13,410.18$ \\
\hline Textile mills and textile product mills & $3,483.11$ & $51 \%$ & $3,317.42$ & $49 \%$ & $6,800.53$ \\
\hline Electrical equipment, appliances, and components & $135,893.83$ & $53 \%$ & $121,772.57$ & $47 \%$ & $257,666.40$ \\
\hline Utilities & $16,757.83$ & $53 \%$ & $14,845.53$ & $47 \%$ & $31,603.36$ \\
\hline Insurance carriers and related activities & 1.47 & $53 \%$ & 1.28 & $47 \%$ & 2.75 \\
\hline Chemical products & $18,495,380.55$ & $56 \%$ & $14,463,042.89$ & $44 \%$ & $32,958,423.44$ \\
\hline Federal Reserve banks, credit intermediation, and related activities & 17.67 & $59 \%$ & 12.48 & $41 \%$ & 30.15 \\
\hline Performing arts, spectator sports, museums, and related activities & 92.55 & $59 \%$ & 64.76 & $41 \%$ & 157.31 \\
\hline Rental and leasing services and lessors of intangible assets & $7,986.70$ & $59 \%$ & $5,557.95$ & $41 \%$ & $13,544.65$ \\
\hline Petroleum and coal products & $3,047,541.81$ & $59 \%$ & $2,084,237.24$ & $41 \%$ & $5,131,779.05$ \\
\hline Motion picture and sound recording industries & $2,314.87$ & $60 \%$ & $1,536.62$ & $40 \%$ & $3,851.49$ \\
\hline Legal services & - & $63 \%$ & - & $37 \%$ & \\
\hline Truck transportation & $1,537.67$ & $66 \%$ & 796.89 & $34 \%$ & $2,334.56$ \\
\hline Securities, commodity contracts, and investments & 510.15 & $67 \%$ & 246.61 & $33 \%$ & 756.75 \\
\hline Broadcasting and telecommunications & $4,774.19$ & $68 \%$ & $2,219.19$ & $32 \%$ & $6,993.38$ \\
\hline Rail transportation & $8,528.94$ & $70 \%$ & $3,698.06$ & $30 \%$ & $12,227.00$ \\
\hline Farms & $1,190.16$ & $71 \%$ & 477.64 & $29 \%$ & $1,667.80$ \\
\hline Paper products & $14,479.45$ & $79 \%$ & $3,788.75$ & $21 \%$ & $18,268.20$ \\
\hline Plastics and rubber products & $49,936.84$ & $79 \%$ & $12,915.68$ & $21 \%$ & $62,852.52$ \\
\hline Waste management and remediation services & $2,514,061.62$ & $81 \%$ & $582,281.82$ & $19 \%$ & $3,096,343.44$ \\
\hline Other transportation and support activities & $25,890.40$ & $82 \%$ & $5,522.69$ & $18 \%$ & $31,413.09$ \\
\hline Fabricated metal products & $886,514.37$ & $83 \%$ & $179,705.70$ & $17 \%$ & $1,066,220.07$ \\
\hline Information and data processing services & 24.31 & $85 \%$ & 4.45 & $15 \%$ & 28.75 \\
\hline Mining, except oil and gas & $3,667.92$ & $86 \%$ & 592.37 & $14 \%$ & $4,260.29$ \\
\hline Management of companies and enterprises & 161.55 & $86 \%$ & 26.04 & $14 \%$ & 187.59 \\
\hline Forestry, fishing, and related activities & 384.60 & $87 \%$ & 56.23 & $13 \%$ & 440.83 \\
\hline Miscellaneous professional, scientific and technical services & $40,917.30$ & $90 \%$ & $4,546.55$ & $10 \%$ & $45,463.85$ \\
\hline Nonmetallic mineral products & $55,007.09$ & $90 \%$ & $5,946.74$ & $10 \%$ & $60,953.84$ \\
\hline Primary metals & $2,209,242.80$ & $91 \%$ & $222,219.54$ & $9 \%$ & $2,431,462.34$ \\
\hline Printing and related support activities & $25,249.41$ & $91 \%$ & $2,536.69$ & $9 \%$ & $27,786.09$ \\
\hline Wood products & $44,785.74$ & $92 \%$ & $4,033.96$ & $8 \%$ & $48,819.70$ \\
\hline Administrative and support services & $89,928.77$ & $93 \%$ & $6,795.33$ & $7 \%$ & $96,724.10$ \\
\hline Oil and gas extraction & $11,321.76$ & $94 \%$ & 668.93 & $6 \%$ & $11,990.69$ \\
\hline Pipeline transportation & $6,023.70$ & $94 \%$ & 355.05 & $6 \%$ & $6,378.75$ \\
\hline Warehousing and storage & $135,779.20$ & $98 \%$ & $2,289.18$ & $2 \%$ & $138,068.37$ \\
\hline
\end{tabular}


final demand can be calculated. Table 2.5 shows the breakdowns of direct hazardous waste generation for intermediate and final demand by industry that have been sorted from highest to lowest in terms of their proportion of hazardous waste generated for final demand.

Not surprisingly, many of the industries that generate a large percentage of direct hazardous waste for final demand, and therefore would be good candidates for policies that attempt to reduce the final demand of their output (consumption-based policy), are service industries belonging to such categories as health and entertainment services. However, these industries do not necessarily generate large amounts of hazardous waste compared to many of the manufacturing industries, which directly generate only a small percentage of hazardous waste for final demand. In these cases, even successful consumption-based policies, such as the educational campaign mentioned above, are not likely to have a large impact on hazardous waste generation. Due to their larger amounts of hazardous waste generation for final demand, the manufacturing industries that do stand out as candidates for consumption-based policies are Construction; Miscellaneous manufacturing; Motor vehicles, bodies and trailers, and parts; Machinery; and Computer and electronic products.

Computer and electronic products is the only industry previously highlighted as being a top hazardous waste generator that produced a majority of its hazardous waste for final demand. Many of the others; namely Chemical Products; Petroleum and Coal Products; Waste Management and Remediation Services; Primary Metals; and Fabricated Metal Products, all produce a majority of their output and hazardous waste for intermediate demand. This result implies that Computer and electronic products is the only top hazardous waste generator that might be a candidate for hazardous waste reduction through consumptionbased policy and source reduction. Considering the fact that computers and other electronic products are such a mainstay in everyday life, this emphasizes the importance of considering reduction strategies for both the production and consumption sides of the economy. Rather than, or in addition to, regulating the direct or total hazardous waste intensity of the Computer and electronic products industry, policymakers might consider that policies aimed at the reduction of the amount of electronic products purchased, or at least the discouragement of trading working electronic products in for newer versions, are all possibilities for reducing hazardous waste generation from this sector. 
This discussion of intermediate and final demand provides the foundation for the next section, which will examine the results of different techniques for attributing commodity output and hazardous waste generation to final demand categories. Using these techniques, industrial hazardous waste generation will be reallocated to the final demand categories that are accountable for its production.

\subsubsection{Consumption Accounting}

If policymakers consider that production - and in turn, hazardous waste generation occurs in order to meet final demand, then consumption-based policy approaches should also be considered for reducing industrial hazardous waste generation. Rather than, or in addition to, posing restrictions on producers, focus might be directed towards curbing the consumption of goods that are directly or indirectly produced by hazardous waste intensive industries. The intention here is clearly not to advocate for hazardous waste reduction by means of depressing overall final demand levels. However, policymakers can use the information available within this analysis to levy taxes or implement public education programs that will shift consumption away from the output of hazardous waste intensive industries and towards cleaner alternatives.

Using the input-output based accounting framework and a partial consumption accounting method, industrial hazardous waste generation can be consistently attributed to the respective final demand categories. This approach is considered partial consumption accounting, or attribution analysis, to distinguish it from full consumption accounting; i.e., a full hazardous waste footprint analysis. The intention of this attribution analysis is not to assign blame on the consumers but to highlight an alternative (or possibly complementary) approach to the hazardous waste production accounting methods described in section 2.4.1. This approach provides information that will prove useful if decisionmakers attempt to curb hazardous waste generation through consumption-based policies as well as production-based policies.

Table 2.6 displays the results from the attribution analysis for four categories of final demand: household consumption, government expenditures, investment, and foreign exports. 
Following the right-hand side of equation (2.12), these results were calculated as $\hat{\omega}\left(\mathbf{L}_{\mathbf{I} \times \mathbf{C}}\right) \mathbf{e}$, where e has been disaggregated into the four components described above. The results for Farms indicate that 1,273 tons of hazardous waste directly generated by the Farms industry are attributable to household consumption, 55 tons are attributable to government expenditure, 82 tons are attributable to investment demand, and 258 tons are attributable to foreign export demand.

Table 2.7 represents the breakdowns of the hazardous waste intensity of the different consumption categories. Given the current distribution of each final demand category, the sum of each column represents the tons of hazardous waste generated per dollar of total final demand in each category. The values in the table then represent each industry's contribution to the final demand category's overall hazardous waste intensity. These values can be expected to change as the distribution of the final demand category changes. Overall, 6.83 tons of hazardous waste are generated per million dollars of foreign export final demand and 2.82 tons of hazardous waste are generated per million dollars of household final demand. Investment final demand is accountable for 2.38 tons of hazardous waste per million dollars of spending and 1.96 tons of hazardous waste are generated per million dollars of government expenditures. The results for each industry's contribution to these summary final demand hazardous waste intensities suggest that the two largest direct hazardous waste generating industries are once again responsible for a large portion of these intensities, Chemical products and Waste management and remediation services.

Results indicate that overall, hazardous waste generation in the U.S. is largely attributable to household consumption demand, which is not surprising since it is the largest component of final demand activity. However, it is important to remember that the accountability of different sectors of final demand varies widely across industries. With this information, should policymakers attempt any type of consumption-based hazardous waste minimization approach, they can easily identify the category(ies) of final demand that are most accountable for hazardous waste generation within a certain industry.

Although the partial consumption accounting analysis can identify the final demand groups that are accountable for industrial hazardous waste generation, the degrees of accountability vary widely across sectors of the economy making it difficult, if not impossible, 
Table 2.6: Hazardous Waste Attribution by Final Consumer (tons)

\begin{tabular}{|c|c|c|c|c|}
\hline Industry & Households & Government & Investment & Exports \\
\hline Farms & 1,273 & 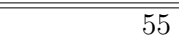 & 82 & 258 \\
\hline Forestry, fishing, and related activities & 271 & 34 & 63 & 73 \\
\hline Oil and gas extraction & 7,582 & 2,025 & 1,084 & 1,300 \\
\hline Mining, except oil and gas & 1,660 & 698 & 1,038 & 865 \\
\hline Support activities for mining & 88 & 25 & 2,104 & 18 \\
\hline Utilities & 25,250 & 3,619 & 1,591 & 1,144 \\
\hline Construction & 3,224 & 11,197 & 28,394 & 2395 \\
\hline Food and beverage and tobacco products & 4,107 & 156 & 75 & 324 \\
\hline Textile mills and textile product mills & 4,339 & 454 & 890 & 1,124 \\
\hline Apparel and leather and allied products & 6,359 & 116 & 108 & 313 \\
\hline Wood products & 15,703 & 8,703 & 20,571 & 3,923 \\
\hline Paper products & 10,993 & 2,018 & 2,090 & 3,204 \\
\hline Printing and related support activities & 16,404 & 4,767 & 4,071 & 2,571 \\
\hline Petroleum and coal products & $3,174,394$ & 867,562 & 487,009 & 602,810 \\
\hline Chemical products & $20,306,142$ & $2,679,446$ & $2,638,684$ & $7,334,171$ \\
\hline Plastics and rubber products & 35,214 & 6,825 & 11,106 & 9,752 \\
\hline Nonmetallic mineral products & 19,084 & 11,745 & 24,346 & 5,787 \\
\hline Primary metals & 739,271 & 274,879 & 761,277 & 668,145 \\
\hline Fabricated metal products & 359,235 & 170,334 & 354,581 & 186,930 \\
\hline Machinery & 7,527 & 4,028 & 27,496 & 14,861 \\
\hline Computer and electronic products & 278,396 & 148,108 & 401,702 & 268,429 \\
\hline Electrical equipment, appliances, and components & 94,053 & 28,480 & 83,339 & 51,877 \\
\hline Motor vehicles, bodies and trailers, and parts & 38,468 & 4,335 & 27,346 & 14,363 \\
\hline Other transportation equipment & 16,116 & 26,284 & 17,032 & 44,310 \\
\hline Furniture and related products & 7,768 & 2,038 & 6,630 & 711 \\
\hline Miscellaneous manufacturing & 23,438 & 2,909 & 8,427 & 6,007 \\
\hline Wholesale trade & 55,477 & 7,958 & 17,869 & 15,055 \\
\hline Retail trade & 3,254 & 74 & 300 & 14 \\
\hline Air transportation & 2,382 & 258 & 204 & 885 \\
\hline Rail transportation & 6,142 & 1,604 & 2,005 & 2,475 \\
\hline Water transportation & 2,916 & 344 & 223 & 1,705 \\
\hline Truck transportation & 1,213 & 286 & 425 & 411 \\
\hline Transit and ground passenger transportation & 10,732 & 1,877 & 476 & 325 \\
\hline Pipeline transportation & 4,289 & 1,091 & 421 & 577 \\
\hline Other transportation and support activities & 18,211 & 3,049 & 3,424 & 6,729 \\
\hline Warehousing and storage & 85,960 & 15,713 & 20,199 & 16,196 \\
\hline Publishing industries (includes software) & 64 & 16 & 45 & 12 \\
\hline Motion picture and sound recording industries & 2,718 & 254 & 164 & 716 \\
\hline Broadcasting and telecommunications & 5,112 & 783 & 695 & 403 \\
\hline Information and data processing services & 17 & 6 & 3 & 3 \\
\hline Federal Reserve banks, credit intermediation, and related activities & 24 & 2 & 2 & 3 \\
\hline Securities, commodity contracts, and investments & 582 & 48 & 33 & 94 \\
\hline Insurance carriers and related activities & 2 & 0 & 0 & 0 \\
\hline Funds, trusts, and other financial vehicles & 4 & 0 & 0 & 0 \\
\hline Real estate & 26,032 & 1,101 & 2,054 & 555 \\
\hline Rental and leasing services and lessors of intangible assets & 7,129 & 1,259 & 1,348 & 3,808 \\
\hline Legal services & 0 & 0 & 0 & 0 \\
\hline Miscellaneous professional, scientific, and technical services & 24,899 & 8,583 & 7,968 & 4,014 \\
\hline Computer systems design and related services & 29 & 35 & 94 & 11 \\
\hline Management of companies and enterprises & 105 & 12 & 28 & 42 \\
\hline Administrative and support services & 65,223 & 13,969 & 11,315 & 6,206 \\
\hline Waste management and remediation services & $2,124,519$ & 801,617 & 232,201 & 141,755 \\
\hline Educational services & 15,753 & 1,200 & 213 & 209 \\
\hline Ambulatory health care services & 4,077 & 10 & 1 & 0 \\
\hline Hospitals and nursing and residential care facilities & 11,513 & 83 & 1 & 1 \\
\hline Social assistance & 41 & 2 & 0 & 0 \\
\hline Performing arts, spectator sports, museums, and related activities & 130 & 11 & 10 & 6 \\
\hline Amusements, gambling, and recreation industries & 1,871 & 49 & 18 & 9 \\
\hline Accomodation & 69 & 6 & 4 & 2 \\
\hline Food services and drinking places & 10,725 & 373 & 210 & 163 \\
\hline Other services, except government & 19,510 & 1,601 & 1,147 & 660 \\
\hline Government & 33,684 & 130,156 & 1,370 & 986 \\
\hline
\end{tabular}


Table 2.7: Hazardous Waste Attribution by Final Consumer (intensities)

\begin{tabular}{|c|c|c|c|c|}
\hline Industry & Households & Government & Investment & Exports \\
\hline Farms & 0.0001 & 0.0000 & 0.0000 & 0.0002 \\
\hline Forestry, fishing, and related activities & 0.0000 & 0.0000 & 0.0000 & 0.0001 \\
\hline Oil and gas extraction & 0.0008 & 0.0008 & 0.0005 & 0.0009 \\
\hline Mining, except oil and gas & 0.0002 & 0.0003 & 0.0005 & 0.0006 \\
\hline Support activities for mining & 0.0000 & 0.0000 & 0.0010 & 0.0000 \\
\hline Utilities & 0.0026 & 0.0014 & 0.0007 & 0.0008 \\
\hline Construction & 0.0003 & 0.0042 & 0.0130 & 0.0002 \\
\hline Food and beverage and tobacco products & 0.0004 & 0.0001 & 0.0000 & 0.0002 \\
\hline Textile mills and textile product mills & 0.0004 & 0.0002 & 0.0004 & 0.0008 \\
\hline Apparel and leather and allied products & 0.0006 & 0.0000 & 0.0000 & 0.0002 \\
\hline Wood products & 0.0016 & 0.0033 & 0.0094 & 0.0028 \\
\hline Paper products & 0.0011 & 0.0008 & 0.0010 & 0.0023 \\
\hline Printing and related support activities & 0.0017 & 0.0018 & 0.0019 & 0.0019 \\
\hline Petroleum and coal products & 0.3227 & 0.3242 & 0.2224 & 0.4366 \\
\hline Chemical products & 2.0645 & 1.0012 & 1.2049 & 5.3118 \\
\hline Plastics and rubber products & 0.0036 & 0.0026 & 0.0051 & 0.0071 \\
\hline Nonmetallic mineral products & 0.0019 & 0.0044 & 0.0111 & 0.0042 \\
\hline Primary metals & 0.0752 & 0.1027 & 0.3476 & 0.4839 \\
\hline Fabricated metal products & 0.0365 & 0.0636 & 0.1619 & 0.1354 \\
\hline Machinery & 0.0008 & 0.0015 & 0.0126 & 0.0108 \\
\hline Computer and electronic products & 0.0283 & 0.0553 & 0.1834 & 0.1944 \\
\hline Electrical equipment, appliances, and components & 0.0096 & 0.0106 & 0.0381 & 0.0376 \\
\hline Motor vehicles, bodies and trailers, and parts & 0.0039 & 0.0016 & 0.0125 & 0.0104 \\
\hline Other transportation equipment & 0.0016 & 0.0098 & 0.0078 & 0.0321 \\
\hline Furniture and related products & 0.0008 & 0.0008 & 0.0030 & 0.0005 \\
\hline Miscellaneous manufacturing & 0.0024 & 0.0011 & 0.0038 & 0.0044 \\
\hline Wholesale trade & 0.0056 & 0.0030 & 0.0082 & 0.0109 \\
\hline Retail trade & 0.0003 & 0.0000 & 0.0001 & 0.0000 \\
\hline Air transportation & 0.0002 & 0.0001 & 0.0001 & 0.0006 \\
\hline Rail transportation & 0.0006 & 0.0006 & 0.0009 & 0.0018 \\
\hline Water transportation & 0.0003 & 0.0001 & 0.0001 & 0.0012 \\
\hline Truck transportation & 0.0001 & 0.0001 & 0.0002 & 0.0003 \\
\hline Transit and ground passenger transportation & 0.0011 & 0.0007 & 0.0002 & 0.0002 \\
\hline Pipeline transportation & 0.0004 & 0.0004 & 0.0002 & 0.0004 \\
\hline Other transportation and support activities & 0.0019 & 0.0011 & 0.0016 & 0.0049 \\
\hline Warehousing and storage & 0.0087 & 0.0059 & 0.0092 & 0.0117 \\
\hline Publishing industries (includes software) & 0.0000 & 0.0000 & 0.0000 & 0.0000 \\
\hline Motion picture and sound recording industries & 0.0003 & 0.0001 & 0.0001 & 0.0005 \\
\hline Broadcasting and telecommunications & 0.0005 & 0.0003 & 0.0003 & 0.0003 \\
\hline Information and data processing services & 0.0000 & 0.0000 & 0.0000 & 0.0000 \\
\hline Federal Reserve banks, credit intermediation, and related activities & 0.0000 & 0.0000 & 0.0000 & 0.0000 \\
\hline Securities, commodity contracts, and investments & 0.0001 & 0.0000 & 0.0000 & 0.0001 \\
\hline Insurance carriers and related activities & 0.0000 & 0.0000 & 0.0000 & 0.0000 \\
\hline Funds, trusts, and other financial vehicles & 0.0000 & 0.0000 & 0.0000 & 0.0000 \\
\hline Real estate & 0.0026 & 0.0004 & 0.0009 & 0.0004 \\
\hline Rental and leasing services and lessors of intangible assets & 0.0007 & 0.0005 & 0.0006 & 0.0028 \\
\hline Legal services & 0.0000 & 0.0000 & 0.0000 & 0.0000 \\
\hline Miscellaneous professional, scientific and technical services & 0.0025 & 0.0032 & 0.0036 & 0.0029 \\
\hline ign and related services & 0.0000 & 0.0000 & 0.0000 & 0.0000 \\
\hline Management of companies and enterprises & 0.0000 & 0.0000 & 0.0000 & 0.0000 \\
\hline Administrative and support services & 0.0066 & 0.0052 & 0.0052 & 0.0045 \\
\hline Waste management and remediation services & 0.2160 & 0.2995 & 0.1060 & 0.1027 \\
\hline Educational services & 0.0016 & 0.0004 & 0.0001 & 0.0002 \\
\hline Ambulatory health care services & 0.0004 & 0.0000 & 0.0000 & 0.0000 \\
\hline Hospitals and nursing and residential care facilities & 0.0012 & 0.0000 & 0.0000 & 0.0000 \\
\hline Social assistance & 0.0000 & 0.0000 & 0.0000 & 0.0000 \\
\hline Performing arts, spectator sports, museums, and related activities & 0.0000 & 0.0000 & 0.0000 & 0.0000 \\
\hline Amusements, gambling, and recreation industries & 0.0002 & 0.0000 & 0.0000 & 0.0000 \\
\hline Accommodation & 0.0000 & 0.0000 & 0.0000 & 0.0000 \\
\hline Food services and drinking places & 0.0011 & 0.0001 & 0.0001 & 0.0001 \\
\hline Other services, except government & 0.0020 & 0.0006 & 0.0005 & 0.0005 \\
\hline Government & 0.0034 & 0.0486 & 0.0006 & 0.0007 \\
\hline SUM & 2.8204 & 1.9634 & 2.3816 & 6.8279 \\
\hline
\end{tabular}


to single out individual final demand groups as policy targets. The information on the proportion of hazardous waste generated for final demand is helpful in this context in that it provides targets for consumption-based policies in terms of the amount of hazardous waste directly generated for final demand. However, in practice, consumption-based policies could be far more difficult to implement than production-based policies. Since the final consumer has little authority over the direct or total hazardous waste intensity of a hazardous waste generating industry, it might be difficult (or at least very unpopular) for policymakers to hold them accountable for industrial hazardous waste generation. Also, the results in Table 2.7 suggest that foreign demand (exports) has the highest hazardous waste intensity per million dollars of expenditure. Should domestic industries be held accountable for hazardous waste generated for foreign demand? One option related to a consumption-based policy approach is to consider taxing the foreign country for the hazardous waste generated in the production of the goods for export.

\subsection{Conclusions}

This chapter uses an input-output framework and data on hazardous waste generation to highlight and implement different hazardous waste accounting techniques. This exercise is intended to provide U.S. policymakers with a "snapshot" of the hazardous waste economy using data on hazardous waste generation and the economy to describe comprehensively the economic relationships that drive hazardous waste generation. Specifically, the information in this chapter can be used as a guide for identifying the industries or the types of final demand that might best be targeted in hazardous waste minimization policies. More generally, the methodologies used can be extended to perform similar analyses for any region and for any type of pollutant, provided the data are available.

The information within the production accounting analyses allows us to go beyond the ability to rank industries in terms of hazardous waste generation and to also consider direct hazardous waste intensity and total hazardous waste intensity in the decisionmaking process. Results from the production accounting approach indicate that only a few industries are accountable for much of the direct hazardous waste generation in the U.S. The hazardous 
waste multiplier analysis provides additional insights into the allocation of hazardous waste generation associated with intermediate demands and introduces information highlighting the differences between direct and total hazardous waste intensity. Also, the information on the breakdown of direct hazardous waste generation for intermediate and final demand is useful in determining whether to consider policies related to the production or consumption side of the economy.

Although U.S. policymakers are currently focused on the production side of the hazardous waste economy, they should also consider the information available through the final demand attribution analyses. Results from this approach consistently attribute all industrial hazardous waste generation to final demand categories. Decisionmakers can use this information to determine which categories of final demand are accountable for hazardous waste generation within industries of interest. They can also use the analysis of the hazardous waste intensity of final demand spending to guide decisions on which final demand categories to focus on in any consumption-based policies or educational programs. 


\section{Chapter 3}

\section{Examining Sub-National Hazardous Waste Flows in the United Kingdom}

As society's generation of waste increases, so does the need for locations to manage and dispose of it. However, individuals are not in favor of a waste management or disposal site being located in close proximity to their home or community, giving rise to what is known as a "Not-In-My-Backyard" attitude. It is this type of behavior, shared around the world, that has created a global market for waste management and disposal, which has only recently become the focus of government regulation and academic research.

As researchers strive to understand and model the relationships that exist within waste shipments, waste that is harmful, or potentially harmful, to human health and the environment - hazardous waste - should take top priority. In the past, the primary focus of the multi-disciplinary literature on waste trade has been the international trade of hazardous waste, especially that from developed to developing countries. However, it is prudent to focus first on intranational hazardous waste shipments. Not only does a majority of hazardous waste generated remain within national boundaries for management or disposal, but a national government also has complete jurisdictional authority over all aspects of hazardous waste trade that occurs within national boundaries. This jurisdictional authority makes changing the nature of this trade possible and more efficient if it is found to be biased, discriminatory, or undesirable in any way.

Trade in hazardous waste has traditionally been modeled as the one-sided relationship 
between management or disposal location and various destination-related characteristics. These models, reviewed in Section 3.1, often rely on variables such as management and disposal taxes to determine the amount of waste imported by a location. Until recently, the relationships that exist within the origin-destination flows themselves had not been modeled at all. This chapter proposes a spatial interaction approach to analyze and provide a clearer understanding of the characteristics responsible for hazardous waste flows in the United Kingdom (U.K.).

The waste trade literature is briefly reviewed in Section 3.1, and Section 3.2 gives an overview of hazardous waste regulations in the U.K. Section 3.3 describes spatial interaction modeling and the methodology that is used in this paper. Section 3.4 describes the data on hazardous waste flows and the economic, demographic, and waste-related characteristics that are used to analyze these flows. Section 3.5 presents and explores the results from a spatial interaction model application for U.K. hazardous waste flows, and Section 3.6 concludes.

\subsection{Hazardous Waste Trade}

Virtually all national and international bills, regulations, laws, and treaties regarding hazardous waste focus on 1) reducing its generation and level of hazardousness and 2) reducing the number and size of its transboundary movements. Many of these policies are grounded in the notion that hazardous waste intensive industries are generating vast amounts of hazardous waste to satisfy the consumptive behavior of developed areas and are then dumping this hazardous waste on unsuspecting developing areas for a pittance, if there is any recompense at all. However, this focus on hazardous waste dumping might be misdirected.

O'Neill (2000) points out that even though the trade of hazardous waste produced in rich countries is often associated with cases of hazardous waste dumping on poorer countries, the majority of this trade (around 80\%) consists of legal trade between industrialized countries. According to data collected through the national reporting system of the Basel Convention on the Control of Transboundary Movements of Hazardous Wastes and their Disposal (hereafter, Basel Convention), only 15,367 metric tons of hazardous waste were exported from Organisation for Economic Co-operation and Development (OECD) countries to non-OECD 
countries in $2002^{1}$. This represents less than $0.25 \%$ of the $6,797,341$ metric tons of hazardous waste exported by reporting parties to the Basel Convention in that year. According to the latest national reporting data, less than $2 \%$ of international shipments of hazardous waste moved from OECD countries to non-OECD countries. Although this number appears to be growing, it is important to note that over this same time period, 14 additional countries ratified the Basel Convention; and the group of parties that submitted national reporting data had changed. These statistics show that the literature focuses on only a small (albeit, important) portion of international trade in hazardous waste.

In fact, it is not only true that a majority of the international trade in hazardous waste takes place between OECD countries but that an even larger portion of hazardous waste movements never even leave national boundaries. In 2007, $97 \%$ of all hazardous waste shipments originating in the U.K. remained in the U.K., a percentage that is strikingly similar for all hazardous waste shipments originating in the United States. These statistics suggest that examining sub-national hazardous waste flows is more informative to modelers and policymakers than research that focuses on international hazardous waste flows. Such an analysis can also provide an understanding of hazardous waste origin-destination relationships to policymakers with full jurisdictional authority.

During the late 1980s and 1990s, literature examining international trade in hazardous waste began to emerge in many fields of academic writing; see for example Allen (1995), O'Neill (1998), or Frey (1998). Oftentimes, the main focus within the international trade and law disciplines is on hazardous waste dumping that occurs in developing countries, usually examining equity and social justice issues (Williams, 1991; Marbury, 1995; Cusack, 1990). However, as highlighted above, there is also an extensive hazardous waste trade network that exists between and within developed countries. Due to the inherent danger and risks associated with hazardous waste, data are often collected and publicly available for hazardous waste generation, shipments, and trade within and across national borders.

Even though data are often available, less work has been done to focus on hazardous

\footnotetext{
${ }^{1}$ Although 2002 is well after the introduction of the BAN Amendment in 1995, it is prior to its signing/ratification by many of the current signatory nations. This is one of the first years for which relevant and reliable national reporting data are available for such a comparison.
} 
waste trade within national borders, though examples do exist. A majority of these articles restrict the model to only one side of the origin-destination relationship, the destination. These models have typically focused on the relationships between management or disposal locations and various destination characteristics. Sigman (1996) examines hazardous waste shipments in the United States and how hazardous waste management prices, in terms of taxes, affect generation and disposal decisions for a specific type of hazardous waste, chlorinated solvent waste from metal cleaning. She finds that facilities respond quite readily and negatively to changes in the cost of incineration as a disposal method but does not find a similar relationship for changes in land disposal costs.

Levinson (1999a,b) also explores the relationship between disposal taxes and hazardous waste disposal locations in the United States. He finds that state taxes matter not only theoretically, but also empirically, and concludes that hazardous waste disposal taxes have significantly contributed to the decentralization of hazardous waste disposal. Alberini and Bartholomew (1999) take a slightly different approach and estimate a conditional logit model for shipments of halogenated solvents to identify the determinants of hazardous waste disposal choice. They find that this choice is dependent upon the cost of disposal and the existing contamination and track record of the disposal facility.

Others take steps towards identifying relationships on both sides of the hazardous waste origin-destination flow. McGlinn (2000) characterizes the spatial agglomeration of both hazardous waste generation and management. Using 1995 data for the United States, he investigates where hazardous waste is generated (origins) and where it is managed or disposed (destinations). McGlinn concludes that the petroleum and petrochemical industries located on the Gulf Coast are responsible for a large portion of hazardous waste generation and that much of this waste is managed in the same locations. However, many smaller generators are likely to ship their hazardous waste an average of 200 miles for management and disposal. The destination of these shipments is in part attributed to state-specific disposal fees. Although he describes spatial patterns of hazardous waste in the United States, McGlinn does not focus on the trade relationships.

Baggs (2009) is the first explicit treatment of the origin-destination relationships of hazardous waste flows. Using data collected through the Basel Convention reporting system, 
she models international hazardous waste flows using a traditional gravity model and twostage regression analysis. Baggs finds that there is some evidence that hazardous waste does indeed flow from more developed to less developed nations but that this effect is better explained by differences in capital per worker than per capita income. This finding could be related to the capital intensity of hazardous waste management and disposal.

\subsection{Hazardous Waste Regulation}

Heightened environmental consciousness influenced many governing bodies at various levels to begin regulating hazardous waste in the latter part of the $20^{\text {th }}$ century. Regulations on environmental protection and, more specifically, on hazardous waste primarily take place on two jurisdictional levels in the U.K. As part of the European Union (EU), the U.K. and its constituent parts are bound by EU legislation and any international regulations to which the EU is a signatory or party. The U.K. also has its own government bodies that impart regulations on waste, hazardous waste, and waste transportation within the U.K. Similar to the relationship between federal and state regulation within the United States, U.K. regulations cannot counter any regulations imposed by the EU or international agreements they are a party to but must be just as stringent, if not more.

Much of the EU legislation on waste originated from the European Community Policy and Action Programme on the Environment that functioned during the years 1987-1992. In 1991, the EU drafted the Council Directive on Hazardous Waste. This was the first time that EU legislation provided a formal definition of hazardous waste and declared their goal to ensure ecologically sound management of such wastes by requiring permits for establishments that would handle management or disposal. This particular directive also implemented requirements for traceability of hazardous waste generation, movement, management, and disposal and forbade the mixture of hazardous waste with any other types of waste. The definitions, protections, and policies within the Council Directive on Hazardous Waste ultimately became part of the EU Waste Framework Directive.

In 1994, the European Community became party to the Basel Convention. The Basel Convention controls the movement of hazardous waste across international borders. Al- 
though this particular agreement does not affect hazardous waste shipments within the U.K., it does ultimately encourage the U.K. to properly manage and dispose of its own hazardous waste at locations as close to the site of generation as possible. To comply with the Basel Convention, the EU adopted legislation in 2006 that regulated the shipments of waste within the EU, the Regulation of the European Parliament and of the Council on Shipments of Waste. With the goals of preservation and protection of human health and the environment, this regulation standardizes the paperwork and supervisory process for hazardous waste movements in the EU.

The U.K. has also implemented many regulations at the national level related to hazardous waste. Initially, the Environmental Protection Act of 1990 was established to improve and control the pollution of air, water, and land in the U.K. This piece of legislation also contained many sections on different aspects of waste and waste management, including a section of special provisions for hazardous waste. The Environment Act of 1995 established two new government bodies that would henceforth be in charge of environmental protection in the U.K. The Environment Act transferred the liabilities, rights, and functions related to environmental protection to the Environment Agency in England and Wales and to the Scottish Environment Protection Agency in Scotland. Afterwards, these bodies handled waste strategies separately for the combined region of England and Wales and for Scotland.

In 1996, the Special Waste Regulations, which apply to hazardous waste, were introduced and implemented for the entire U.K. At the time, this was the principle piece of legislation governing hazardous waste generation, handling, disposal, and transport. Since then, these regulations have been amended as well as new hazardous waste regulations adopted in 2005 by Wales and by the combined region of England and Wales. The ultimate result of these hazardous waste regulations is a system similar to that established by the Resource Conservation and Recovery Act in the United States, described in Chapter 2. As hazardous waste is generated, a special waste consignment note is required to follow the hazardous waste on any movements until its ultimate fate. These consignment notes provide a cradle-to-grave tracking system for all hazardous waste that is generated in the U.K. 


\subsection{Methodology}

Spatial interaction is a broad term relating to many types of interactive behavior associated with locations in space such as commuting to work, migration, commodity flows, information flows, etc. Spatial interaction modeling emerged as an attempt to model and measure the concepts of relative location. This type of modeling has been used in many branches of physical and social science including physics, biology, geography, economics, city and regional planning, transportation engineering, archaeology, anthropology, and even linguistics. Before proceeding with the methodological description of the model in this chapter, this section provides a brief overview on the evolution of gravity and spatial interaction models in the social sciences. Deardorff (1998) and Evenett and Keller (2002) provide more detailed information for readers that are interested in the broader history of spatial interaction modeling.

Traditional gravity models are based upon Newtonian physics, or more specifically, Isaac Newton's Law of Gravity, which states that the gravitational attraction between two objects is a function of the size of the objects and the distance between them; see (3.1):

$$
F=G \frac{m_{1} m_{2}}{r^{2}}
$$

where $F$ is the gravitational force between objects 1 and $2, G$ is the gravitational constant, $m_{1}$ and $m_{2}$ are the masses of objects 1 and 2 respectively, and $r$ is the distance between objects 1 and 2. A model of this type specifically focuses on the scale and distance impacts on spatial interaction.

Beginning in the late 1800s and continuing for some time afterwards, social scientists introduced the gravity model as a means of using the concepts of Newtonian physics to explore fundamental and generalizable concepts basic to social behavior. One particular economic variant of this model was used by Isard (1956):

$$
I_{i j}=G \frac{w_{i}\left(m_{i}\right)^{\alpha} w_{j}\left(m_{j}\right)^{\beta}}{d_{i j}^{b}}
$$

In this model, $I_{i j}$ represents the level of interaction between regions $i$ and $j, m_{i}$ and $m_{j}$ are measures of economic mass at $i$ and $j$ respectively, often defined as gross domestic product, 
employment, or population, $d_{i j}$ is a measure of distance between $i$ and $j, w_{i}$ and $w_{j}$ are weights applied to $\left(m_{i}\right)^{\alpha}$ and $\left(m_{j}\right)^{\beta}$ respectively, $G$ is an appropriate constant, and $\alpha$, $\beta$, and $b$ are the adjustment factors (constant or variable) applied to $m_{i}, m_{j}$, and $d_{i j}$ respectively.

However, related to their reliance on Newtonian physics, early empirical applications of the gravity model in social sciences (Ravenstein, 1885; Young, 1924; Dodd, 1950) were plagued by theoretical issues regarding model specification and model interpretation. In the latter half of the $20^{\text {th }}$ century, many authors began to explicitly refine the theoretical and practical issues related to the traditional gravity model as used in social science (Tinbergen, 1962; Linnemann, 1966; Wilson, 1967, 1971; March and Batty, 1975; Anderson, 1979; Bergstrand, 1985, 1989). Again, the reader is referred to Deardorff (1998) and Evenett and Keller (2002) for more detail. Together, these significant advancements removed the reliance on the Newtonian physics framework and associated a broader range of spatial interaction models with modern statistical concepts and microeconomic foundations.

This chapter begins with a rudimentary form of the spatial interaction model:

$$
h_{i j}=f\left(X_{i}, X_{j}, d_{i j}\right)
$$

where $i$ and $j$ represent regions in the U.K., $h_{i j}$ is the flow of hazardous waste from region $i$ to region $j, X_{i}$ is a matrix of explanatory variables describing the origin region $i$ (i.e. the "push" factors), $X_{j}$ is a matrix of explanatory variables characterising the destination region $j$ (i.e. the "pull" factors), and $d_{i j}$ is the distance between the centroids of regions $i$ and $j$.

Two issues that often plague spatial interaction models are large diagonal flow matrix elements and the presence of a large percentage of zero flows (LeSage and Fischer, 2010). The analysis of interregional interaction, rather than intraregional interaction, is usually the primary focus of a spatial interaction model. Oftentimes, these intraregional flows are considered a nuisance and dropped. However, this approach is discarding information. A problem arises when the diagonal elements of the flow matrix (those representing intraregional flows) are large relative to the off-diagonal elements (those representing interregional flows). Within the hazardous waste flow matrix used in this chapter and the next, $48 \%$ of the total hazardous waste flows are intraregional flows. This implies that nearly half of the flows are encompassed in the diagonal elements of the hazardous waste flow matrix. Rather 
than dropping (or ignoring) these intraregional hazardous waste flows, they are modeled separately, following LeSage and Pace (2008), to avoid interference with the analysis of interregional hazardous waste flows. After also adding a dummy variable to capture the effect of the adjacency of region $i$ and region $j, a_{i j}$, the model can be defined as:

$$
h_{i j}=\alpha+\iota+\beta_{i} X_{i}+\beta_{j} X_{j}+\beta_{r} X_{r}+\delta a_{i j}+\gamma d_{i j}+\varepsilon
$$

where $h_{i j}, X_{i}, X_{j}$, and $d_{i j}$ are defined as in equation (3.3), $X_{r}$ is the matrix of explanatory variables associated with the intra-regional flows, $a_{i j}$ is a dummy variable representing adjacency between regions $i$ and $j, \beta_{i}, \beta_{j}, \beta_{r}, \delta$, and $\gamma$ are coefficient estimates on the respective explanatory variables, $\alpha$ is the constant term associated with the interregional shipments, $\iota$ is the constant term associated with the intraregional shipments, and $\varepsilon$ is an i.i.d. error term.

The second issue regarding a large percentage of zero flows also needs to be resolved for this application. Hazardous waste flows, $h_{i j}$, is a continuous variable but the range is constrained. In this case, there are no hazardous waste flows (i.e. $h_{i j}$ takes on a value of 0) for about $38 \%$ of the region-to-region pairs and a large range of positive flows for the remainder of the region-to-region pairs. When such a large proportion of zeros (observations at the limit) are included as if they are ordinary observations, ordinary least squares (OLS) estimates are usually biased. Similar to the case of large diagonal flows, truncation of zero flows is one option for handling this type of data. Truncation would allow for the estimation of (3.4) using OLS methods; however, not only does this method discard information on known zero flows, but it is possible that truncation introduces bias as well (Helpman et al., 2008).

To resolve this issue, the preferred model for estimation using U.K. hazardous waste flow data is the traditional Tobit model (Tobin, 1958) ${ }^{2}$ :

$$
h_{i j}^{*}=\alpha+\iota+\beta_{i} X_{i}+\beta_{j} X_{j}+\beta_{r} X_{r}+\delta a_{i j}+\gamma d_{i j}+\varepsilon
$$

where $h_{i j}=h_{i j}^{*}$ if $h_{i j}^{*}>0$ and $h_{i j}=0$ if $h_{i j}^{*} \leqslant 0$. We estimate (3.4) using the Bayesian

\footnotetext{
${ }^{2}$ Baggs (2009) uses a Heckman two-step estimation procedure that is appropriate in the case of international hazardous waste shipments. Her data differ from the U.K. data in that zero flows could be missing values and are not necessarily known zero flows.
} 
variant of the traditional Tobit model as implemented by James P. LeSage's econometrics toolbox in Matlab ${ }^{3}$ as described below.

By way of notation, let $\theta$ denote a vector of parameters of interest, $\pi(\theta)$ the prior probability density function (pdf) for $\theta$, and let $f(y \mid \theta)$ represent the likelihood function. The posterior distribution of the parameters, namely $\pi(\theta \mid y)$, is derived via Bayes' Rule:

$$
\pi(\theta \mid y)=\frac{\pi(y \mid \theta) \pi(\theta)}{\pi(y)}
$$

here, $\pi(y)$ is the integrating constant that ensures that the posterior probability density integrates to unity.

Given that $\pi(y)$ does not involve the parameter vector $\theta$, we can ignore this constant in subsequent analyses and write Bayes' Theorem as follows:

$$
\pi(\theta \mid y) \propto \pi(y \mid \theta) \times \pi(\theta)
$$

Ideally, we would like to draw inferences regarding the parameters of the model by analytically integrating the joint posterior distribution for each of the model's parameters, resulting in a marginal distribution for each parameter. However, the analytical solution to this integration problem is available only in a few select cases. In deriving the marginal distributions, these complications force us to draw inferences using iterative procedures, referred to generically, as Markov Chain Monte Carlo (MCMC) methods. Specifically, this model makes use of the Gibbs sampler to provide robust inferences regarding the model parameters.

The Gibbs sampler is an algorithm used to generate a sequence of samples from the joint posterior distribution of the parameters when an analytical solution is unavailable. There are two necessary conditions for Gibbs sampling: 1) the full conditional distributions comprising the joint posterior must be available in closed form and 2) these forms must be tractable in the sense that it is easy to draw samples from them. In terms of the regression coefficients, these requirements are met in that random draws from the multivariate normal distribution are used to obtain parameter estimates. This is also true in terms of the error variance parameter, $\sigma^{2}$, whereby inferences are obtained via random draws from the inverse Gamma distribution. ${ }^{4}$

\footnotetext{
${ }^{3}$ Available at www.spatial-econometrics.com

${ }^{4}$ This brief description of Bayesian methods draws heavily upon a more detailed description of Bayesian estimation in a spatial econometrics context found in Jensen et al. (2010).
} 
The formula for Bayes' Rule explicitly allows for prior information to be included in the statistical analysis. This model makes use of proper prior distributions with fairly uninformative values. The prior for the $\beta$ s is set to come from a multivariate normal distribution with mean $\hat{\beta} \equiv 0_{K}$ and covariance $C_{\hat{\beta}} \equiv 10,000 \times I_{K}$. The prior values for the $\sigma$ parameter, which come from the inverted Gamma distribution, are $v_{0} \equiv 1$ and $s_{0}^{2} \equiv 1$.

\subsection{Data}

Data for 2006 were collected for all variables at the unitary authority, metropolitan district/county, non-metropolitan district, and London borough level. The following regions of the U.K. were dropped due to data availability: Northern Ireland, Isle of Man, Channel Islands, Arran \& Cumbrae, and Helensburgh \& Lomond. The regions of Badenoch \& Strathspey, Caithness \& Sutherland, Inverness \& Nairn, Ross \& Cromarty, Skye \& Lochalsh, and Lochaber were aggregated into the Highlands and Islands region of Scotland because data for variables other than hazardous waste flows were unavailable at a more disaggregate level.

Figure 3.1: 57 U.K. Regions of Analysis

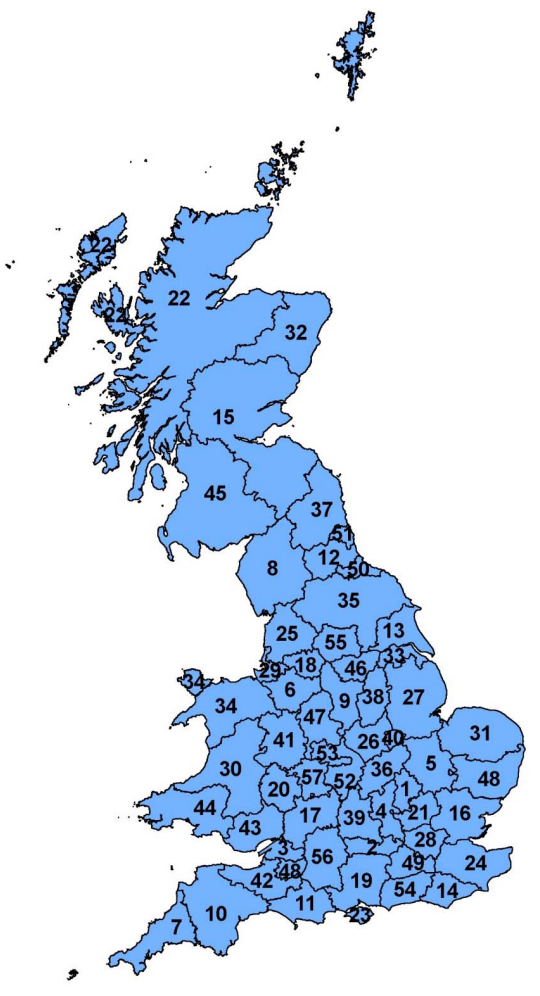

\begin{tabular}{|r|l|r|l|}
\hline 1 & Bedfordshire & 30 & Mid Wales \\
\hline 2 & Berkshire & 31 & Norfolk \\
\hline 3 & Bristol/Bath Area & 32 & North Eastern Scotland \\
\hline 4 & Buckinghamshire & 33 & North Lincolnshire \\
\hline 5 & Cambridgeshire & 34 & North Wales \\
\hline 6 & Cheshire & 35 & North Yorkshire \\
\hline 7 & Cornwall \& Isles of Scilly & 36 & Northamptonshire \\
\hline 8 & Cumbria & 37 & Northumberland \\
\hline 9 & Derbyshire & 38 & Nottinghamshire \\
\hline 10 & Devon & 39 & Oxfordshire \\
\hline 11 & Dorset & 40 & Rutland \\
\hline 12 & Durham & 41 & Shropshire \\
\hline 13 & East Riding & 42 & Sorrerset \\
\hline 14 & East Sussex & 43 & South East Wales \\
\hline 15 & Eastern Scotland & 44 & South West Wales \\
\hline 16 & Essex & 45 & Sonth Western Scotland \\
\hline 17 & Gloucestershire & 46 & South Yorkshire \\
\hline 18 & Greater Manchester & 47 & Staffordshire \\
\hline 19 & Hampshire & 48 & Suffolk \\
\hline 20 & Herefordshire & 49 & Surrey \\
\hline 21 & Hertfordshire & 50 & Tees Valley \\
\hline 22 & Highlands and Islands & 51 & Tyne and Wear \\
\hline 23 & Isle of Wight & 52 & Warwickshire \\
\hline 24 & Kent & 53 & West Midlands \\
\hline 25 & Lancashire & 54 & West Sussex \\
\hline 26 & Leicestershire & 55 & West Yorkshire \\
\hline 27 & Lincolnshire & 56 & Wiltshire \\
\hline 28 & London & 57 & Worcestershire \\
\hline 29 & Merseyside & & \\
\hline & & \\
\hline
\end{tabular}


These initial edits resulted in 408 unique U.K. regions. These regions were then aggregated into 57 regions loosely based on the Nomenclature Units for Territorial Statistics (NUTS) regions of the U.K., developed by the EU. The 57 region aggregation scheme used in this chapter and the next lies between the official NUTS 2 and NUTS 3 subdivisions of the U.K. A map of this aggregation scheme can be found in Figure 3.1.

Table 3.1: Hazardous Waste and Regional Characteristics Variables

\begin{tabular}{|c|c|c|}
\hline Variable & Tag & Description \\
\hline hazardous waste flows & fllows & $\begin{array}{l}\text { Amount of hazardous waste bound } \\
\text { for management, recovery, or disposal, } \\
\text { which moved between regions within } \\
\text { the U.K. in } 2006 \text { (metric tons) }\end{array}$ \\
\hline population density & popdens & $\begin{array}{l}\text { Population density using the mid-year } \\
\text { population estimate and the geographi- } \\
\text { cal area of a region as measured in } 2006 \\
\text { (people/hectare) }\end{array}$ \\
\hline \% population under 19 & under19 & $\begin{array}{l}\text { Estimate of the percentage of the } 2006 \\
\text { population that is under the age of } 19\end{array}$ \\
\hline$\%$ population over 59 & over59 & $\begin{array}{l}\text { Estimate of the percentage of the } 2006 \\
\text { population that is over the age of } 59\end{array}$ \\
\hline$\%$ population in good health & goodhealth & $\begin{array}{l}\text { Percentage of population who rated } \\
\text { their own health 'good' or 'very good' } \\
\text { during the } 2001 \text { Census }\end{array}$ \\
\hline$\%$ with no qualifications & noquals & $\begin{array}{l}\text { Percentage of the population aged 16- } \\
74 \text { with no formal educational qualifi- } \\
\text { cations during the } 2001 \text { Census }\end{array}$ \\
\hline$\%$ manufacturing employment & manufemp & $\begin{array}{l}\text { Percentage of persons aged } 16-74 \text { in em- } \\
\text { ployment who worked in manufacturing }\end{array}$ \\
\hline income & income & $\begin{array}{l}\text { Per capita income for } 2006 \text { (thousands } \\
\text { of British pounds) }\end{array}$ \\
\hline hazardous waste landfill & landfill & $\begin{array}{l}\text { Dummy variable indicating whether } \\
\text { the region was permitted for any haz- } \\
\text { ardous waste landfill capacity in } 2006\end{array}$ \\
\hline distance & distance & $\begin{array}{l}\text { Distance between the centroid of the } \\
\text { origin region and the centroid of the } \\
\text { destination region (kilometers) }\end{array}$ \\
\hline
\end{tabular}

Data on hazardous waste flows are drawn from the Hazardous Waste Interrogator, 2006, which is a database available from the U.K. Environment Agency. This database provides detailed information on hazardous waste flows including, but not limited to, origin and 
destination districts, amount of hazardous waste, and fate of the shipment. The hazardous waste flows analyzed in the following two chapters do not include shipments destined for a transfer station. This is to avoid double-counting and to focus the analyses on hazardous waste shipments for management or disposal. These data are aggregated to the 57 region scheme defined above resulting in a $57 \times 57$ matrix of hazardous waste flows between regions in the U.K.

Table 3.2: Descriptive Statistics for Hazardous Waste and Regional Characteristics Variables

\begin{tabular}{lrrrr}
\hline Variable & Min & Max & Mean & Std. Dev. \\
\hline \hline hazwasteflows & 0.00 & $1,678,585.36$ & $1,569.20$ & $29,207.01$ \\
popdens & 0.11 & 48.00 & 5.40 & 7.99 \\
empdens & 0.05 & 24.21 & 2.38 & 3.78 \\
under19 & 22.23 & 27.43 & 24.70 & 1.16 \\
over59 & 16.36 & 28.36 & 21.94 & 2.53 \\
goodhealth & 61.79 & 89.79 & 67.93 & 6.17 \\
noquals & 6.62 & 26.18 & 19.53 & 4.49 \\
manufemp & 6.66 & 25.52 & 16.14 & 4.31 \\
income & 22.88 & 42.33 & 27.68 & 4.37 \\
landfill & 0.00 & 1.00 & 0.54 & 0.50 \\
distance & 0.00 & 801.03 & 236.56 & 20.99 \\
\hline
\end{tabular}

All descriptive statistics values are prior to taking the natural logarithm.

For scaling purposes, percentage variables in decimal form were multiplied by 100 .

Data for explanatory variables for regions in England and Wales were collected from the Office of National Statistics (http://neighbourhood.statistics.gov.uk). Similar data for regions in Scotland were collected from the the Scottish Neighbourhood Statistics (http: //www.sns.gov.uk). Descriptions of the variables collected can be found in Table 3.1 and descriptive statistics are displayed in Table 3.2. Distance, adjacency, population density, employment density, manufacturing employment, income, and all hazardous waste data are current for 2006. All other data are estimated based on data collected in the 2001 Census. Data for all variables except those expressed as percentages are in natural log form. 


\subsection{Analytical Results}

Many demographic characteristics are included in this model. These types of characteristics provide valuable insight into the relationships that exist in U.K. hazardous waste flows but must be interpreted carefully noting problems of causality. Many of these variables will call issues of timing into question. For example, suppose that average land price was one of the explanatory variables and the results showed that hazardous waste flows into regions with lower average land prices. This result could be explained in two very different ways: 1) a hazardous waste landfill was sited making surrounding land values low, or 2) low average land prices already existed and a hazardous waste landfill was sited taking advantage of these low average land prices. This implies that there is not always a clear environmental justice argument, similar to that of waste dumping, even when waste appears to be moving from regions with higher property values to those with lower property values. Further details on hazardous waste management or disposal locations and the year in which they were planned or became functional are needed to come closer to answering questions of causality such as these. Without this information, the results in this chapter and the next can still suggest characteristics that are associated with flows without necessarily determining the exact cause of these relationships.

Table 3.3 contains the results from the Tobit specification of the spatial interaction model. Results are derived after running the model for 110,000 iterations using the initial 10,000 iterations as "burn in" of the sampler. As is the standard practice in Bayesian regression analyses, 95\% credible intervals from the Gibbs samples for the regression coefficients were calculated and will be used to determine "significance." Those intervals that do not contain zero are considered "significant" in the sense that the variable is associated with explaining variation in the dependent variable, hazardous waste flows. Where the results in Table 3.3 are in bold-faced type, the respective coefficient is associated with the dependent variable at the $95 \%$ level; i.e., the $95 \%$ credible interval points to a posterior distribution for the parameter estimate that is far enough away from zero, giving credence to an important role played by these variables in explaining the interregional hazardous waste flows.

As expected, the coefficient estimate on the distance variable is negative and significant. 
Table 3.3: Variable Associations with Hazardous Waste Flows

\begin{tabular}{|c|c|c|c|}
\hline & Mean Beta & Lower $5 \%$ & Upper $95 \%$ \\
\hline$\alpha$ & 51.132 & 34.362 & 67.805 \\
\hline$\iota$ & -13.893 & -95.358 & 66.805 \\
\hline d-popdens & -1.142 & -3.198 & 0.920 \\
\hline d-empdens & 1.808 & -0.214 & 3.833 \\
\hline d-under19 & 0.123 & -0.076 & 0.323 \\
\hline d-over59 & -0.356 & -0.472 & -0.241 \\
\hline d-goodhealth & -0.368 & -0.435 & -0.302 \\
\hline d-noquals & 0.034 & -0.061 & 0.128 \\
\hline d-manufemps & -0.067 & -0.111 & -0.024 \\
\hline d-income & -0.950 & -2.726 & 0.867 \\
\hline d-hwlandfill & 1.034 & 0.778 & 1.291 \\
\hline o-popdens & 0.377 & -1.575 & 2.307 \\
\hline o-empdens & 0.002 & -1.913 & 1.930 \\
\hline o-under 19 & -0.322 & -0.516 & -0.128 \\
\hline o-over59 & -0.101 & -0.212 & 0.009 \\
\hline o-goodhealth & 0.151 & 0.097 & 0.204 \\
\hline o-noquals & 0.204 & 0.111 & 0.297 \\
\hline o-manufemps & -0.129 & -0.173 & -0.086 \\
\hline o-income & -0.924 & -2.379 & 0.531 \\
\hline o-hwlandfill & 0.757 & 0.498 & 1.017 \\
\hline i-popdens & -15.087 & -29.655 & -0.555 \\
\hline i-empdens & 14.673 & 0.353 & 29.022 \\
\hline i-under19 & 1.012 & -0.396 & 2.429 \\
\hline i-over 59 & 1.011 & 0.208 & 1.821 \\
\hline i-goodhealth & -0.291 & -0.751 & 0.142 \\
\hline i-noquals & 0.129 & -0.568 & 0.814 \\
\hline i-manufemps & 0.128 & -0.178 & 0.432 \\
\hline i-income & 11.078 & -0.589 & 23.464 \\
\hline i-hwlandfill & -1.371 & -3.186 & 0.450 \\
\hline adjacency & 0.665 & 0.177 & 1.152 \\
\hline distance & -2.967 & -3.242 & -2.692 \\
\hline
\end{tabular}

Bold-faced type indicates that the respective coefficient is associated with the dependent variable at the $95 \%$ level. 
This implies that the larger the distance between the centroids of two regions, the less likely they are to trade in hazardous waste. Considering the expenses associated with monitoring and transporting hazardous waste, this result is not at all surprising. This paper focuses on shipments of all types of hazardous waste bound for management or diposal. Depending on the type of hazardous waste, the value of this coefficient could change dramatically. Different regulations in place on transportation modes, routes, and timing for different types of hazardous waste, as well as differences in transportation costs and destination options, will all have an effect on the distance that hazardous waste will travel.

The other measure of transaction costs within this model specification is adjacency. The coefficient on adjacency is positive and significant indicating that if two regions are neighbors (here, neighbors are defined using queen contiguity) then they are more likely to trade in hazardous waste. This result and the result discussed above for distance seem to indicate that when hazardous waste crosses regional borders in the U.K., it tends to be traded to closer regions rather than more distant regions. These results suggest that the U.K. is implementing the goal that appears in the Basel Convention and other E.U. regulations of managing hazardous waste as close to its point of generation as possible.

Relatively few characteristics are significant for both the origin and destination regions of hazardous waste flows. These characteristics are the percentage of the population that claims to be in good health, the percentage of the employees that work in manufacturing, and the presence of hazardous waste landfill capacity. The positive coefficient estimate for the percentage of the population that claims to be in good health in the origin regions indicates that more hazardous waste flows out of regions with larger percentages of people claiming good health. The negative coefficient estimate for the destination regions suggests that less hazardous waste flows into regions where larger percentages of the population claim to be in good health. Note that these results do not indicate that populations that ship out more hazardous waste are healthier due to its absence or that populations in destinations receiving more hazardous waste are in poor health due to receiving hazardous waste, which are often arguments against citing hazardous waste management or disposal locations. Another possible explanation is that many types of medical wastes are often classified as hazardous and are not managed or disposed on site. If populations are reporting good health as a result of 
greater access to healthcare, in terms of more medical establishments, and these establishments ship their hazardous waste to regions with fewer medical facilities (and poor access to healthcare for their populations) for managment or disposal, then this could partially explain these results.

The coefficient estimates for the percentage of employees in manufacturing are negative and significant for both the origin and the destination regions. These results suggest that when the percentage of employees in manufacturing within a region is higher, less hazardous waste flows into the region from outside and also that less hazardous waste flows out to other regions. If, similar to the case of the United States, as discussed in Chapter 2, large amounts of hazardous waste are generated and managed on site by large manufacturing industries, then manufacturing based regions might not need to send large amounts of hazardous waste out of the region to be managed or disposed. This suggestion does not explain the result for the destination regions. Perhaps if manufacturing based regions are capable of managing hazardous waste, one would expect that more hazardous waste would flow in to be managed. However, it is also possible that these manufacturing sites are at their managing capacity through their own generation of hazardous waste and do not accept hazardous waste from outside for management.

The dummy variable that indicates whether a region has any type of hazardous waste landfill capacity also has coefficient estimates that are significant at both the origin and the destination and are both positive. This dummy variable takes on a value of 1 if any type of hazardous waste landfill capacity exists within a region including permitted hazardous waste landfills and non-hazardous waste landfills that have been permitted to operate separate cells for certain stable, non-reactive hazardous waste. Not all of these landfills are permitted to accept all types of hazardous waste. This variable was intended as an initial proxy for a region's ability to handle hazardous waste as data are not available on capacity levels for the different types of hazardous waste landfills at this level of disaggregation nor are they available for the number and location of management facilities. These coefficients indicate that the presence of some type of hazardous waste landfill in the region is both a push and pull factor for hazardous waste flows. The result suggesting that more hazardous waste flows into districts with hazardous waste landfills is logical. However, the fact that districts with 
hazardous waste landfills also ship more hazardous waste out is, at first glance, a bit puzzling. The presence of a hazardous waste landfill might be more likely in a region that produces large amounts of hazardous waste but it might not be economical or politically favorable for there to be enough hazardous waste landfill capacity to handle all of the region's hazardous waste. Therefore, regions with hazardous waste landfills might still ship potentially large amounts of hazardous waste out. Also, recall that the hazardous waste flows include hazardous waste destined for not only a landfill but also that destined for management, incineration, reuse, or recycling. It might be that the wastes destined for these other types of final destinations are more likely to leave districts with hazardous waste landfills.

The literature on waste dumping often suggests that hazardous waste is dumped on less developed areas that likely have lower income and lower education levels. Here, the insignificant coefficient estimates for the income and educational level variables in the destination regions suggest no support for hazardous waste being shipped to such regions in the U.K. The coefficient estimate on origin income is also not significant. Indeed, the origin coefficient estimate for the percentage of the population with no formal educational qualifications is positive and significant indicating that more hazardous waste flows out of regions that have larger percentages of the population with no such qualifications. A reasonable explanation for this result lies in the inherent characteristics of hazardous waste management and disposal. Hazardous waste management and disposal are both capital intensive and highly regulated in developed countries such as the U.K. This means that employees involved with such industries are likely to have some educational qualifications, if not be highly educated. It is also possible that hazardous waste generating industries employ those with low educational qualifications and that these employees are not able to handle the management or disposal of the hazardous waste generated and therefore must send it to another region.

Population density is insignificant for both the origin and the destination regions. However, coefficient estimates on the age breakdowns of a region's population suggest some influence on hazardous waste flows in the U.K. Significant coefficient estimates on the age distributions of the population suggest that less hazardous waste flows into districts with larger proportions of older people (those over the age of 59) and that regions with larger proportions of young people (those under the age of 19) send less hazardous waste out. The 
coefficient estimate for the percentage of older population is not significant for the origin regions and that for the percentage of younger population is not significant for the destination regions. These results could be due to a selection effect; older populations are more capable of choosing where they live and this choice is likely based on the quality of life within a region. Assuming that the existence of large inflows of hazardous waste does not add to the quality of life within a region, it seems logical that the older populations would choose to live in areas that do not accept large amounts of hazardous waste. Also, children are not only less likely to make such a decision for themselves but are likely members of a younger family with fewer options available to them than the older population. This might be an explanation for these results but the detailed relationships existing in the network of hazardous waste management and disposal and the different characteristics of different types of hazardous waste should be explored for more clarification.

Very few of the coefficient estimates for explanatory variables on the intraregional hazardous waste flows are significant. However, recall that modeling these flows separately is not an exercise in determining the characteristics associated with intraregional hazardous waste flows but is intended to be a way of avoiding any biasing effect of large diagonal flows. As such, the few significant results on population density, employment density, and the percentage of the population that is over the age of 59 are not discussed. However, since the coefficient estimates on population density and employment density were not significant for the origin or the destination within the interregional flows, these results suggest that the characteristics associated with intraregional flows are indeed very different from those associated with interregional flows.

\subsection{Conclusions}

This chapter estimates a Tobit specification of a spatial interaction model for hazardous waste flows between 57 regions of the U.K. The model specifically corrects for both large diagonal flows and a large percentage of zero flows, which are both inherent characteristics of the U.K. hazardous waste flow matrix. Multiple economic, demographic, and hazardous waste-related characteristics that might be considered "push" or "pull" factors for hazardous 
waste destined for management or disposal are examined.

Results suggest that lower percentages of the population under the age of 19, higher percentages of the population claiming to be in good health, higher percentages of the population with no educational qualifications, lower percentages of employment in manufacturing, and the existence of hazardous waste landfill capacity are all "push" factors for flows of hazardous waste in the U.K. Further, lower percentages of the population over the age of 59, lower percentages of the population claiming good health, lower percentage of employment in manufacturing, and the existence of hazardous waste landfill capacity are all "pull" factors for hazardous waste flows in the U.K. Also, both adjacency and distance play an important role for hazardous waste flows in the U.K. The results suggest that adjacent regions trade more in hazardous waste and that distance has a negative effect on the flow of hazardous waste between regions.

These results by no means represent final work on this topic but are meant to be a starting point for a discussion on hazardous waste flows in the U.K. and their determinants. However, policymakers can use the information provided within this chapter to combat the notion of hazardous waste dumping within the U.K. According to the parameter estimates on the income variable, the results show no evidence that hazardous waste is moving from higher income regions to lower income regions. Regarding educational qualifications, the results also show no evidence of hazardous waste moving from regions with low percentages of the population with no educational qualifications to regions with high percentages of the population with no educational qualifications. In fact, the result for the origins suggests the contrary. Regions where larger percentages of the population have no educational qualifications actually ship more hazardous waste out. The parameter estimates for the adjacency and distance variables also indicate that progress is being made with respect to managing and disposing hazardous waste as close to the site of generation as possible.

Futhermore, policymakers could use this modeling framework to examine other hypotheses and notions related to hazardous waste trade. This would be a useful exercise during the formulation of new policies on hazardous waste flows whether they are being considered within the U.K. or within the larger communities of nations to which the U.K. belongs. The examination of these hazardous waste flows continues in the next chapter. 


\section{Chapter 4}

\section{Spatial Dependence in Hazardous Waste Flow Relationships}

Spatial interaction data measure observations that are associated with a pair of origindestination locations. The typical method for analyzing this type of data is a spatial interaction model such as the traditional gravity model or the Tobit specification used to examine U.K. hazardous waste flows in Chapter 3. The specification in Chapter 3 was designed to correct for two common issues that often plague spatial interaction models - large diagonal flows and a large percentage of zero flows. However, LeSage and Pace (2008) also point out that another common issue for spatial interaction models is spatial dependence.

Oftentimes, modelers have either assumed independence among the origin-destination flows or have assumed that the inclusion of distance as an explanatory variable absolves the model of any spatial dependence among flows. These assumptions have often been challenged (Curry, 1972; Griffith and Jones, 1980; LeSage and Pace, 2008, 2009), and it has been argued that many types of spatial dependence could still be present in different types of spatial interaction data. See Griffith (1993) for a review of the subject of spatial dependence in interregional flows.

This chapter considers the existence of spatial dependence in the context of interregional hazardous waste flows in the U.K. and uses a spatial econometric variant of the spatial interaction model to extend the analysis from Chapter 3. Section 4.1 briefly reviews the literature on spatial dependence in origin-destination flows and the spatial econometric methods that 
are used in conjunction with spatial interaction modeling to correct for this issue. Section 4.2 motivates and describes the methodology used in this chapter and Section 4.3 examines the results from the spatial interaction model with spatially structured origin and destination effects. Section 4.4 concludes.

\subsection{Spatial Econometric Spatial Interaction Literature}

A generalized form of spatial interaction model (structurally equivalent to the logtransformation of a traditional gravity model), similar to that alluded to in equation 3.3, can be defined as follows:

$$
y=\alpha \iota_{n}+\beta_{o} X_{o}+\beta_{d} X_{d}+\gamma d+\varepsilon
$$

where $y$ is the dependent variable representing spatial interaction (or flows) from an origin to a destination, $X_{o}$ and $X_{d}$ represent the explanatory variables characterizing the origin and destination region characteristics respectively, $d$ is a measure of distance between the origin and the destination regions, $\iota_{n}$ is a constant term, $\alpha, \beta_{o}, \beta_{d}$, and $\gamma$ represent parameter estimates of the effects of the respective explanatory variables, and $\varepsilon$ is an i.i.d. error term where $\varepsilon \sim N\left[0, \sigma_{\varepsilon}^{2} I_{N}\right]$. Typically, the spatial interaction values or flows represented within the dependent variable $y$ are assumed to be independent of one another, resulting in a model that is consistent with the Gauss-Markov assumptions for ordinary-least-squares estimation. However, as spatial interaction data are most often associated with interactions between an origin and destination that represent locations in geographic space, it is likely that spatial dependence is an issue.

The assumption of independence among flows has been called into question by many authors since Curry (1972). Following a long debate in the regional science literature, reviewed by Griffith (1993), the argument that spatial dependence could indeed be present in many forms within spatial interaction relationships has prevailed. Later authors have focused their efforts on describing the types of spatial dependence present within spatial interaction relationships and how to account for it within analytical models.

Griffith and Jones (1980) examined the influence of spatial structure on spatial interac- 
tion models defining a spatial interdependence or autocorrelation effect. Griffith and Jones first describe this effect using a journey-to-work type application, writing that "...the number of interactees supplied by origins is enhanced or diminished in accordance with attributes displayed by neighboring origin locations" and that "the number of interactees received by destinations is enhanced or diminished in accordance with attributes displayed by neighboring destination locations" (p. 187). This type of relationship seems to allude to that found in modern spatial econometric models that include a spatial lag of explanatory variables, or SLX models. However, they also describe a situation in which "the number of interactees supplied by an origin is enhanced or diminished in accordance with the propensity of emissiveness of its neighboring origin locations" and that "the number of interactees received by a destination is enhanced or diminished in accordance with the propensity of attractiveness of its neighboring destination locations" (p. 190). This second description is more like the relationship that exists in a spatial autoregressive (SAR) model in which there is a spatial lag of the dependent variable.

Similar to the second description of Griffith and Jones (1980), LeSage and Pace (2008) and LeSage and Pace (2009) discuss several different manners in which spatial dependence could still be present within the dependent variable observations of spatial interaction models. They propose the following spatial autoregressive extension of equation (4.1):

$$
y=\rho_{d} W_{d} y+\rho_{o} W_{o} y+\rho_{w} W_{w} y+\alpha \iota_{n}+\beta_{o} X_{o}+\beta_{d} X_{d}+\gamma d+\varepsilon
$$

where $\rho_{d}, \rho_{o}$, and $\rho_{w}$ are the spatial dependence parameters representing spatial dependence at the origins, the destinations, and within the flows respectively and $W_{d}, W_{o}$, and $W_{w}$ represent row-normalized spatial weights matrices for the origin regions, the destination regions, and the flows respectively. All other variables retain the same definitions as in (4.1). This equation is capable of testing for and measuring multiple types of spatial dependence in the dependent variable. They also discuss that this model can be extended to account for spatial dependence within the explanatory variables (as in the traditional spatial Durbin model) and note that this also implies that restrictions on the spatial parameters can lead to a model representing a spatial error model specification where spatial dependence exists within the error term. 
LeSage and Llano (2007) also discuss manners in which the flows embodied in a spatial interaction matrix could exhibit spatial dependence. Citing references from literature as diverse as interregional input-output analysis, commodity flows, and social networking, LeSage and Llano (2007) describe a situation where underlying unobserved or latent behaviors are at work allowing neighboring origins and destinations to exhibit similar estimation errors. They suggest a hierarchical variant of the gravity model to capture spatially structured region-specific effects for the origins and the destinations. Using their notation, the model takes the following form:

$$
\begin{gathered}
y=Z \delta+V \theta+W \phi+\varepsilon \\
\theta=\rho_{o} D \theta+u_{o} \\
\phi=\rho_{d} D \phi+u_{d}
\end{gathered}
$$

where $Z$ contains the explanatory variable elements of the original model (in terms of (4.2), $\left.Z=\left[\iota_{n}, X_{d}, X_{o}, d\right]\right), V$ identifies the region as an origin, $W$ identifies the region as a destination, and $u_{o}$ and $u_{d}$ are error terms associated with the region-specific effects, distributed as $u_{o} \sim N_{n}\left[0, \sigma_{o}^{2} I_{n}\right]$ and $u_{d} \sim N_{n}\left[0, \sigma_{d}^{2} I_{n}\right]$. Such a model is capable of not only testing for any significant region-specific effects but also whether these effects exhibit spatial dependence.

The spatial econometric spatial interaction literature, as well as the broader literature on spatial interaction, suggests that not only should one consider spatial dependence in spatial interaction models but that it is important to consider the type of spatial dependence considered to properly specify an analytical model.

\subsection{Methodology}

This chapter proposes that the spatial econometric approach of LeSage and Llano (2007) is the most appropriate first extension to the model of U.K. hazardous waste flows in Chapter 3 for two reasons: 1) this method tests for unobserved region-specific behaviors at both the origin and the destination that affect hazardous waste flows and 2) this method explicitly 
considers that U.K. regions are not spatially independent entities and that they could be closely related through characteristics that are unobservable within quantitative models. Coefficient estimates from such a model are also directly comparable to those in Chapter 3 meaning that differences observed can be explained by the inclusion of the region-specific effects within the modeling framework.

Within the hazardous waste analyses in this dissertation, there are many examples of omitted or unobservable explanatory variables. For example, information on the types of industries that are generating or managing this hazardous waste is not available in the Hazardous Waste Interrogator provided by the Environment Agency. This information would provide more insight into how the regional economic structure could be affecting hazardous waste flows at the origins and destinations and how it should be measured. Also, the opinions and attitudes of the population as they relate to hazardous waste could be an important factor. Regions in which "Not-In-My-Backyard" (NIMBY) attitudes are unusually strong could be expected to ship out any hazardous waste that is generated within the region and receive very little, if any, from outside of the region.

It is also true that many characteristics of hazardous waste regulation, management, and disposal are not included within the model. The list of desired and unavailable data on hazardous waste related characteristics is long. A dummy variable indicating whether or not a region has any type of hazardous waste landfill capacity is used as a proxy for general hazardous waste management and disposal capability within the region. However, were data available on the locations and capacities of management facilities, they should also be included. Also, consider that there are likely to be regulations on hazardous waste transportation such as restrictions on transportation modes or routes. It is likely that such restrictions play an important role in how and why hazardous waste moves from one region to another in the U.K.

Once again, these unobserved behaviors that dictate region-specific effects are not only important to consider and model on their own, but it is also likely that they are responsible for spatial dependence among regions. Consider the example of omitted variables related to hazardous waste transport and the following spatial configuration: 
Figure 4.1: Barrier to trade between spatial units A and B (hashed units)

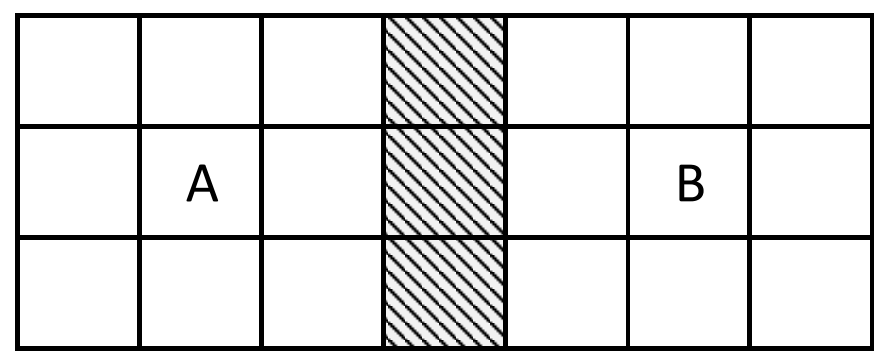

If hazardous waste cannot be transported through the hashed spatial units, $\mathrm{A}$ and $\mathrm{B}$ are unlikely to trade in hazardous waste. For the same reason, neighbors of A (B) are also unlikely to trade with B (A). By considering an explicit spatial dependence structure for the region-specific effects, relationships such as these can be captured.

The model in Chapter 3 is extended by introducing the estimation of spatially structured region-specfic effects related to the origin and destination regions. The model can be expressed as follows:

$$
\begin{gathered}
h_{i j}=\alpha+\iota+\beta_{i} X_{i}+\beta_{j} X_{j}+\beta_{r} X_{r}+\theta q_{i}+\phi p_{j}+\gamma d_{i j}+\varepsilon \\
\theta=\rho_{o} W \theta+u_{o} \\
\phi=\rho_{d} W \phi+u_{d}
\end{gathered}
$$

where $i$ represents the origin region, $j$ represents the destination region, $h_{i j}$ is the flow of hazardous waste from region $i$ to region $j, X_{i}$ is a matrix of explanatory variables describing the origin region, $X_{j}$ is a matrix of explanatory variables characterizing the destination region, $X_{r}$ is the matrix of explanatory variables associated with the intraregional flows, $q_{i}$ identifies region $i$ as an origin region, $p_{j}$ identifies region $j$ as a destination region, and $d_{i j}$ represents the distance between the centroids of regions $i$ and $j . \beta_{i}, \beta_{j}, \beta_{r}, \theta, \phi$, and $\gamma$ are all coefficient estimates on the respective explanatory variables, $\alpha$ is the constant term associated with the interregional shipments, $\iota$ is the constant term associated with the intraregional shipments, and $\varepsilon$ is an i.i.d. error term distributed $\varepsilon \sim N_{N}\left[0, \sigma_{\varepsilon}^{2} I_{N}\right]$. $\theta$ and $\phi$ are both modeled as spatial autoregressive processes, shown in (4.7) and (4.8) where $\rho_{o}$ 
and $\rho_{d}$ are parameters measuring spatial dependence for the origin and destination regions respectively, $u_{o}$ and $u_{d}$ are error terms associated with the region-specific effects, distributed as $u_{o} \sim N_{n}\left[0, \sigma_{o}^{2} I_{n}\right]$ and $u_{d} \sim N_{n}\left[0, \sigma_{d}^{2} I_{n}\right]$, and $W$ is an $n \times n$ row-normalized spatial weights matrix based upon first-order contiguity.

This model posits that interregional hazardous waste flows in the U.K. are a function of a set of explanatory variables associated with origin characteristics, destination characteristics, the distance between the two regions, and some unobserved effects while separately accounting for intraregional flows. The unobserved effects are modeled as a spatial autoregressive process suggesting that the unobserved aspects of the model are likely to be related to the unobserved aspects of neighboring regions. One advantage of this model is that the interpretation of the parameter estimates for the explanatory variables is exactly the same as described in Chapter 3 allowing for comparison across the two models. The unobserved effects parameters $\theta$ and $\phi$ are centered on zero. This implies that origin (destination) regions with positive effects indicate that latent, unobserved factors that are not included in the model positively affect the amount of hazardous waste flowing out of an origin (into a destination). Origin (destination) regions with negative effects suggest that latent, unobserved factors negatively affect the amount of hazardous waste flowing out of an origin (into a destination). LeSage and Llano (2007) provide additional details on the computational aspects of this model.

This chapter also makes use of Bayesian statistical methods to estimate the model parameters. Recall from section 3.3 that it is unlikely that analytically integrating the joint posterior distribution for each of the model's parameters to draw inferences and obtain the marginal distribution for each parameter will be possible. This chapter once again makes use of MCMC methods to draw inferences using iterative procedures. This particular model makes use of both the Gibbs sampler and the Metropolis-Hastings algorithm. The reader is referred back to 3.3 for more information on the Gibbs sampler, which is used to provide random draws for the regression coefficients and the error variance parameter. The Metropolis-Hastings algorithm performs the same function as the Gibbs sampler but can be used for conditional distributions with no recognizable form, used here for the spatial dependence parameters $\rho_{o}$ and $\rho_{d}$. LeSage and Pace (2009, Chapter 5) provide a source of 
additional reference on these and other MCMC methods.

This model makes use of proper prior distributions with fairly uninformative values identical to those used in Chapter 3. The prior for the $\beta$ s is comes from a multivariate normal distribution with mean $\hat{\beta} \equiv 0_{K}$ and covariance $C_{\hat{\beta}} \equiv 10,000 \times I_{K}$. The prior values for the $\sigma$ parameter come from an inverted Gamma distribution where $v_{0} \equiv 1$ and $s_{0}^{2} \equiv 1$. The prior values for the two $\rho$ parameters come from a univariate normal distribution with mean 0 and standard deviation 10,000.

\subsection{Analytical Results}

Tables $4.1-4.4$ contain the results from the Tobit specification of the spatial interaction model with spatial autoregressive region-specific effects. Consistent with Chapter 3, results are derived after running the model for 110,000 iterations using the initial 10,000 iterations as "burn in" of the sampler. Also, 95\% credible intervals are calculated from the Gibbs samples for the regression coefficients and effects estimates to determine "significance." Results in bold-faced type signify that the respective coefficient is associated with the dependent variable at the $95 \%$ level.

Table 4.1 contains the Bayesian model posterior estimates for the explanatory variables and the spatial dependence parameters. As the purpose of this chapter is to control for region-specific origin and destination effects, the discussion of these estimates focuses on a comparison with the results in Chapter 3. The results are largely similar to those in Table 3.3, although there are some differences. The coefficient estimates for the origin characteristics and the distance variable are all consistent with previous results in terms of significance, sign, and size. The proportion of the origin population that is under the age of 19 is the one origin characteristic that was previously significant in Chapter 3 that is no longer significant. Although the adjacency variable is still positive and significant, it is much smaller in value (indicating less influence on the hazardous waste flows) when the region-specific effects are included. The coefficient estimates for characteristics related to intraregional flows exhibit some differences, largely in terms of additional significance. As these intraregional flows are not the focus of this chapter, these results are once again not discussed. 
Table 4.1: Variable Associations with Hazardous Waste Flows with Region-Specific Effects

\begin{tabular}{lrrr}
\hline Region & Mean & Lower $\mathbf{5 \%}$ & Upper $\mathbf{9 5 \%}$ \\
\hline \hline$\alpha$ & -7.618 & -93.065 & 70.627 \\
$\iota$ & -63.833 & -150.984 & 16.335 \\
d-popdens & -13.864 & -32.687 & 6.341 \\
d-empdens & 13.744 & -5.522 & 32.734 \\
d-under19 & 1.193 & -0.533 & 3.122 \\
d-over59 & 0.421 & -0.479 & 1.358 \\
d-goodhealth & $\mathbf{- 1 . 1 2 3}$ & $\mathbf{- 1 . 7 5 3}$ & $\mathbf{- 0 . 5 1 2}$ \\
d-noquals & 0.311 & -0.466 & 1.044 \\
d-manufemps & 0.005 & -0.405 & 0.378 \\
d-income & $\mathbf{2 0 . 4 7 4}$ & $\mathbf{7 . 4 4 6}$ & $\mathbf{4 1 . 5 2 5}$ \\
d-hwlandfill & -0.726 & -1.536 & 2.928 \\
o-popdens & -0.094 & -4.322 & 4.120 \\
o-empdens & 0.444 & -3.715 & 4.603 \\
o-under19 & -0.423 & -0.835 & 0.001 \\
o-over59 & -0.092 & -0.387 & 0.154 \\
o-goodhealth & $\mathbf{0 . 1 8 5}$ & $\mathbf{0 . 0 7 7}$ & $\mathbf{0 . 2 9 7}$ \\
o-noquals & $\mathbf{0 . 2 6 3}$ & $\mathbf{0 . 0 7 5}$ & $\mathbf{0 . 4 6 1}$ \\
o-manufemps & $\mathbf{- 0 . 1 6 3}$ & $\mathbf{- 0 . 2 5 8}$ & $\mathbf{- 0 . 0 5 8}$ \\
o-income & -0.935 & -4.064 & 2.188 \\
o-hwlandfill & $\mathbf{0 . 9 1 2}$ & $\mathbf{0 . 3 4 2}$ & $\mathbf{1 . 4 5 5}$ \\
i-popdens & $\mathbf{- 1 0 . 5 8 0}$ & $\mathbf{- 1 6 . 0 6 8}$ & $\mathbf{- 5 . 2 8 1}$ \\
i-empdens & $\mathbf{1 0 . 5 9 6}$ & $\mathbf{5 . 5 0 0}$ & $\mathbf{1 5 . 8 6 8}$ \\
i-under19 & $\mathbf{0 . 9 1 7}$ & $\mathbf{0 . 4 2 0}$ & $\mathbf{1 . 4 1 0}$ \\
i-over59 & $\mathbf{0 . 9 2 9}$ & $\mathbf{0 . 6 5 5}$ & $\mathbf{1 . 2 0 5}$ \\
i-goodhealth & -0.124 & -0.416 & 0.160 \\
i-noquals & -0.050 & -0.274 & 0.197 \\
i-manufemps & $\mathbf{0 . 1 5 3}$ & $\mathbf{0 . 0 6 8}$ & $\mathbf{0 . 2 3 8}$ \\
i-income & 5.734 & -1.461 & 13.121 \\
i-hwlandfill & $\mathbf{- 1 . 3 1 5}$ & $\mathbf{- 1 . 7 9 8}$ & $\mathbf{- 0 . 8 1 7}$ \\
\hline adjacency & $\mathbf{0 . 1 7 3}$ & $\mathbf{0 . 0 4 1}$ & $\mathbf{0 . 3 0 5}$ \\
distance & $\mathbf{- 3 . 1 7 7}$ & $\mathbf{- 3 . 2 7 3}$ & $\mathbf{- 3 . 0 8 2}$ \\
$\rho_{o}$ & -0.266 & -0.820 & 0.455 \\
$\rho_{d}$ & -0.222 & -0.855 & 0.504 \\
\hline Bor & \\
\hline
\end{tabular}

Bold-faced type indicates that the respective coefficient is associated with the dependent variable at the $95 \%$ level. 
The interesting differences reveal themselves in the results related to the destinationrelated characteristics. After controlling for the region-specific origin and destination effects, three of the destination-related characteristics that were previously significant in Chapter 3 are no longer significant - the percentage of the population that is over the age of 59 , the percentage of employment in manufacturing, and the existence of hazardous waste landfill capacity. Also, after controlling for the region-specific effects, the destination coefficient estimate for the percentage of the population that claims to be in good health is much larger, indicating a stronger association with hazardous waste flows. Finally, the destination coefficient estimate for income is significant in this model. Previously, the income variable was insignificant at both the origin and the destination providing no evidence of hazardous waste flowing from higher income regions to lower income regions in the U.K. This new result on the destination income variable provides evidence of the opposite relationship that regions with higher average income levels receive more hazardous waste.

The coefficient estimates for the spatial dependence parameters, $\rho_{o}$ and $\rho_{d}$, do not show any evidence of spatial dependence for the region-specific effects for the origins or the destinations. These results suggest that there are no unobserved or latent variables creating origin effects levels similar to those in neighboring origins and also that there are no unobserved or latent variables creating destination effects levels similar to those in neighboring destinations. Additional model specifications could be run in the future to determine if this result is robust regarding the level of aggregation of the U.K. regions and/or the specification of the weight matrix.

Even though there is no evidence of spatial dependence within the region-specific effects, the results still provide information on how region-specific effects at the origins and destinations affect hazardous waste flows into or out of a region. Coefficient estimates for the origin and destination effects are presented in Tables 4.2 and 4.3. A positive origin effect indicates that unobserved or latent variables lead to more hazardous waste flows at the origin than predicted by the explanatory variables related to origin region characteristics. Similarly, a positive destination effect suggests that unobserved or latent variables lead to more hazardous waste flows at the destination than predicted by the explanatory variables related to destination region characteristics. Negative origin effects indicate that unobserved variables 
lead to fewer hazardous waste flows at the origin than predicted by the origin's explanatory variables. Finally, a negative destination effect suggests that unobserved variables lead to fewer hazardous waste flows at the destination than predicted by the destination-specific explanatory variables.

Origins or destinations with positive region-specific effects exhibit high levels of hazardous waste flows that are not explained by the included explanatory variables alone. Had the spatial dependence parameters provided evidence of spatial dependence among the region-specific effects, the regions with positive effects could be partially explained through benefits from spatial spillovers. However, as no spatial dependence exists within this application, these results are driven by unobserved variables, possibly a natural advantage related to hazardous waste flows. Alternatively, origins or destinations exhibiting negative effects, suggesting lower hazardous waste flows than expected given their regional characteristics, could be suffering from some natural disadvantage related to hazardous waste flows, a type of negative effect of unobserved characteristics.

As displayed in Table 4.2, there are 15 regions that have significant origin effects. Of these 15, 7 regions experience positive effects and 8 regions experience negative effects. Significant origin effects are also displayed in Figure 4.2 where positive effects are blue and negative effects are yellow. The origin regions experiencing more hazardous waste flows than predicted by the origin-related characteristics, as suggested by a positive individual effect, include (listed in order of magnitude from largest to smallest): Hampshire, South West Wales, South East Wales, Kent, Gloucestershire, North Wales, and Lancashire. Unobserved characteristics that could lead to larger flows out of these regions include low hazardous waste management and/or disposal capacity, better accessibility to transportation infrastructure for moving hazardous waste out of the region, or perhaps strong NIMBY attitudes within these regions. For example, many of these regions are located on the coast. If one mode of interregional hazardous waste transportation is by sea, then increased flows out of regions with ports and access to the sea is expected.

In order of magnitude from largest to smallest (in absolute value), the origin regions with negative region-specific effects are: Rutland, Isle of Wight, Merseyside, Mid Wales, Warwickshire, East Riding, Herefordshire, and Cumbria. Perhaps there are some barriers 
Table 4.2: Region-Specific Effects for the Origins of Hazardous Waste Flows $(\theta)$

\begin{tabular}{|c|c|c|c|}
\hline Region & Mean $\theta$ & Lower $5 \%$ & Upper $95 \%$ \\
\hline Bedfordshire & -0.168 & -1.206 & 0.686 \\
\hline Berkshire & -0.080 & -0.971 & 0.763 \\
\hline Bristol/Bath Area & -0.446 & -1.266 & 0.469 \\
\hline Buckinghamshire & -0.493 & -1.314 & 0.262 \\
\hline Cambridgeshire & 0.347 & -0.309 & 0.979 \\
\hline Cheshire & -0.403 & -0.992 & 0.185 \\
\hline Cornwall \& Isles of Scilly & 0.162 & -0.652 & 1.278 \\
\hline Cumbria & -0.834 & -1.614 & -0.040 \\
\hline Derbyshire & 0.802 & -0.153 & 1.650 \\
\hline Devon & 0.517 & -0.175 & 1.468 \\
\hline Dorset & 0.558 & -0.361 & 1.745 \\
\hline Durham & -0.380 & -1.503 & 0.576 \\
\hline East Riding & -0.940 & -1.485 & -0.424 \\
\hline East Sussex & -0.261 & -1.130 & 0.850 \\
\hline Eastern Scotland & 0.585 & -0.460 & 1.629 \\
\hline Essex & 0.244 & -0.459 & 0.983 \\
\hline Gloucestershire & 1.312 & 0.681 & 1.908 \\
\hline Greater Manchester & -0.593 & -1.276 & 0.089 \\
\hline Hampshire & 2.048 & 1.530 & 2.576 \\
\hline Herefordshire & -0.863 & -1.452 & -0.232 \\
\hline Hertfordshire & -0.175 & -0.759 & 0.443 \\
\hline Highlands and Islands & -0.037 & -1.117 & 1.051 \\
\hline Isle of Wight & -2.099 & -3.063 & -0.792 \\
\hline Kent & 1.656 & 0.936 & 2.430 \\
\hline Lancashire & 0.858 & 0.264 & 1.408 \\
\hline Leicestershire & -0.214 & -0.979 & 0.357 \\
\hline Lincolnshire & 0.065 & -0.488 & 0.678 \\
\hline London & 0.021 & -1.121 & 1.200 \\
\hline Merseyside & -1.665 & -2.579 & -0.690 \\
\hline Mid Wales & -1.232 & -2.122 & -0.252 \\
\hline Norfolk & 0.535 & -0.194 & 1.336 \\
\hline North Eastern Scotland & -0.480 & -1.603 & 0.521 \\
\hline North Lincolnshire & 0.101 & -0.798 & 0.901 \\
\hline North Wales & 1.047 & 0.508 & 1.581 \\
\hline North Yorkshire & -0.563 & -1.176 & 0.082 \\
\hline Northamptonshire & 0.149 & -0.817 & 0.872 \\
\hline Northumberland & 0.153 & -0.793 & 1.116 \\
\hline Nottinghamshire & -0.209 & -0.936 & 0.415 \\
\hline Oxfordshire & -0.262 & -0.900 & 0.358 \\
\hline Rutland & -2.528 & -3.700 & -1.366 \\
\hline Shropshire & -0.611 & -1.280 & 0.067 \\
\hline Somerset & 0.144 & -0.528 & 0.931 \\
\hline South East Wales & 1.710 & 1.075 & 2.289 \\
\hline South West Wales & 1.744 & 1.026 & 2.560 \\
\hline South Western Scotland & 0.256 & -0.591 & 1.097 \\
\hline South Yorkshire & -0.071 & -0.834 & 0.565 \\
\hline Staffordshire & 0.606 & -0.525 & 1.438 \\
\hline Suffolk & 0.434 & -0.157 & 1.120 \\
\hline Surrey & -0.745 & -1.693 & 0.405 \\
\hline Tees Valley & -0.157 & -0.900 & 0.547 \\
\hline Tyne and Wear & -0.882 & -1.843 & 0.030 \\
\hline Warwickshire & -1.046 & -1.686 & -0.433 \\
\hline West Midlands & 0.126 & -0.824 & 1.104 \\
\hline West Sussex & -0.056 & -0.944 & 1.170 \\
\hline West Yorkshire & 0.073 & -0.610 & 0.696 \\
\hline Wiltshire & -0.021 & -0.577 & 0.540 \\
\hline Worcestershire & 0.355 & -0.574 & 1.148 \\
\hline
\end{tabular}


to hazardous waste being shipped out of these regions such as high transportation costs, regulations on hazardous waste export, or geographical trade barriers that work to decrease the amount of hazardous waste flows out of these regions.

Figure 4.2: Significant Region-Specific Effects for Origins of Hazardous Waste Flows

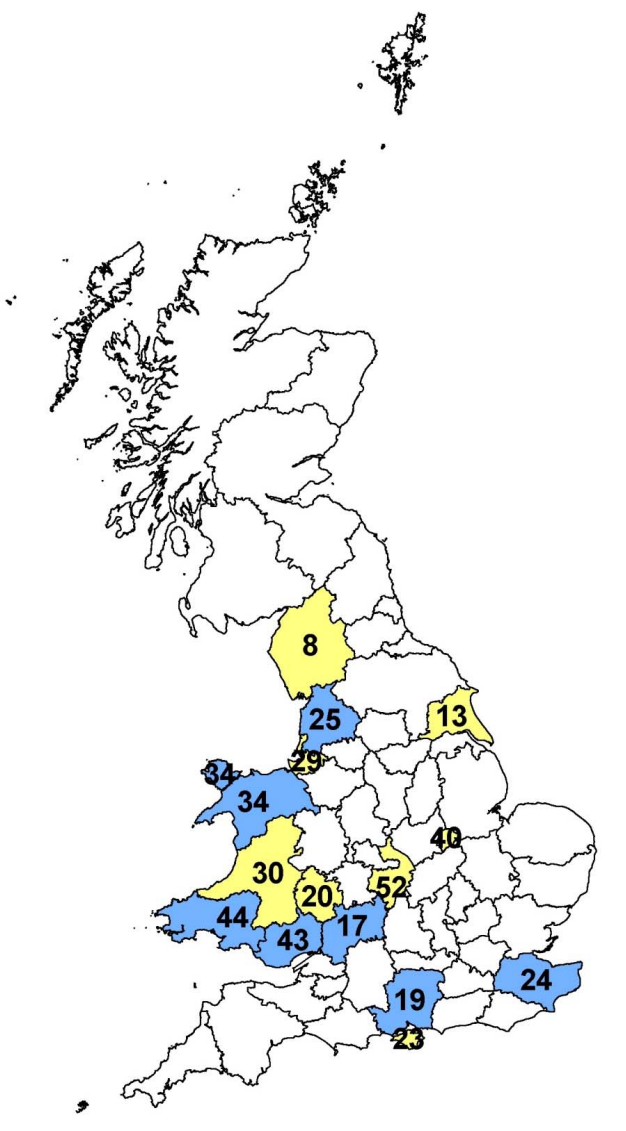

\begin{tabular}{|r|l|r|l|}
\hline 1 & Bedfordshire & 30 & Mid Wales \\
\hline 2 & Berkshire & 31 & Norfolk \\
\hline 3 & Bristol/Bath Area & 32 & North Eastern Scotland \\
\hline 4 & Buckinghamshire & 33 & North Lincolnshire \\
\hline 5 & Cambridgeshire & 34 & North Wales \\
\hline 7 & Cheshire & 35 & North Yorkshire \\
\hline 7 & Cornwall \& Isles of Scilly & 36 & Northamptonshire \\
\hline 9 & Cumbria & 37 & Northumberland \\
\hline 10 & Devon & 38 & Nottinghamshire \\
\hline 11 & Dorset & 39 & Oxfordshire \\
\hline 12 & Durham & 40 & Rutland \\
\hline 13 & East Riding & 41 & Shropshire \\
\hline 14 & East Sussex & 42 & Somerset \\
\hline 15 & Eastern Scotland & 43 & South East Wales \\
\hline 16 & Essex & 44 & South West Wales \\
\hline 17 & Gloucestershire & 45 & South Western Scotland \\
\hline 18 & Greater Manchester & 46 & South Yorkshire \\
\hline 19 & Hampshire & 47 & taffordshire \\
\hline 20 & Herefordshire & 48 & Suffolk \\
\hline 21 & Hertfordshire & 49 & Surrey \\
\hline 22 & Highlands and Islands & 50 & Tees Valley \\
\hline 23 & Isle of Wight & 51 & Tyne and Wear \\
\hline 24 & Kent & 52 & Warwickshire \\
\hline 25 & Lancashire & 53 & West Midlands \\
\hline 26 & Leicestershire & 54 & West Sussex \\
\hline 27 & Lincolnshire & 55 & West Yorkshire \\
\hline 28 & London & 56 & Wiltshire \\
\hline 29 & Merseyside & 57 & Worcestershire \\
\hline & & \\
\hline & & \\
\hline & & \\
\hline
\end{tabular}

Table 4.3 displays the destination effects and indicates that there are 13 regions that have significant individual effects. Of these 13, 4 regions experience positive effects and 9 regions experience negative effects. The significant destination effects are also displayed in Figure 4.3, where once again positive effects are blue and negative effects are yellow.

Regions with positive destination effects, indicating that they receive more hazardous waste than predicted by the included explanatory variables include (in order of magnitude from largest to smallest): Hampshire, Tees Valley, North Yorkshire, and Cheshire. Many of these regions contain, or are on the outskirts of, larger urban areas within the U.K. such as Newcastle, Manchester, and Portsmouth. Many of these cities were once large industrial centers and served as major hubs for rail and sea transportation. Perhaps one would expect 
Table 4.3: Region-Specific Effects for the Destinations of Hazardous Waste Flows $(\phi)$

\begin{tabular}{|c|c|c|c|}
\hline Region & Mean $\phi$ & Lower $5 \%$ & Upper $95 \%$ \\
\hline Bedfordshire & $\overline{-2.834}$ & 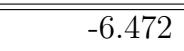 & 0.181 \\
\hline Berkshire & 0.517 & -3.606 & 5.353 \\
\hline Bristol/Bath Area & -0.429 & -3.391 & 2.121 \\
\hline Buckinghamshire & -4.813 & -8.093 & -2.471 \\
\hline Cambridgeshire & 1.419 & -0.962 & 3.920 \\
\hline Cheshire & 2.731 & 0.820 & 4.599 \\
\hline Cornwall \& Isles of Scilly & 0.768 & -2.167 & 3.632 \\
\hline Cumbria & -4.002 & -6.924 & -0.878 \\
\hline Derbyshire & 2.400 & -1.655 & 5.893 \\
\hline Devon & -1.191 & -3.558 & 1.593 \\
\hline Dorset & 2.515 & -1.008 & 6.138 \\
\hline Durham & -3.633 & -7.860 & -0.232 \\
\hline East Riding & -2.175 & -4.024 & -0.736 \\
\hline East Sussex & 1.860 & -2.725 & 4.630 \\
\hline Eastern Scotland & -1.309 & -12.228 & 9.856 \\
\hline Essex & 1.820 & -1.308 & 4.382 \\
\hline Gloucestershire & 2.135 & -0.139 & 4.055 \\
\hline Greater Manchester & 0.437 & -1.849 & 2.976 \\
\hline Hampshire & 4.195 & 2.045 & 6.077 \\
\hline Herefordshire & -0.570 & -2.655 & 1.978 \\
\hline Hertfordshire & 1.298 & -0.926 & 3.152 \\
\hline Highlands and Islands & 1.025 & -14.398 & 12.193 \\
\hline Isle of Wight & -7.586 & -13.131 & -3.736 \\
\hline Kent & -0.505 & -2.983 & 1.962 \\
\hline Lancashire & 0.555 & -1.061 & 2.340 \\
\hline Leicestershire & -2.148 & -4.284 & -0.265 \\
\hline Lincolnshire & 0.615 & -1.562 & 2.678 \\
\hline London & -5.338 & -9.717 & -1.707 \\
\hline Merseyside & 2.918 & -0.566 & 6.044 \\
\hline Mid Wales & 0.546 & -3.905 & 4.400 \\
\hline Norfolk & -1.154 & -3.741 & 1.274 \\
\hline North Eastern Scotland & -1.427 & -11.097 & 9.884 \\
\hline North Lincolnshire & -3.721 & -6.605 & -0.585 \\
\hline North Wales & 1.886 & -0.533 & 3.891 \\
\hline North Yorkshire & 2.962 & 0.297 & 5.037 \\
\hline Northamptonshire & 1.146 & -1.426 & 3.360 \\
\hline Northumberland & 1.278 & -3.254 & 5.547 \\
\hline Nottinghamshire & 0.882 & -1.885 & 3.013 \\
\hline Oxfordshire & 0.886 & -2.658 & 4.890 \\
\hline Rutland & -3.356 & -7.934 & 0.608 \\
\hline Shropshire & -1.300 & -3.962 & 1.189 \\
\hline Somerset & -4.105 & -6.221 & -1.157 \\
\hline South East Wales & -0.245 & -2.136 & 1.515 \\
\hline South West Wales & -1.001 & -4.211 & 1.939 \\
\hline South Western Scotland & -2.040 & -19.348 & 11.670 \\
\hline South Yorkshire & 0.309 & -2.460 & 2.844 \\
\hline Staffordshire & 0.620 & -2.135 & 3.386 \\
\hline Suffolk & 0.719 & -1.358 & 2.409 \\
\hline Surrey & 0.330 & -3.053 & 3.630 \\
\hline Tees Valley & 3.334 & 1.032 & 5.812 \\
\hline Tyne and Wear & -2.504 & -5.883 & 1.229 \\
\hline Warwickshire & -0.618 & -3.119 & 2.098 \\
\hline West Midlands & -0.918 & -4.379 & 2.801 \\
\hline West Sussex & -2.674 & -5.410 & 0.387 \\
\hline West Yorkshire & -0.665 & -2.887 & 1.725 \\
\hline Wiltshire & 1.892 & -0.457 & 4.558 \\
\hline Worcestershire & 2.159 & -0.652 & 4.846 \\
\hline
\end{tabular}


that as these cities have become more service-oriented, they receive fewer hazardous waste flows. However, the long-established transportation network infrastructure and remaining heavy industry could both have a large, positive influence on hazardous waste flows in these regions.

Figure 4.3: Significant Region-Specific Effects for Destinations of Hazardous Waste Flows

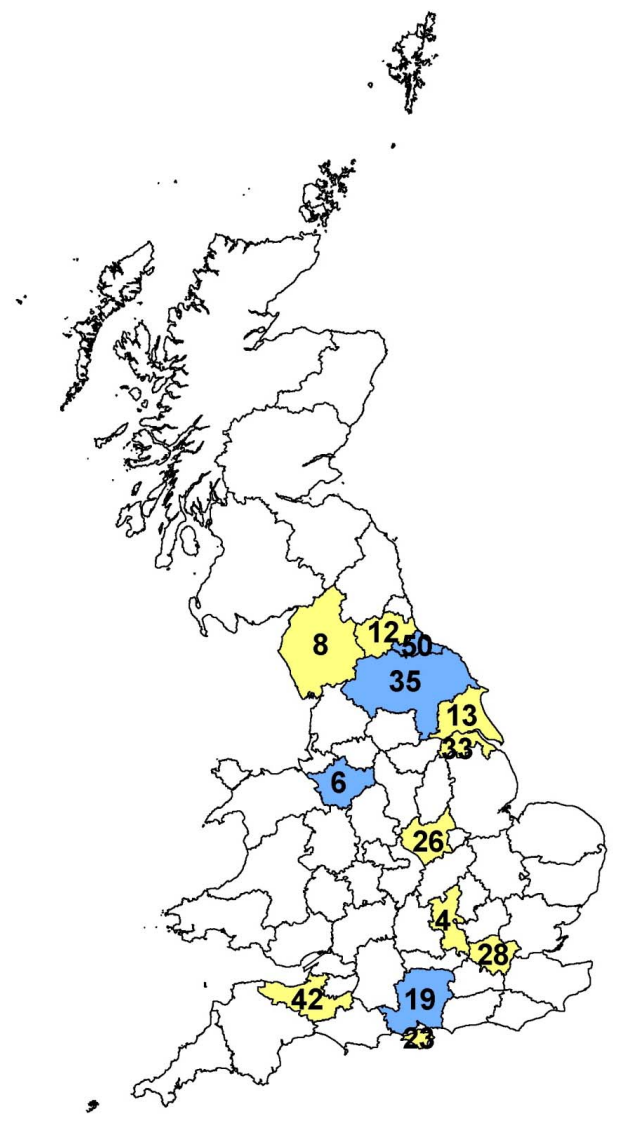

\begin{tabular}{|r|l|r|l|}
\hline 1 & Bedfordshire & 30 & Mid Wales \\
\hline 2 & Berkshire & 31 & Norfolk \\
\hline 3 & Bristol/Bath Area & 32 & North Eastern Scotland \\
\hline 4 & Buckinghamshire & 33 & North Lincolnshire \\
\hline 5 & Cambridgeshire & 34 & North Wales \\
\hline 6 & Cheshire & 35 & North Yorkshire \\
\hline 7 & Cornwall \& Isles of Scilly & 36 & Northamptonshire \\
\hline 8 & Cumbria & 37 & Northumberland \\
\hline 9 & Derbyshire & 38 & Nottinghamshire \\
\hline 10 & Devon & 39 & Oxfordshire \\
\hline 11 & Dorset & 40 & Rutland \\
\hline 12 & Durham & 41 & Shropshire \\
\hline 13 & East Riding & 42 & Somerset \\
\hline 14 & East Sussex & 43 & South East Wales \\
\hline 15 & Eastern Scotland & 44 & South West Wales \\
\hline 16 & Essex & 45 & South Western Scotland \\
\hline 17 & Gloucestershire & 46 & South Yorkshire \\
\hline 18 & Greater Manchester & 47 & Staffordshire \\
\hline 19 & Hampshire & 48 & Suffolk \\
\hline 20 & Herefordshire & 49 & Surrey \\
\hline 21 & Hertfordshire & 50 & Tees Valley \\
\hline 22 & Highlands and Islands & 51 & Tyne and Wear \\
\hline 23 & Isle of Wight & 52 & Warwickshire \\
\hline 24 & Kent & 53 & West Midlands \\
\hline 25 & Lancashire & 54 & West Sussex \\
\hline 26 & Leicestershire & 55 & West Yorkshire \\
\hline 27 & Lincolnshire & 56 & Wiltshire \\
\hline 28 & London & Worcestershire \\
\hline 29 & Merseyside & & \\
\hline & & & \\
\hline & &
\end{tabular}

Other regions had negative and significant region-specific effects suggesting that they receive less hazardous waste than predicted by their destination-specific characteristics. In order of largest to smallest absolute values, these regions are: Isle of Wight, London, Buckinghamshire, Somerset, Cumbria, North Lincolnshire, Durham, East Riding, and Leicestershire. Many of these regions contain only small- and medium-sized cities. Perhaps unobserved explanatory variables, such as accessibility, are driving these results. The one exception is London. It is likely that the negative destination effect for London is driven by unobserved characteristics such as NIMBY attitudes, average land price, and regulations on hazardous waste transport. It could be that, as is the case in the United States, some types of haz- 
Table 4.4: Region-Specific Summary Effects of Hazardous Waste Flows $(\theta+\phi)$

\begin{tabular}{|c|c|c|c|}
\hline Region & Mean $\theta+\phi$ & Lower 5\% & Upper $95 \%$ \\
\hline Bedfordshire & 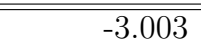 & 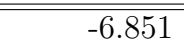 & 0.084 \\
\hline Berkshire & 0.436 & -3.925 & 5.350 \\
\hline Bristol/Bath Area & -0.875 & -3.865 & 2.015 \\
\hline Buckinghamshire & -5.306 & -8.808 & -2.799 \\
\hline Cambridgeshire & 1.766 & -0.734 & 4.445 \\
\hline Cheshire & 2.328 & 0.317 & 4.440 \\
\hline Cornwall \& Isles of Scilly & 0.930 & -2.148 & 3.923 \\
\hline Cumbria & -4.836 & -7.761 & -1.582 \\
\hline Derbyshire & 3.201 & -0.802 & 6.792 \\
\hline Devon & -0.674 & -3.162 & 2.124 \\
\hline Dorset & 3.073 & -0.554 & 6.764 \\
\hline Durham & -4.013 & -8.251 & -0.477 \\
\hline East Riding & -3.115 & -5.015 & -1.563 \\
\hline East Sussex & 1.599 & -3.105 & 4.410 \\
\hline Eastern Scotland & -0.725 & -11.581 & 10.234 \\
\hline Essex & 2.063 & -1.114 & 4.673 \\
\hline Gloucestershire & 3.448 & 1.167 & 5.443 \\
\hline Greater Manchester & -0.157 & -2.602 & 2.435 \\
\hline Hampshire & 6.243 & 4.023 & 8.157 \\
\hline Herefordshire & -1.433 & -3.633 & 1.279 \\
\hline Hertfordshire & 1.122 & -1.255 & 3.128 \\
\hline Highlands and Islands & 0.989 & -14.250 & 12.036 \\
\hline Isle of Wight & -9.686 & -15.310 & -5.802 \\
\hline Kent & 1.151 & -1.391 & 3.656 \\
\hline Lancashire & 1.413 & -0.339 & 3.366 \\
\hline Leicestershire & -2.362 & -4.489 & -0.387 \\
\hline Lincolnshire & 0.680 & -1.564 & 2.819 \\
\hline London & -5.318 & -9.790 & -1.376 \\
\hline Merseyside & 1.254 & -2.220 & 4.545 \\
\hline Mid Wales & -0.686 & -5.037 & 3.336 \\
\hline Norfolk & -0.619 & -3.352 & 1.823 \\
\hline North Eastern Scotland & -1.907 & -11.542 & 9.363 \\
\hline North Lincolnshire & -3.621 & -6.627 & -0.341 \\
\hline North Wales & 2.933 & 0.461 & 4.982 \\
\hline North Yorkshire & 2.399 & -0.236 & 4.602 \\
\hline Northamptonshire & 1.295 & -1.388 & 3.618 \\
\hline Northumberland & 1.430 & -3.230 & 5.795 \\
\hline Nottinghamshire & 0.673 & -2.157 & 2.938 \\
\hline Oxfordshire & 0.624 & -2.878 & 4.725 \\
\hline Rutland & -5.884 & -10.640 & -1.860 \\
\hline Shropshire & -1.911 & -4.505 & 0.719 \\
\hline Somerset & -3.961 & -6.116 & -0.900 \\
\hline South East Wales & 1.465 & -0.629 & 3.348 \\
\hline South West Wales & 0.743 & -2.515 & 3.908 \\
\hline South Western Scotland & -1.784 & -19.119 & 11.971 \\
\hline South Yorkshire & 0.237 & -2.574 & 2.769 \\
\hline Staffordshire & 1.225 & -1.631 & 4.048 \\
\hline Suffolk & 1.154 & -0.938 & 3.137 \\
\hline Surrey & -0.416 & -4.039 & 3.098 \\
\hline Tees Valley & 3.177 & 0.691 & 5.706 \\
\hline Tyne and Wear & -3.385 & -6.882 & 0.316 \\
\hline Warwickshire & -1.664 & -4.270 & 1.154 \\
\hline West Midlands & -0.792 & -4.337 & 3.097 \\
\hline West Sussex & -2.729 & -5.601 & 0.594 \\
\hline West Yorkshire & -0.592 & -2.966 & 1.807 \\
\hline Wiltshire & 1.871 & -0.505 & 4.756 \\
\hline Worcestershire & 2.514 & -0.364 & 5.265 \\
\hline
\end{tabular}


ardous waste are forbidden from being managed, disposed, or even transported through large metropolitan areas, such as London.

Figure 4.4: Significant Region-Specific Summary Effects of Hazardous Waste Flows

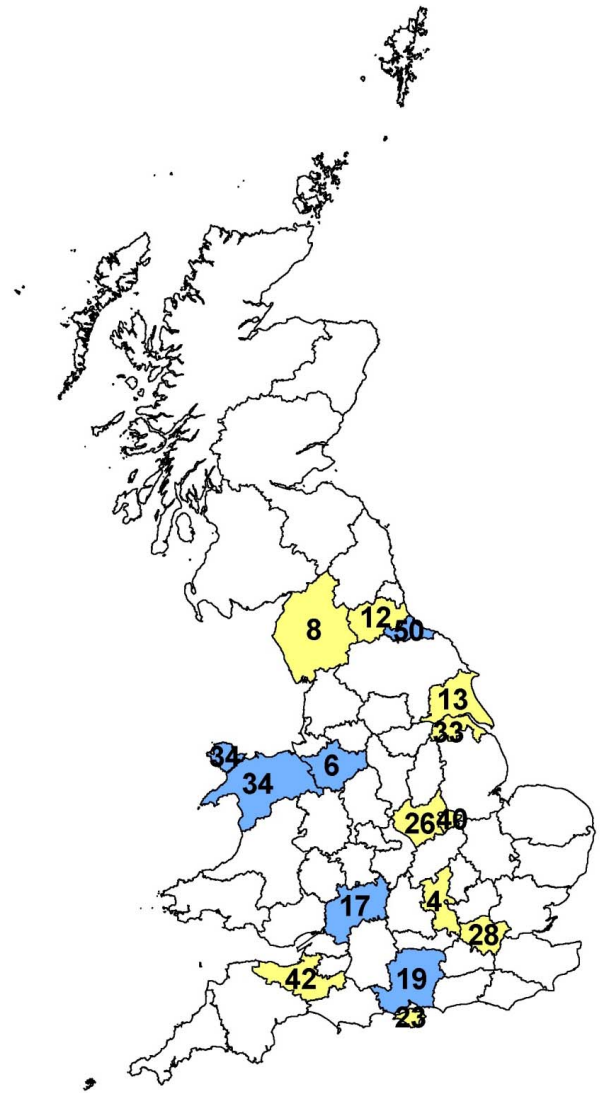

\begin{tabular}{|r|l|r|l|}
\hline 1 & Bedfordshire & 30 & Mid Wales \\
\hline 2 & Berkshire & 31 & Norfolk \\
\hline 3 & Bristol/Bath Area & 33 & North Lincolnshire \\
\hline 4 & Buckinghamshire & 34 & North Wales \\
\hline 5 & Cambridgeshire & 35 & North Yorkshire \\
\hline 6 & Cheshire & 36 & Northamptonshire \\
\hline 7 & Cornwall \& Isles of Scilly & 37 & Northumberland \\
\hline 8 & Cumbria & 38 & Nottinghamshire \\
\hline 9 & Derbyshire & 39 & Oxfordshire \\
\hline 10 & Devon & 40 & Rutland \\
\hline 11 & Dorset & 41 & Shropshire \\
\hline 12 & Durham & 42 & Somerset \\
\hline 13 & East Riding & 43 & South East Wales \\
\hline 14 & East Sussex & 44 & South West Wales \\
\hline 15 & Eastern Scotland & 45 & South Western Scotland \\
\hline 16 & Essex & 46 & South Yorkshire \\
\hline 17 & Gloucestershire & 47 & Staffordshire \\
\hline 18 & Greater Manchester & 48 & Suffolk \\
\hline 19 & Hampshire & 49 & Surrey \\
\hline 20 & Herefordshire & 50 & Tees Valley \\
\hline 21 & Hertfordshire & 51 & Tyne and Wear \\
\hline 22 & Highlands and Islands & 52 & Warwickshire \\
\hline 23 & Isle of Wight & 53 & West Midlands \\
\hline 24 & Kent & 54 & West Sussex \\
\hline 25 & Lancashire & 55 & West Yorkshire \\
\hline 26 & Leicestershire & 57 & Wiltshire \\
\hline 27 & Lincolnshire & & \\
\hline 28 & London & \\
\hline 29 & Merseyside & \\
\hline & & \\
\hline
\end{tabular}

Table 4.4 displays additional results obtained by summing the origin and destination individual effects on each iteration of the Gibbs sampler and then calculating estimates of the mean sum and a $95 \%$ credible interval for these sums. When interpreting similar results from a model investigating interregional commodity flows, LeSage and Llano (2007) explain that, "[p]ositive values for these combined parameter estimates provide us with an indication of which regions benefit from unobserved positive forces at work that lead to high levels of interregional commodity flows that originate and terminate in the region. Similarly, negative combined values for these parameters point to regions that suffer disadvantages leading to lower interregional commodity flow levels" (p. 27). As the benefits of commodity trade are well established, their inherent assumption that higher commodity flows are a "benefit" to a region and lower commodity flows lead to "suffering" in a region is not surprising. 
However, due to the nature of hazardous waste and the negative externalities inherent in the waste itself, as well as its management and disposal, this assumption might not hold for trade in hazardous waste. In this context, a positive effect suggests that as a result of unobserved effects, there are higher levels of interregional hazardous waste flows that originate and terminate in the region. The 5 regions that experience such an effect are Hampshire, Gloucestershire, Tees Valley, North Wales, and Cheshire. A negative effect on the summary parameter indicates that there are lower levels of interregional hazardous waste flows that originate and terminate in the region as a result of unobserved characteristics. The Isle of Wight, Rutland, London, Buckinghamshire, Cumbria, Durham, Somerset, North Lincolnshire, East Riding, and Leicestershire all have negative and significant summary effects. Significant results for the positive (blue) and negative (yellow) summary effects are displayed in Figure 4.4.

\subsection{Conclusions}

This chapter uses a Tobit specification of a spatial interaction model with spatially structured origin and destination effects to begin examining the issue of spatial dependence in U.K. hazardous waste flows. Specifically, this model simultaneously estimates region-specific effects for the origin and destination regions and also tests whether these individual effects exhibit spatial dependence.

The inclusion of these region-specific effects within the model does not have any substantial impact on the parameter estimates for the explanatory variables describing the origins but does have some impacts on parameter estimates for the destination-specific explanatory variables. Whereas the model in Chapter 3 suggested there was no evidence for hazardous waste moving from regions with higher income levels to those with lower income levels, this model actually provides evidence of just the opposite. Results for the region-specific effects indicate that although neither the origin nor the destination effects exhibit spatial dependence, many of the region-specific effects are significant. It appears that many coastal regions are likely to ship more hazardous waste out than predicted by the explanatory variables within the model. The results can also indicate regions that "benefit" or "suffer" from 
unobserved characteristics when it comes to hazardous waste trade within the U.K.

The results and insights from this model can be used to not only inform policymakers of the observed characteristics that are associated with hazardous waste flows in the U.K. but also to highlight the regional effects on hazardous waste flows that result from characteristics that are not included in this model. As previously suggested in Chapter 3, U.K. policymakers can use these results as additional evidence to combat environmental justice arguments relating to hazardous waste dumping in their country. After controlling for region-specific effects for the origins and the destinations, this model not only provided no evidence of hazardous waste dumping, but provided some evidence to the contrary.

This chapter provides an additional variant of a modeling framework that policymakers should be using to examine and fully comprehend the hazardous waste movements that are taking place in their country. These modeling frameworks could also be used to test additional hypotheses and notions regarding hazardous waste flows. With some additional modifications, these models can also be extended to the realm of international hazardous waste shipments. 


\section{Chapter 5}

\section{Conclusions}

\subsection{Conclusions}

This dissertation research has successfully demonstrated the application of models traditionally used within the disciplines of economics and regional science for the integration of economic and environmental information - specifically information on hazardous waste. The use of different economic modeling techniques, whether it be for hazardous waste accounting or examining hazardous waste trade relationships, provides decisionmakers in industry and policy much richer information on the hazardous waste economy. The results of the dissertation are an important extension of the straightforward, descriptive presentation of hazardous waste data currently available from the U.S. Environmental Protection Agency and the U.K. Environment Agency.

The methodology and results presented in Chapter 2 on hazardous waste accounting are an important step towards the effectiveness of future hazardous waste minimization policies. Rather than providing information solely on the amount and type of hazardous waste produced directly by different generators, these hazardous waste accounting techniques provide information on the direct, indirect, and total accountability of industries in hazardous waste generation across the economy and also the attribution of hazardous waste to different final demand categories based upon their demand for output from these industries.

Overall, the results suggest that only a few sectors of the economy are accountable for most of the direct hazardous waste generation in the economy. The hazardous waste 
multiplier results show that the breakdowns of direct, indirect, and total hazardous waste generation vary widely across industries and suggest that considering the total hazardous waste intensity in conjunction with the ratio of direct to total hazardous waste intensity might be a useful way of choosing focus industries for source reduction. Also, the final demand attribution analysis is capable of consistently attributing the industrial hazardous waste generation to the final demand sectors of the economy. Although these results also vary widely across the sectors of the economy, the household consumption category is responsible for the largest proportion of hazardous waste generation in the United States. This result is not surprising given the dominance of household consumption over other final demand categories in general. However, in terms of the hazardous waste intensity of the final demand groups, foreign exports are accountable for the largest amount of hazardous waste generation per million dollars of expenditures.

With information to inform both industry-based policies and consumption-based policies, analytical results are also provided that can help policymakers consider which type of policy would be more effective in certain sectors of the economy. The analysis of the breakdown of direct hazardous waste generation for intermediate and final demand is particularly useful in this context. In fact, this analysis suggests that perhaps the only sector of the economy that is not only a large generator of hazardous waste but also produces a large percentage of this hazardous waste for final demand is Computer and electronic products. This result suggests that this sector is ideal for both policies aimed at source reduction and reduction from the demand side of the economy.

The results from Chapters 3 and 4 provide information on the economic, demographic, and hazardous waste related characteristics that are associated with hazardous waste flows in the U.K. This research not only represents the only research of its kind being done for these hazardous waste flows but also is the first known example of the Tobit specification within the spatial econometric framework.

The results from both chapters suggest that characteristics related to the health, educational qualification, and the existence of hazardous waste landfill capacity are all characteristics associated with hazardous waste flows in the U.K. Also, these analyses are consistent with other spatial interaction analyses in showing that distance has a negative and significant 
effect on regional interaction. Although the region-specific effects are not found to exhibit any spatial dependence, these region-specific effects are found to be an important factor for hazardous waste trade.

The results and insights from these different specifications of the spatial interaction model for U.K. hazardous waste flows can be used to not only inform policymakers of the observed characteristics that are associated with the flows but also to highlight the regional effects on hazardous waste flows that result from characteristics that are not included in this model. They can also be used to combat the notion of hazardous waste dumping occurring within the U.K. Policymakers could also use these modeling frameworks to examine other hypotheses related to hazardous waste flows in the U.K. The implementation of such models would be a useful exercise during the formulation of new policies regarding hazardous waste trade for both policymakers in the U.K. and in other countries. Larger communities of nations such as the European Union or the United Nations could also implement this methodology for the examination of international hazardous waste shipments.

\section{$5.2 \quad$ Future Research}

Priority directions for future research on hazardous waste accounting are twofold, the first dealing with issues of aggregation and the second with the relaxation of model assumptions. It is well known that different levels of aggregation on many dimensions can produce different results. Some interesting extensions of this research involve disaggregating the data and analyses with respect to geography, economic structure, and hazardous waste characteristics.

As characteristics such as consumption patterns, production technology, and industry structure vary across space, results could be markedly different for different regions or states within the U.S. Input-output data can be regionalized for use in conjunction with available hazardous waste generation data by region to explore these differences.

Also, as results are already shown to vary across aggregate industry and commodity sectors, it might be useful to examine results derived from less aggregated industries and commodities. Aggregate sectors represent "average technologies" and can mask some variation in hazardous waste intensity within the sector. Examinations of the variations within 
aggregate sectors and an analysis of deviation from best practices might prove just as informative as the variation across aggregate sectors. The partial consumption accounting analyses could also be performed using more disaggregated final demand activities, such as different types of government expenditures and different categories of households.

Further, relationships within the hazardous waste economy can also be expected to vary across different characteristics of hazardous waste. There are varying degrees of danger to human health and the environment with different types of hazardous waste and also with different management or disposal methods. This accounting framework can be used to conduct analyses on only the most dangerous types of hazardous waste or the least desirable methods of disposal such as incineration or burial. Hazardous waste, as defined by the U.S. Environmental Protection Agency, has one or more of the following characteristics: ignitability, corrosivity, reactivity, or toxicity. To date, there is no specific weighting procedure based on "hazardousness" such as the toxicity weighting schemes associated with data from the Toxics Release Inventory. The construction of such a weighting scheme for BRS data is in fact another important direction for future investigation.

At this stage, this work only discusses an accounting framework and does not extend the analyses into the realm of behavioral modeling. The final priority direction for further research is to begin to extend the analysis of the hazardous waste economy to other modeling frameworks that are capable of capturing additional behaviors and answering broader questions. For example, how much additional hazardous waste would be generated if the U.S. were to produce its entire imported commodity final demand domestically? Or, even more broadly, assuming that the current domestic waste and production technologies do not change, how much hazardous waste would the U.S. generate if all of its commodity imports (both intermediate and final) were produced domestically?

Production often occurs, and hazardous waste is generated, in one region to satisfy intermediate and final consumption demand in another region. To understand these relationships, the first step might be to move forward with the regional analyses mentioned above and then use an interregional input-output framework, which can also capture interregional feedback effects. Finally, some relatively restrictive assumptions inherent within the input-output framework could be relaxed in a move towards more complex behavioral modeling. Exten- 
sions towards general equilibrium modeling frameworks would allow the modeler to move from a descriptive to a prescriptive tool in which they could model different policy shocks (whether they were directly related to hazardous waste generation or not) and examine their comprehensive impacts on both the economy and hazardous waste generation.

Future directions for the research on hazardous waste trade include refining the data and the model in ways that might be more consistent with examining these types of flows. Knowing that hazardous waste transport, management, and disposal are all highly regulated, the form of the distance variable and the model in general can be greatly improved by including information on the transportation networks used by hazardous waste movements. Rather than using distance measured "as the crow flies" between the centroids of two regions, information on the locations of management and disposal sites would allow distance to be measured as the actual road, rail, or sea distance between the generation site and the management or disposal site or even as the travel time between the two sites.

Information for characteristics of the management and disposal sites other than the location would also improve the model. Data on managing or disposal capacity and the types of hazardous waste that can be accepted would allow for more detailed examination of the regional attributes associated with hazardous waste flows. One other characteristic that has been deemed an important factor within the literature on hazardous waste trade is the reliability or riskiness of certain management locations. Detailed information on the number of "incidents" at a particular management or disposal facility would also be useful.

The percentage of the population that claims to be in good health is a variable that provides an additional area of focus for future research due to its consistently significant result within the analyses. Perhaps the first extension would be to collect information on medical facilities within a region to see if, as suspected, proximity to or access to healthcare is in fact driving this result.

Some "ground-truthing" of the results by means of survey or interview will also be helpful in determining the exact reasons for hazardous waste trade within the U.K. Provided the opportunity, the collection and consideration of knowledge from industry participants might provide a type of qualitative analysis that could be used to support the list of characteristics associated with hazardous waste trade by this dissertation and also to suggest characteristics 
not yet considered.

Since there was no evidence of spatial dependence within the regional effects structure modeled in this dissertation, spatial econometric techniques can be used to test for other types of spatial dependence, which provides a final priority direction for future research on hazardous waste flows. LeSage and Pace (2008) provide a general model for introducing spatial dependence in the independent variable for the origins, the destinations, and within the flows themselves. Preliminary results using this model have suggested that there is indeed spatial dependence present in hazardous waste flows for the origin regions, the destination regions, and within hazardous waste flows themselves.

This dissertation has successfully produced and implemented a set of models that enhance our understanding of the Who, Why, and Where of hazardous waste. The current applications of these models already provide many significant results for U.S. and U.K. researchers and policymakers. Additional research in the areas mentioned above will only provide a more complete understanding of the hazardous waste economy in both locations. 


\section{References}

Alberini, A. and Bartholomew, J. (1999). The determinants of hazardous waste disposal choice: An empirical analysis of halogenated solvent waste shipments. Contemporary Economic Policy, 17(3):309-320.

Allan, G. J., Hanley, N. D., McGregor, P. G., Swales, J. K., and Turner, K. R. (2007). Augmenting the input-output framework for 'common pool' resources: Operationalising the full Leontief environmental model. Economic Systems Research, 19(1):1-22.

Allen, M. E. (1995). Slowing Europe's hazardous waste trade: Implementing the Basel Convention into European Union law. Colorado Journal of International Law and Policy, 6:163-182.

Anderson, J. E. (1979). A theoretical foundation for the gravity equation. The American Economic Review, 69(1):106-116.

Andrew, R. and Forgie, V. (2008). A three-perspective view of greenhouse gas emission responsibilities in New Zealand. Ecological Economics, 68(1-2):194-204.

Arrous, J. (1994). The Leontief pollution model: A systematic formulation. Economic Systems Research, 6(1):105 - 107.

Baggs, J. (2009). International trade in hazardous waste. Review of International Economics, $17(1): 1-16$.

Bergstrand, J. H. (1985). The gravity equation in international trade: Some microeconomic foundations and empirical evidence. Review of Economics and Statistics, 67(3):474-481.

Bergstrand, J. H. (1989). The generalized gravity equation, monopolistic competition and the factor-proportions theory in international trade. Review of Economics and Statistics, $71(1): 143-153$.

Bullard, C. W. and Herendeen, R. A. (1975). The energy costs of goods and services: An input/output analysis for the USA, 1963 and 1967. Energy Policy, 3:268-278. 
Cruz, L., Proops, J., and Safanov, P. (2005). Input-output models (in Chapter 3). Edward Elgar.

Cruz, L. M. G. (2010). Application of IO Energy Analysis for $\mathrm{CO}_{2}$ Emission by the Portuguese Economy: The Case of Portugal, pages 507-532. Springer Science + Business Media B.V.

Curry, L. (1972). A spatial analysis of gravity flows. Regional Studies, 6:131-147.

Cusack, M. M. (1989-1990). International law and the transboundary shipment of hazardous waste to the third world: Will the Basel Convention make a difference? American University Journal of International Law and Policy, 5:393-423.

Deardorff, A. V. (1998). Determinants of Bilateral Trade: Does Gravity Work in a Neoclassical World? University of Chicago Press, Chicago, IL.

Dietzenbacher, E. and Velazquez, E. (2007). Analysing andalusian virtual water trade in an input-output framework. Regional Studies, 41(2):185-196.

Dodd, S. C. (1950). The interactance hypothesis: a model fitting physical masses and human groups. American Sociological Review, 15:pp. 245-257.

Duchin, F. (1990). The conversion of biological materials and wastes to useful products. Structural Change and Economic Dynamics, 1(2):243-261.

EPA (2007). 2007 Hazardous waste report: Instructions and forms. Available at: http: //www.epa.gov/wastes/inforesources/data/br07/07report.pdf.

EPA (2008). Hazardous waste identification. Available at: http://www.epa.gov/epawaste/ inforesources/pubs/orientat/rom31.pdf.

Evenett, S. J. and Keller, W. (2002). On theories explaining the success of the gravity equation. Journal of Political Economy, 110(2):281-316.

Forssell, O. and Polenske, K. R. (1998). Introduction: Input-output and the environment. Economic Systems Research, 10(2):pp. 91-97. 
Forsund, F. R. (1985). Input-output models, national economic models, and the environment, pages 325-341. Elsevier.

Frey, R. S. (1998). The Hazardous Waste Stream in the World-System. Greenwood Press, Westport, CT.

Gale, L. R. (1995). Trade liberalization and pollution: An input-output study of carbon dioxide emissions in Mexico. Economic Systems Research, 7(3):309-320.

Gallego, B. and Lenzen, M. (2005). A consistent input-output formulation of shared producer and consumer responsibility. Economic Systems Research, 17(4):365 - 391.

Griffith, D. A. (1993). Spatial structure and spatial interaction: 25 years later. The Review of Regional Studies, 37(1):pp. 28-38.

Griffith, D. A. and Jones, K. G. (1980). Explorations into the relationship between spatial structure and spatial interaction. Environment and Planning A, 12:187-201.

Helpman, E., Melitz, M., and Rubinstein, Y. (2008). Estimating trade flows: Trading partners and trading volumes. Quarterly Journal of Economics, 123(2):441-487.

Horowitz, K. J. and Planting, M. A. (2006). Concepts and Methods of the US Input Output Accounts. Bureau of Economic Analysis, Dept. of Commerce.

Isard, W. (1956). A General Theory Relating to Industrial Location, Market Areas, Land Use, Trade, and Urban Structure. MIT Press, Cambridge, MA.

Jackson, R. W. (1998). Regionalizing national commodity-by-industry accounts. Economic Systems Research, 10(3):223 - 238.

Jackson, R. W. and Schwarm, W. R. (2011). Accounting foundations for interregional commodity-by-industry input-output models. Letters in Spatial and Resource Sciences, 4(3):187-196.

Jensen, C. D., Lacombe, D. J., and McIntyre, S. G. (2010). A Bayesian Spatial Econometric Analysis of the 2010 UK General Election. Strathclyde Discussion 
Papers in Economics 10-24. http://www.strath.ac.uk/media/departments/economics/ researchdiscussionpapers/2010/10-24July2011.pdf.

Jensen, C. D., McIntyre, S., Munday, M., and Turner, K. (2012). Responsibility for regional waste generation: A single-region extended input-output analysis for Wales. Forthcoming in Regional Studies, pages 1 -21. Available at http://www.tandfonline.com/doi/abs/10. $1080 / 00343404.2011 .599797$.

Kondo, Y. and Nakamura, S. (2004). Evaluating alternative life-cycle strategies for electrical appliances by the waste input-output model. The International Journal of Life Cycle Assessment, 9(4):236-246.

Kondo, Y. and Nakamura, S. (2005). Waste input-output linear programming model with its application to eco-efficiency analysis. Economic Systems Research, 17(4):393-408.

Lenzen, M. and Foran, B. (2001). An input-output analysis of Australian waste usage. Water Policy, 3:321-340.

Lenzen, M., Murray, J., Sack, F., and Wiedmann, T. (2007). Shared producer and consumer responsibility - theory and practice. Ecological Economics, 61(1):27-42.

Leontief, W. (1970). Environmental repercussions and the economic structure: An inputoutput approach. Review of Economics 83 Statistics, 52(3):262-271.

LeSage, J. P. and Fischer, M. M. (2010). Spatial Econometrics Methods for Modeling OriginDestination Flows. Springer-Verlag, Berlin.

LeSage, J. P. and Llano, C. (2007). A Spatial Interaction Model with Spatially Structured Origin and Destination Effects. SSRN Working Paper. http://ssrn. com/abstract=924603.

LeSage, J. P. and Pace, R. K. (2008). Spatial econometric modeling of origin-destination flows. Journal of Regional Science, 48(5):941-967.

LeSage, J. P. and Pace, R. K. (2009). Introduction to Spatial Econometrics. CRC Press, Boca Raton, FL. 
Levinson, A. (1999a). NIMBY taxes matter: the case of state hazardous waste disposal taxes. Journal of Public Economics, 74(1):31-51.

Levinson, A. (1999b). State taxes and interstate hazardous waste shipments. The American Economic Review, 89(3):666-677.

Linnemann, H. (1966). An Econometric Study of International Trade Flows. North Holland, Amsterdam.

Lowe, P. D. (1979). Pricing problems in an input-output approach to environment protection. Review of Economics \& Statistics, 61(1):110-117.

Luptacik, M. and Bohm, B. (1999). A consistent formulation of the Leontief pollution model. Economic Systems Research, 11(3):263 - 276.

Marbury, H. J. (1995). Hazardous waste exportation: The global manifestation of environmental racism. Vanderbilt Journal of Transnational Law, 28:251-294.

March, L. and Batty, M. (1975). Generalized measures of information, Bayes' likelihood ratio and Jayne's formalism. Environment and Planning B, 2:pp. 99-105.

McGlinn, L. (2000). Spatial patterns of hazardous waste generation and management in the United States. Professional Geographer, 52(1):11 - 22.

McGregor, P. G., Swales, J. K., and Turner, K. (2008). The $\mathrm{CO}_{2}$ 'trade balance' between scotland and the rest of the UK: Performing a multi-region environmental input-output analysis with limited data. Ecological Economics, 66(4):662-673.

Miller, R. and Blair, P. (2009). Input-Output Analysis: Foundations and Extensions. Cambridge University Press, Cambridge, UK, 2 edition.

Miller, R. E. and Blair, P. (1985). Input-Output Analysis: Foundations and Extensions. Prentice Hall, Englewood Cliffs, NJ, 1 edition.

Munksgaard, J. and Pedersen, K. A. (2001). $\mathrm{CO}_{2}$ accounts for open economies: producer or consumer responsibility. Energy Policy, 29(4):327-334. 
Nakamura, S. (1999). Input-output analysis of waste cycles. In First International Symposium on Environmentally Conscious Design and Inverse Manufacturing, pages 475-480.

Nakamura, S. and Kondo, Y. (2002). Input-output analysis of waste management. Journal of Industrial Ecology, 6(1):39-63.

Nakamura, S. and Kondo, Y. (2009). Waste Input-Output Analysis: Concepts and Application to Industrial Ecology. Eco-Efficiency in Industry and Science. Springer.

Nakamura, S. and Nakajima, K. (2005). Waste input-output material flow analysis of metals in the Japanese economy. Materials Transactions, 46:2550-2553.

O'Neill, K. (1998). Out of the backyard: the problems of hazardous waste management at a global level. The Journal of Environment and Development, 7(2):138-163.

O’Neill, K. (2000). Waste Trading Among Rich Nations: Building a New Thoery of Environmental Regulation. MIT Press, Cambridge, MA.

Peters, G. P. (2008). From production-based to consumption-based national emission inventories. Ecological Economics, 65(1):13-23.

Qayum, A. (1991). A reformulation of the Leontief pollution model. Economic Systems Research, 3:428-430.

Ravenstein, E. G. (1885). The laws of migration. Journal of the Royal Statistical Society, 48:pp. 167-235.

Rebitzer, G. and Nakamura, S. (2008). Environmental Life Cycle Costing. SETAC Press, Pensacola, FL.

Richardson, H. W. (1972). Input-Output and Regional Economics. John Wiley and Sons, New York.

Sigman, H. (1996). The effects of hazardous waste taxes on waste generation and disposal. Journal of Environmental Economics and Management, 30:199-217. 
Takase, K., Kondo, Y., and Washizu, A. (2005). An analysis of sustainable consumption by the waste input-output model. Journal of Industrial Ecology, 9(1-2):201-219.

Tinbergen, J. (1962). Shaping the World Economy: Suggestions for an International Economic Policy. Twentieth Century Fund, New York, NY.

Tobin, J. (1958). Estimation of relationships for limited dependent variables. Econometrica, 26(1):pp. 24-36.

Wiedmann, T., Minx, J., Barrett, J., and Wackernagel, M. (2006). Allocating ecological footprints to final consumption categories with input-output analysis. Ecological Economics, $56(1): 28-48$.

Williams, J. D. (1991). Trashing developing nations: The global hazardous waste trade. Buffalo Law Review, 39:275-312.

Wilson, A. G. (1967). A statistical theory of spatial distribution models. Transportation Research, 1:pp. 253-269.

Wilson, A. G. (1971). A family of spatial interaction models, and associated developments. Environment and Planning A, 3:pp. 1-32.

Wright, D. J. (1974). Goods and services, an input-output anlaysis. Energy Policy, 2:307315.

Young, E. C. (1924). The movement of farm population. Cornell University, Ithaca, NY. 